DMS: Diagnostic Modeling System

Report 1, Reduction of Sediment Shoaling by Relocation of the Gulf Intracoastal Waterway, Matagorda Bay, Texas

Nicholas C. Kraus, David J. Mark, and Soraya Sarruff

September 2000 
The contents of this report are not to be used for advertising, publication, or promotional purposes. Citation of trade names does not constitute an official endorsement or approval of the use of such commercial products.

The findings of this report are not to be construed as an official Department of the Army position, unless so designated by other authorized documents. 


\section{DMS: Diagnostic Modeling System Report 1, Reduction of Sediment Shoaling by Relocation of the Gulf Intracoastal Waterway, Matagorda Bay, Texas}

by Nicholas C. Kraus, David J. Mark, Soraya Sarruff

Coastal and Hydraulics Laboratory

U.S. Army Engineer Research and Development Center 3909 Halls Ferry Road

Vicksburg, MS 39180-6199

Report 1 of a series

Approved for public release; distribution is unlimited 


\section{Engineer Research and Development Center Cataloging-in-Publication Data}

Kraus, Nicholas C.

DMS : Diagnostic Modeling System. Report 1, Reduction of sediment shoaling by

relocation of the Gulf Intracoastal Waterway, Matagorda Bay, Texas / by Nicholas C. Kraus, David J. Mark, Soraya Sarruff ; prepared for U.S. Army Corps of Engineers, U.S. Army Engineer District, Galveston.

62 p. : ill. ; 28 cm. -- (Technical Report CHL-99-19 rept.1)

Includes bibliographic references.

1. Sedimentation and deposition -- Texas -- Matagorda Bay -- Computer simulation. 2. Gulf Intracoastal Waterway -- Texas -- Matagorda Bay. 3. DMS (Computer system)

4. Channels (Hydraulic engineering) -- Texas. I. Mark, David J. II. Sarruff, Maria S.

III. United States. Army. Corps of Engineers. Galveston District. IV. Engineer Research and Development Center (U.S.) V. Coastal and Hydraulics Laboratory (U.S.) VI. Title. VI. Title: Reduction of sediment shoaling by relocation of the Gulf Intracoastal Waterway, Matagorda Bay, Texas. VII. Series: Technical Report CHL-99-19 rept.1.

TA7 E8 no.Technical Report CHL-99-19 rept.1 


\section{Contents}

Preface vii

Conversion Factors, Non-SI to SI Units of Measurement.............................................. viii

1—Background and Problem Statement................................................................. 1

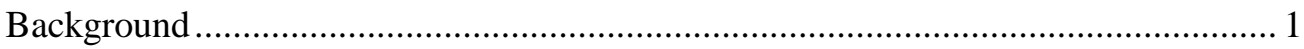

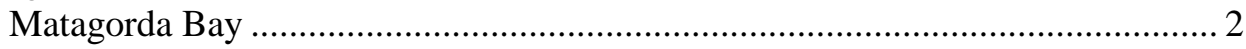

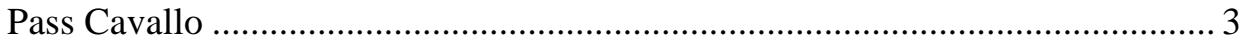

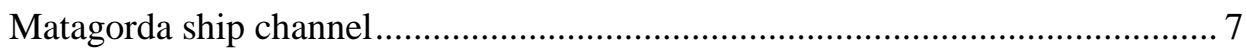

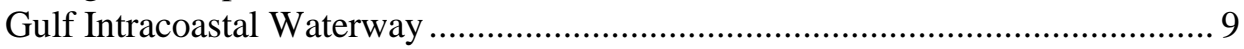

Problem Statement - Relocation of the GIWW ……............................................... 10

Objectives and Procedures of this Study ................................................................. 11

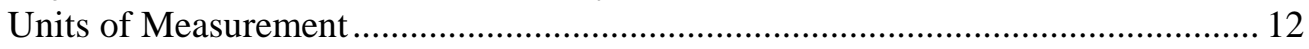

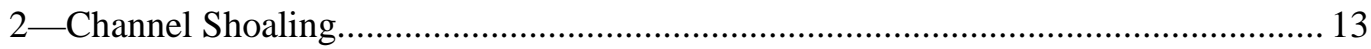

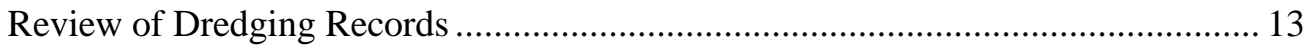

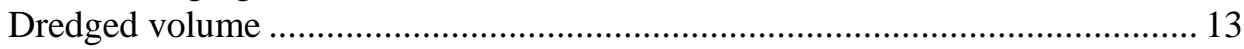

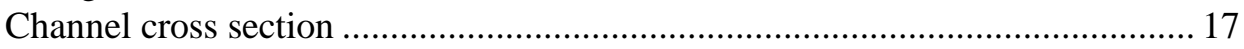

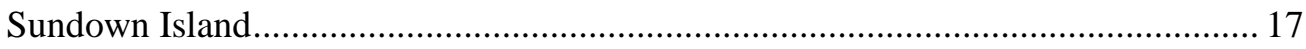

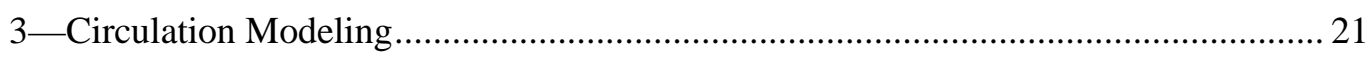

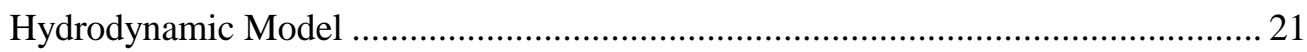

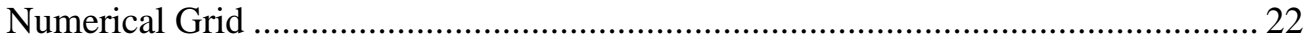

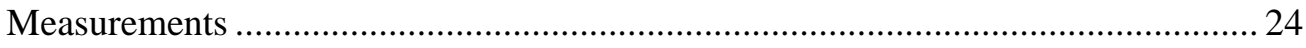

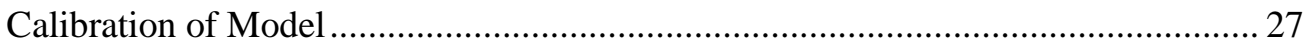

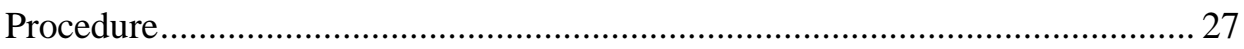

Calibration period conditions …….......................................................... 27

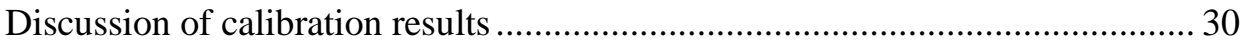

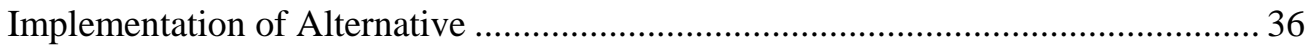

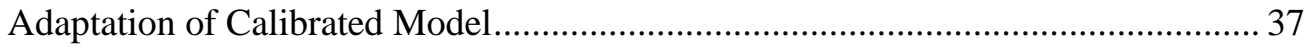

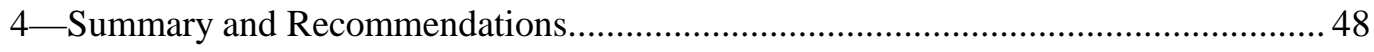

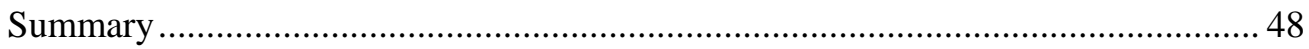

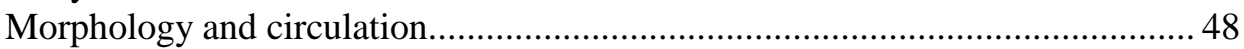

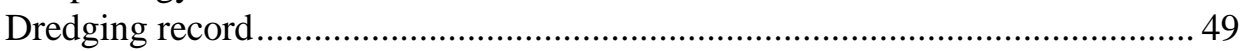




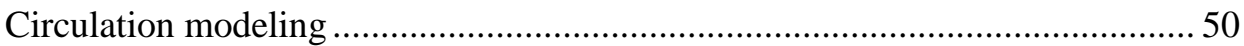

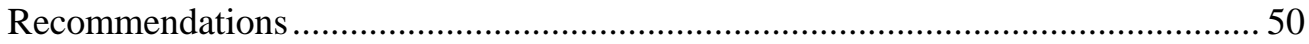

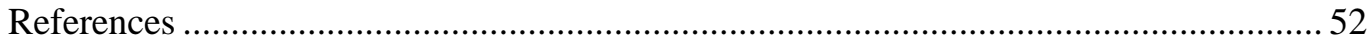

\section{List of Figures}

Figure 1. Location map for the study site and the Texas coast................................ 2

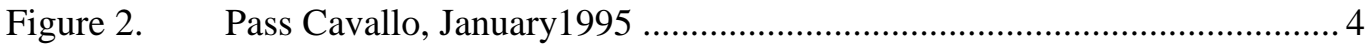

Figure 3. Shrimp boat sunk in Pass Cavallo (September 1997) ...............................5

Figure 4. Eastern side of Pass Cavallo showing Delcros Point and several shoals within the inlet in 1954, before opening of the MSC. 6

Figure 5. Pass Cavallo in 1991, showing much reducted width as compared to 1954. Two channels are observed, with the channel directed to the southwest being larger ........................................ 6

Figure 6. Distal end of Delcros Point, looking gulfward ........................................ 7

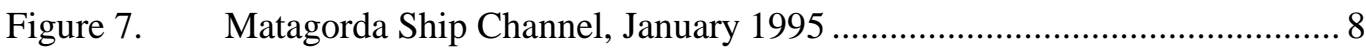

Figure 8. Volume of material dredged for maintenance from the GIWW (1969-1995)

Figure 9. Volume of material dredged for maintenance from the MSC (1965-1994)

Figure 10. Cumulative volume of material dredged for maintenance from the GIWW

Figure 11. Idealized channel infilling pattern by a current with predominant flow direction

Figure 12. Cumulative volume dredged for maintenance from the MSC................... 16

Figure 13. Volume of material dredged for maintenance from the GIWW ................ 16

Figure 14. Volume of material dredged for maintenance from the MSC ................... 17

Figure 15. High-altitude, infra-red photograph (1991) of the MSC, Sundown Island, and Port O'Conner on the left (west) side..... 
Figure 16. Sketch of sediment deposition and flood shoal development by horizontal expansion

Figure 17. Southwest corner of Sundown Island and channel range marker, as seen from the MSC upon entering the bay (May 1997).. 20

Figure 18. Portion of northeast perimeter of Sundown Island, with barge tow in the GIWW, far left (May 1997).

Figure 19. Numerical grid including the offshore, Matagorda Bay, and communicating bays

Figure 20. Numerical grid in vicinity of the MSC-GIWW intersection 23

Figure 21. Locations of deployed current meters and numerical gauges 26

Figure 22. Time series of wind speed measured at the East Matagorda station

Figure 23. Time series of wind direction measured at the East Matagorda station

Figure 24. Time series of water-surface elevation measured at Galveston

Pleasure Pier

Figure 25. Time series of water-surface elevation measured at Port Lavaca station 30

Figure 26. Comparison of calculated and measured velocities at sta 1 31

Figure 27. Comparison of calculated and measured velocities at sta 2 32

Figure 28. Comparison of calculated and measured water-surface elevations at Port Lavaca station (East Matagorda winds were specified in model)

Figure 29. Comparison of calculated and measured water-surface elevations at Port Lavaca station (Lavaca Bay winds specified in model)

Figure 30. Comparison of calculated and measured discharges at MSC entrance for YD 253

Figure 31. Comparison of calculated and measured discharges at Pass Cavallo for YD 253 34 
Figure 32. Comparison of calculated and measured discharges at MSC entrance for YD 274

Figure 33. Comparison of calculated and measured discharges at

Pass Cavallo for YD 274 35

Figure 34. Location map of existing and proposed GIWW ...................................... 38

Figure 35. Numerical grid in vicinity of proposed (relocated) GIWW ....................... 39

Figure 36. Current vector map for existing GIWW ................................................ 39

Figure 37. Current vector map for proposed GIWW relocation ................................ 41

Figure 38. Comparison of currents at the western sides of

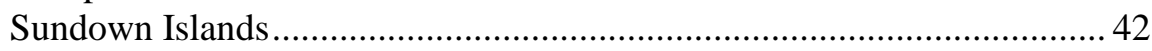

Figure 39. Time series of current differences calculated at western side ...................42

Figure 40. Comparison of currents at the MSC-GIWW intersection ......................... 43

Figure 41. Time series of current differences calculated at the MSC-GIWW intersection 43

Figure 42. Comparison of currents at the waterway sides of Sundown Islands 44

Figure 43. Time series of current differences calculated on the waterway

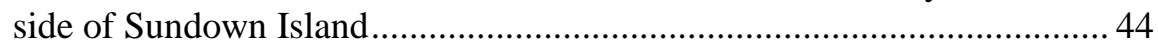

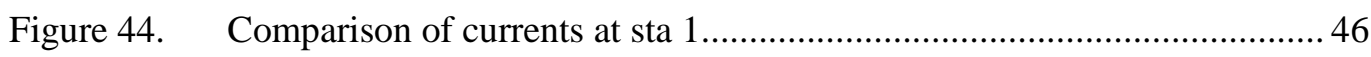

Figure 45. Comparison of currents at the eastern sides of Sundown

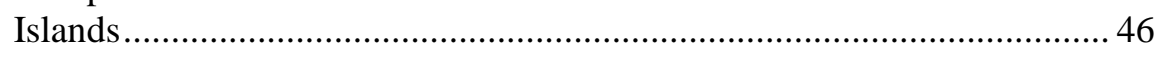

Figure 46. Comparison of currents at the external sides of Sundown Islands.

Figure 47. Idealized flood-shoal development

Figure 48. Idealized channel infilling pattern by a current with predominant flow direction 49 


\section{Preface}

The study described in this report was performed in Fiscal Year 1998 under the Diagnostic Modeling System (DMS) Work Unit of the Coastal Sedimentation and Dredging Program administered by Headquarters, U.S. Army Corps of Engineers (HQUSACE). Research and Development activities of the DMS are being conducted at the U.S. Army Engineer Research and Development Center (ERDC), Coastal and Hydraulics Laboratory (CHL). HQUSACE Technical Monitors were Messrs. Charles B. Chesnutt and Barry W. Holliday.

Work was performed by Dr. Nicholas C. Kraus, Coastal Sediments and Engineering Division (CSED), CHL; Mr. David J. Mark, Coastal Hydrodynamics Branch, Navigation and Harbors Division; and Ms. Soraya Sarruff, Tidal Hydraulics Branch, Estuary and Hydroscience Division. The study was done with the cooperation of the U.S. Army Engineer District, Galveston (CESWG) as a pilot project for evaluating the DMS. Guidance and review were provided by Messrs. Herbie A. Maurer and Johnny Rozsypal, Chief, CESWG Operations Division (OD) and Chief, Navigation Branch (NB), CESWGOD, respectively. Mr. Christopher D. Rossi, was the CESWG-OD-NB liaison in providing data and records in support of the study.

Work at CHL was performed under the general supervision of Dr. James R. Houston and Mr. Charles C. Calhoun, Jr., former Director and former Assistant Director, respectively, and the administrative supervision of Mr. Thomas W. Richardson, Acting Director, CHL.

At the time of publication of this report, Director of ERDC was Dr. James R. Houston, and COL James S. Weller, EN, was Commander. 


\section{Conversion Factors, Non-SI to SI Units of Measurement}

Non-SI units of measurement used in this report can be converted to SI units as follows:

\begin{tabular}{|l|r|l||}
\hline Multiply & \multicolumn{1}{|l|}{ By } & To Obtain \\
\hline \hline acres & 4046.873 & square meters \\
\hline cubic feet & 0.02832 & cubic meters \\
\hline cubic yards & 0.7645549 & cubic meters \\
\hline feet & 0.3048 & meters \\
\hline inch & 0.0254 & meters \\
\hline miles (U.S. nautical) & 1.852 & kilometers \\
\hline miles (U.S. statute) & 1.609344 & kilometers \\
\hline
\end{tabular}




\section{Background and Problem Statement}

The report herein documents a joint demonstration project conducted by the U.S. Army Engineer Research and Development Center (ERDC), Coastal and Hydraulics Laboratory (CHL), and the U.S. Army Engineer District, Galveston, to assess the functioning of the Diagnostic Modeling System (DMS). In this demonstration project, the DMS is applied to understand the causes of erosion at a Federal inland coastal waterway in Matagorda Bay, TX.

\section{Background}

The DMS is being developed under the Coastal Sedimentation and Dredging Program administered by the Headquarters, U.S. Army Corps of Engineer (USACE).

The DMS is intended to provide the USACE with a reliable capability that can be rapidly applied to identify, formulate, and evaluate alternatives for operation and management (O\&M) of Federal navigation channels. It is assumed that DMS methodology and tools will be applied with limited information on the hydrodynamic and sediment-transport conditions at a site. The core of the DMS is a compilation of experiences with highfrequency dredging sites, translating into a "lessons learned" guide called the DMS Manual (Kraus et al., in preparation).

The DMS will allow rapid and inexpensive evaluation or diagnosis of a problem shoaling area and provide guidance for determining possible solutions. The economic lever underlying the DMS concept is that a low-level analysis, possibly supplemented by a modest numerical modeling effort, can yield substantial cost savings while not interrupting ongoing O\&M activities and schedules. That is, the DMS is intended to provide feasible alternatives for reducing O\&M costs within the dredging cycle of the subject project. The application time and effort in applying the DMS are, therefore, relative to the maintenance time of the project.

The Galveston District agreed to serve as a partner in identifying a well-defined problem as the first exercise and evaluation of the DMS concept. The District recommended a specific high-shoaling area in Matagorda Bay, TX. At this site, dredging frequency is increasing and navigation is becoming more difficult. This report describes application of a DMS approach to Matagorda Bay. For the application, the District provided data and evaluated performance of the DMS approach. 


\section{Matagorda Bay}

Matagorda Bay is located in the central region of the Texas coast (Figure 1) and is one of seven major estuarine systems of the State, if Matagorda Bay and East Matagorda Bay are considered as part of the same system. Several smaller bays, notably Lavaca Bay, Carancahua Bay, Tres Palacios Bay, and Espiritu Santo Bay directly connect to Matagorda Bay. Surface area of Matagorda Bay is estimated at 425 square miles ${ }^{-}$(Ward 1982), making it second in size to Galveston Bay of the Texas estuaries (Ward, Wiersema, and Armstrong 1982). Depth over much of the natural (non-dredged) bottom of the inner bay and tributary bays runs between 10 and $12 \mathrm{ft}$ mean lower-low water (mllw). Depths sometimes reach $13 \mathrm{ft}$ as documented in National Oceanic and Atmospheric Administration (NOAA) Chart 11316, dated July 1995.

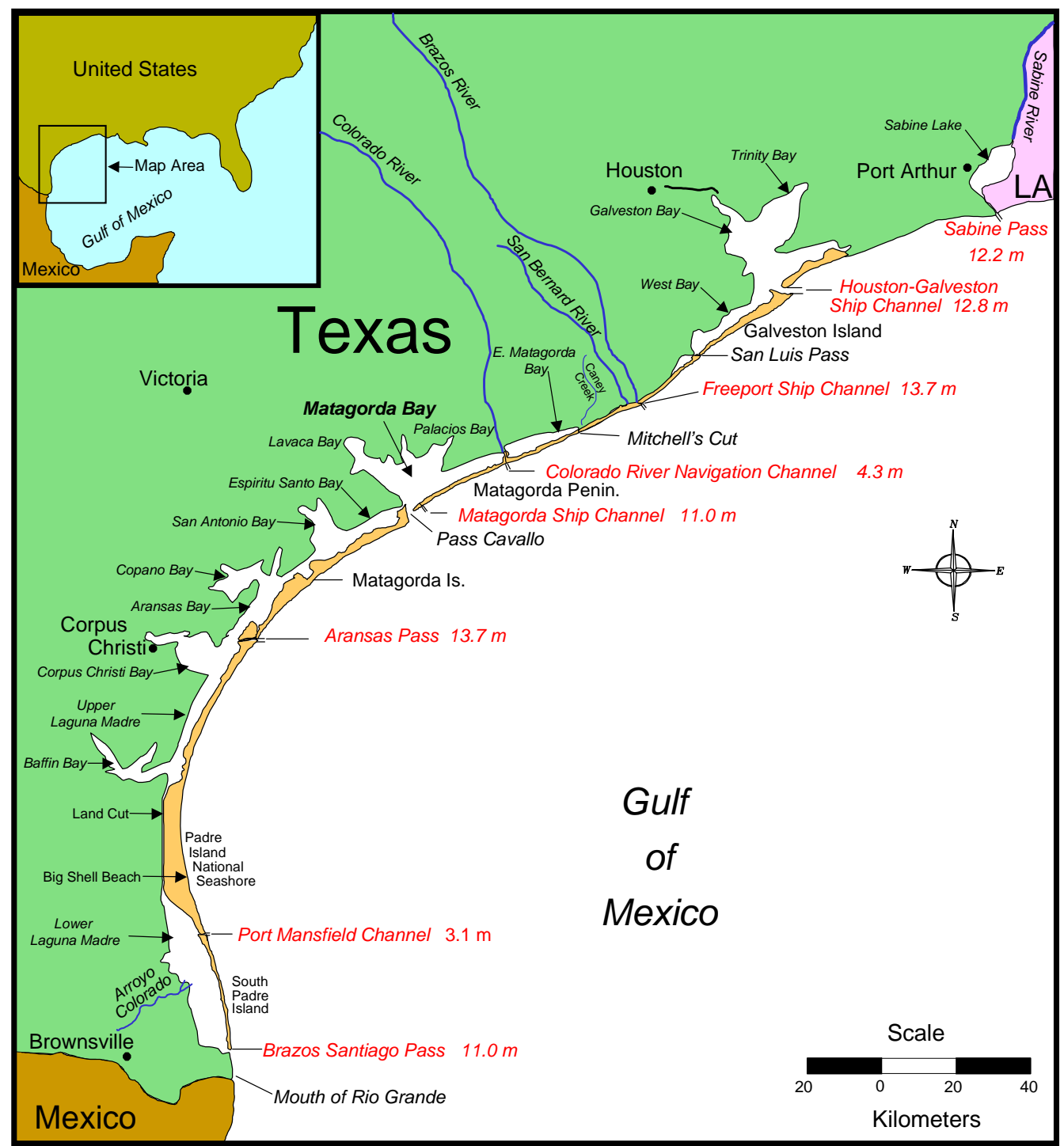

Figure 1. Location map for the study site and the Texas coast

\footnotetext{
${ }^{1}$ A table of factors for converting non-SI units of measurement to SI units is presented on page viii.
} 
The tide along the Texas coast is predominantly diurnal, meaning that there is one high and one low in a (lunar) day. The difference between mean high water and mean low water (mlw) is called the mean range of tide, because it contains both diurnal and semidiurnal components. The difference between mean higher high water and mllw is called the diurnal range of tide and encompasses only the single highest high and lowest low in a day. The mean tide range in the Gulf of Mexico is $1.4 \mathrm{ft}$ at the NOAA National Ocean Service (NOS) tide gauge located at the Galveston Pleasure Pier on the Gulf of Mexico side of Galveston Island. Secondary NOS gauges that have been placed at Port O'Conner, located just inside Pass Cavallo, and at Lavaca Bay, located at the north end of the bay, indicate mean and diurnal tide ranges that are nearly the same, about $0.8 \mathrm{ft}$. Thus, as the tidal wave propagates into and across the bay, bottom friction damps the small semidiurnal component almost completely.

Extreme changes in water level in Matagorda Bay that define navigation-controlling depth are primarily wind induced and accompany weather fronts that occur from about October to May. Seasonal variability in water level is also substantial as compared to the mean range of tide in Texas bays and estuaries. Because extreme low waters along the inland coastal waters of Texas are meteorologically controlled and not deterministic (related to the astronomical tide), the Galveston District has defined a local navigation datum called mean low tide (mlt). This topic has been discussed by Kraus et al. (1997). The mlt datum in Matagorda Bay lies $1 \mathrm{ft}$ below the National Geodetic Vertical Datum (NGVD) of 1929, as shown in Table 1 in Kraus et al. (1997). The geodetic datum NGVD 29 should not be confused with the tidal datum of mean sea level (msl), because they are not necessarily equivalent. Because NGVD monuments are lacking in the area and the NOS is presently updating tidal datums for the new 19-year National Tidal Datum Epoch 1980-1998, for the purpose of numerical modeling within the DMS, in this study mlt will be assumed to lie $1 \mathrm{ft}$ below msl.

Freshwater inflow to Matagorda Bay is moderate (Harwood 1973; Ward, Wiersema, and Armstrong 1982; Mueller and Mathews 1987) and consists primarily of the water discharges of the Colorado River Diversion Channel and the Lavaca River, discussed further in Chapter 3. Matagorda Bay and East Matagorda Bay were once a continuous water body into which the Colorado River discharged. Since the time of the early European settlers, the Colorado River had been plugged by a log jam that entrapped sediment and caused flooding in neighboring areas. In 1929, the log jam was freed by combined dredging and dynamiting. The discharged sediments rapidly crossed Matagorda Bay to form a delta that reached Matagorda Peninsula in 1935, creating a new bay now called East Matagorda Bay (Bouma and Bryant 1969).

In 1992, the Colorado River was rerouted to Matagorda Bay by the Galveston District to supply fresh water to the system. East Matagorda Bay is no longer connected to Matagorda Bay because of the lock system on the Gulf Intracoastal Waterway (GIWW) that facilitates navigation past the Colorado River. The circulation and changes in water level in East Matagorda Bay have been measured and numerically modeled by Kraus and Militello (1996, 1999).

\section{Pass Cavallo}

Matagorda Bay was originally connected to the Gulf of Mexico through a single permanent inlet, Pass Cavallo, located on the southwest end of the bay (Figure 2). Price (1952) found that the large estuaries of Texas tend to possess inlets in their southwest corners and freshwater inflows in their northeast corners. Stability of the southwest 
corner inlets is enhanced by the flows driven toward them by the strong winter winds out of the north and northeast.

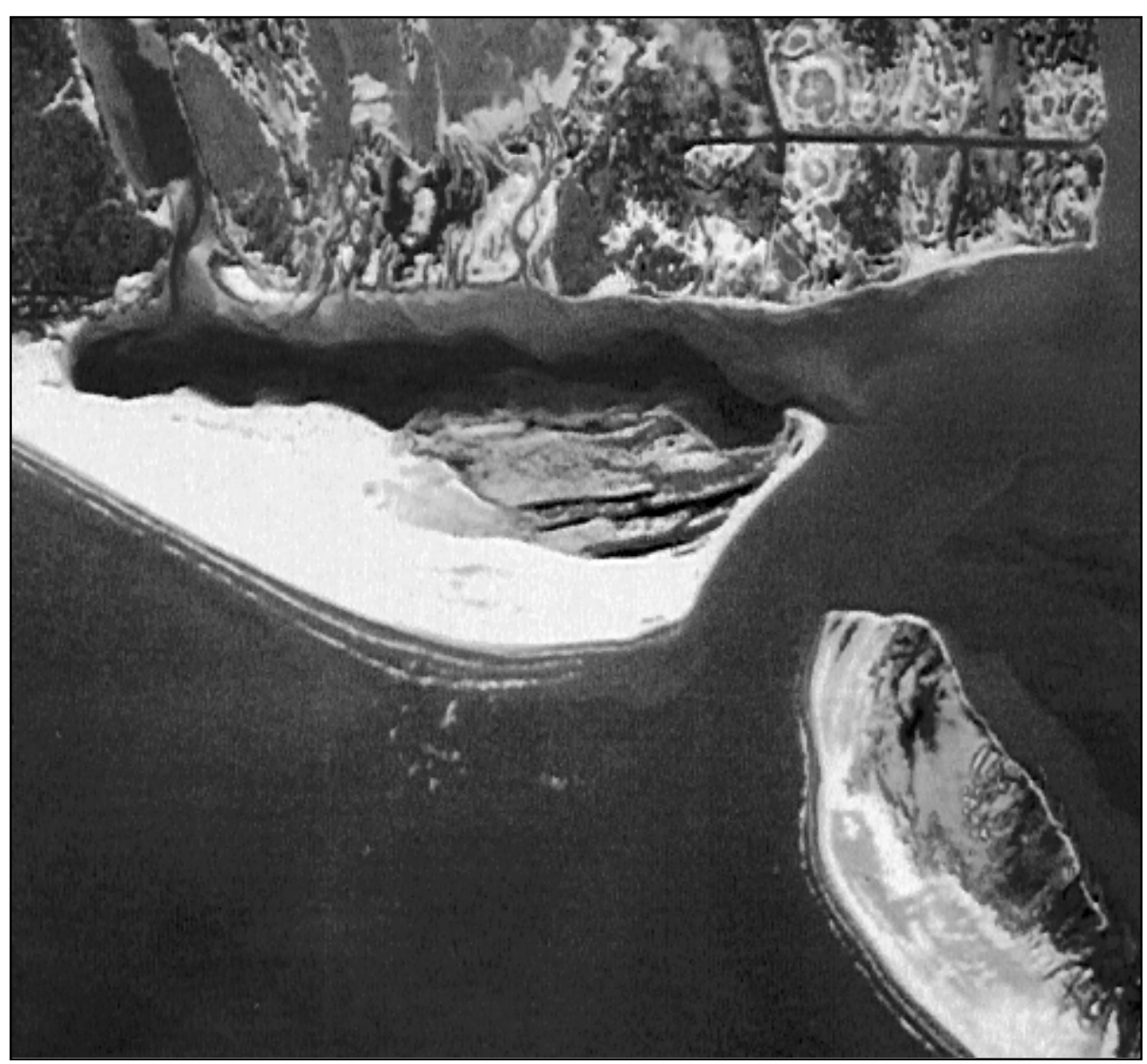

Figure 2. Pass Cavallo, January 1995

Pass Cavallo was one of the largest inlets on the Gulf Coast of the United States and was approximately 1.8 miles wide when first visited by European explorers. The inlet was navigable to small ships, although the deepest channels shifted frequently and were interrupted by shoals. In 1686, the French explorer La Salle lost one of three ships, his supply ship, in Pass Cavallo. Another of his ships, the Belle, was subsequently lost inside Matagorda Bay after it slipped mooring and was driven into the shallows of Matagorda Peninsula by strong wind and high waves. The Belle was recently discovered in $12 \mathrm{ft}$ of water (LaRoe 1997). Pass Cavallo remains treacherous to navigate. A commercial shrimp boat sunk along the southwestern margin of Pass Cavallo, off Matagorda Island (shown in Figure 3) is evidence of this.

The stability, geomorphology, and the flood delta of Pass Cavallo were the subject of the M.A. thesis of Harwood (1973). She concluded that the massive flood delta of Pass Cavallo has received sediments through the pass during times of high surge and strong currents accompanying hurricanes, tropical storms, and the turning winds of northers. The flood delta extends approximately 3 miles from the pass to Port O'Conner and includes the islands and marshes that separate Matagorda Bay and Espiritu Santo Bay. 
Harwood (1973) discounts typical currents flowing through the pass as being capable of creating and supporting either a permanent flood or ebb delta. The reasoning is that flood and ebb deltas are not prominent at other inlets on the Texas coast, nor is a relic ebb delta found opposite Matagorda Peninsula, which would have been abandoned as Delcros Point that migrated to the south in geologic time scales.

The consequence of bearing for the present study is that clear empirical evidence indicates a strong current issuing through an inlet or entrance in Matagorda Bay can transport sediment and deposit it as far as 3 miles bayward of the inlet or entrance.

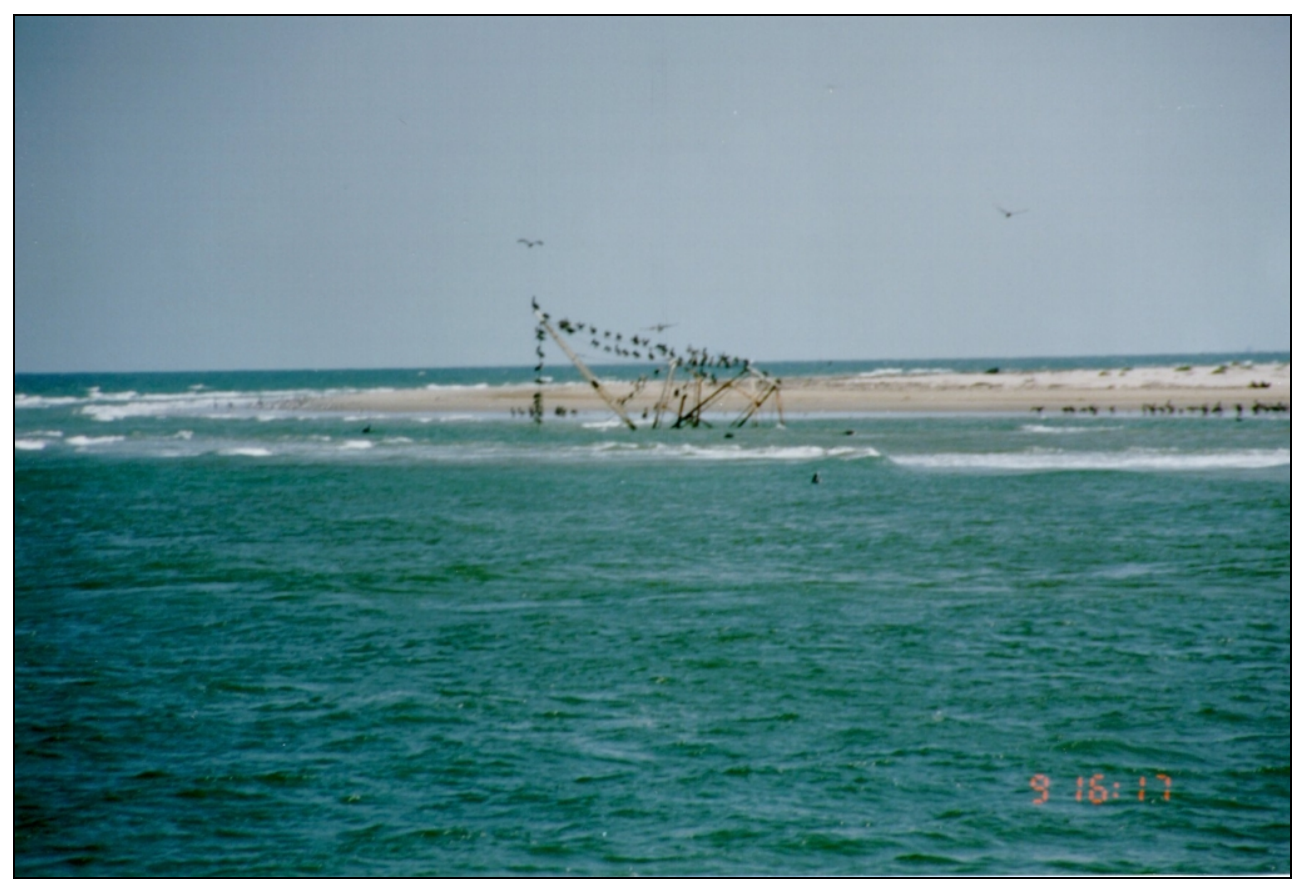

Figure 3. Shrimp boat sunk in Pass Cavallo (September 1997)

Tidal prism is defined as the product of bay water-surface area and the tidal range, typically the spring tidal range. Harwood (1973) concluded that the cross-sectional area of Pass Cavallo decreased after the Colorado River delta eliminated the water-surface area of East Matagorda Bay from the bay system because of the decrease in tidal prism. Her conclusion was based on estimates of the tidal prism and the cross-sectional areas of Pass Cavallo as interpreted from navigation charts and a satellite photograph (for the year 1971). She lists six dates from 1856 to 1971 for which survey data were available for study. By 1971, the discharge through Pass Cavallo had decreased as compared to estimates from earlier dates. With diversion of the Colorado River back to Matagorda Bay in 1992, this cause for a reduction in flow out of the bay was eliminated.

More significantly, the discharge through Pass Cavallo has decreased because the Matagorda Ship Channel (MSC) opened in September 1963, as also noted by Harwood (1973). Ward (1982) compared measured tidal prisms of Pass Cavallo and the MSC available from 1959 to 1976 and showed that the MSC had already captured half the tidal prism by 1976 (Van de Kreeke 1985). Measurements made in the present study, as described in Chapter 3, show that three-fourths of the discharge or prism now goes through the MSC. Pass Cavallo is closing, a situation considered in a physical model 
study performed by the U.S. Army Engineer Research and Development Center's Waterways Experiment Station (Simmons and Rhodes 1966). Figures 4 and 5 respectively show Pass Cavallo before (1954) and after (1991) construction of the MSC.

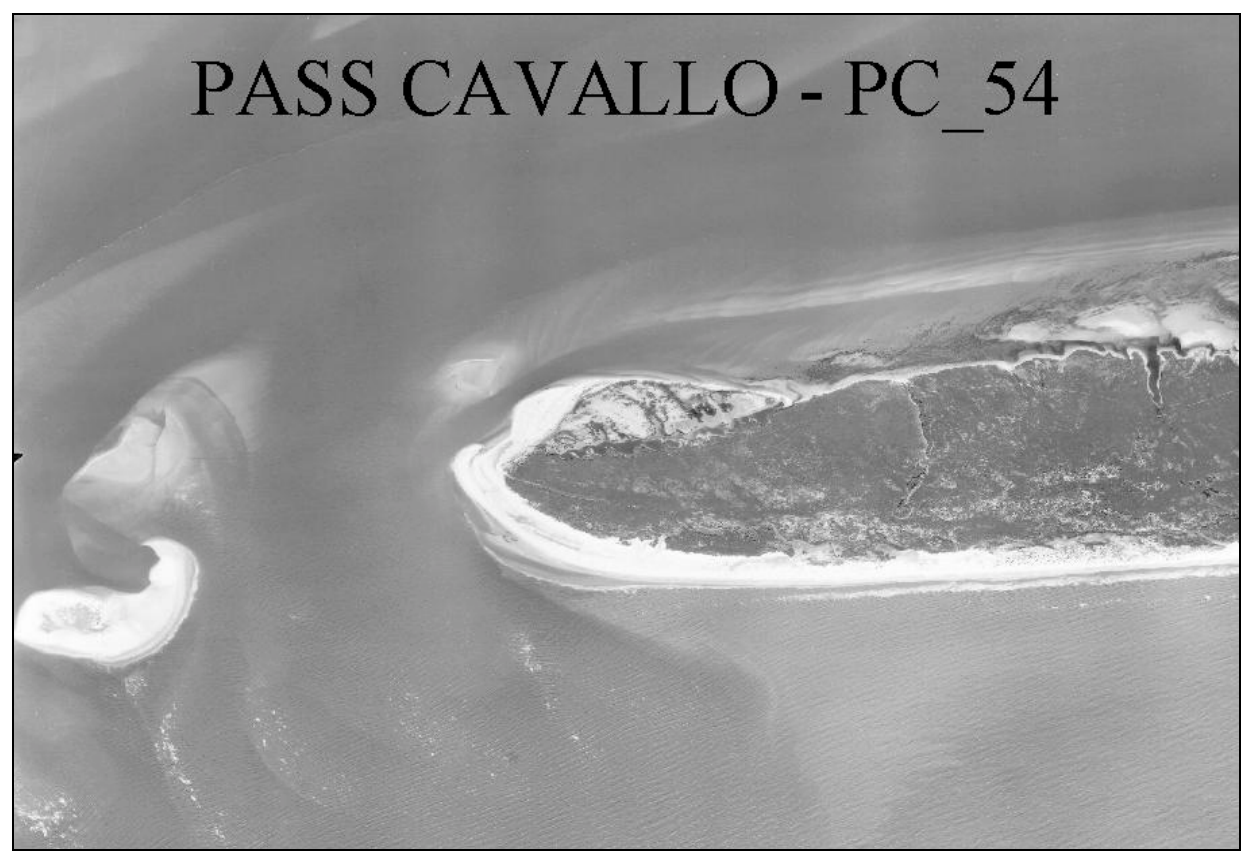

Figure 4. Eastern side of Pass Cavallo showing Delcros Point and several shoals within the inlet in 1954, before opening of the MSC

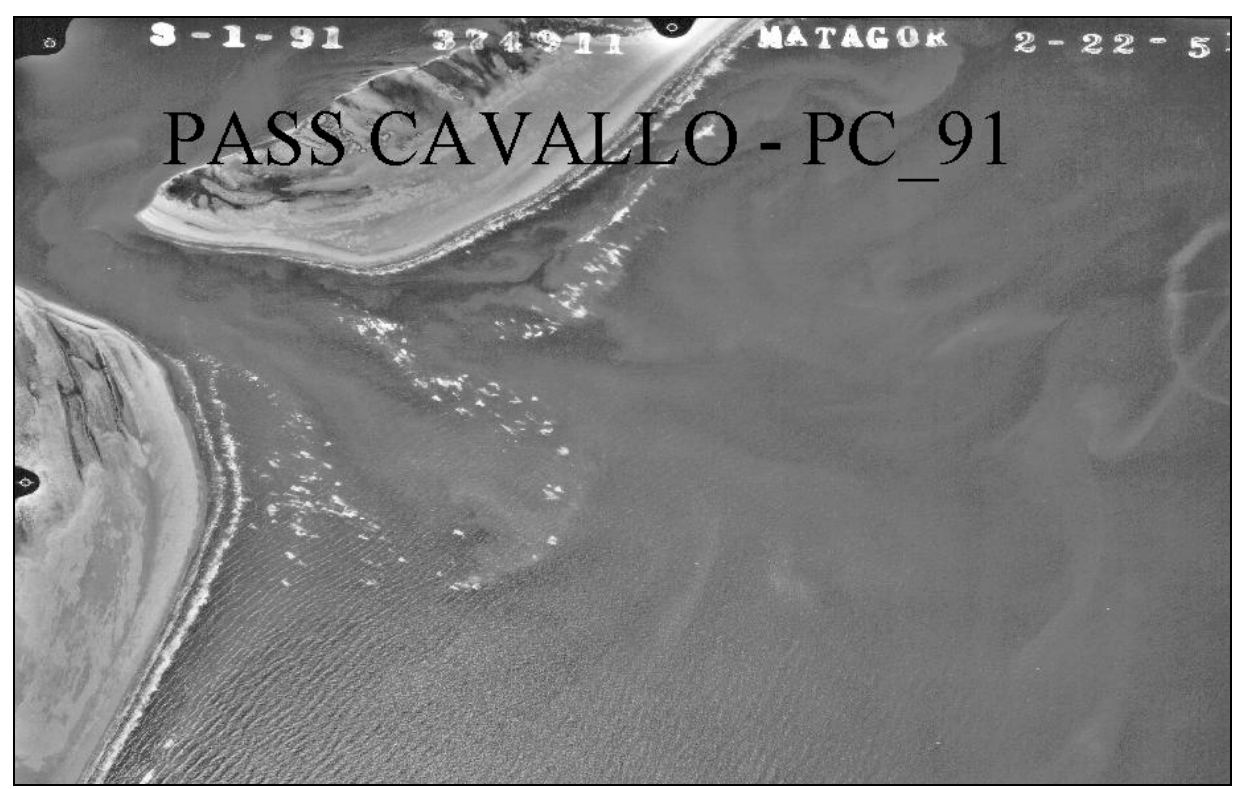

Figure 5. Pass Cavallo in 1991, showing much reduced width as compared to 1954. Two channels are observed, with the channel directed to the southwest being larger 
Figure 6 shows the tip of Delcros Point, located on the opposite side of Pass Cavallo. The photograph was taken on the same day as the photograph in Figure 2. The tip of Delcros Point is low-lying, and the sand on it appears to be newly arrived. Delcros Point is growing into Pass Cavallo, as is the recurved spit growing emerging from Matagorda Island on the other side (Figure 2). Spits can grow from both sides because the discharge through the inlet is decreasing.

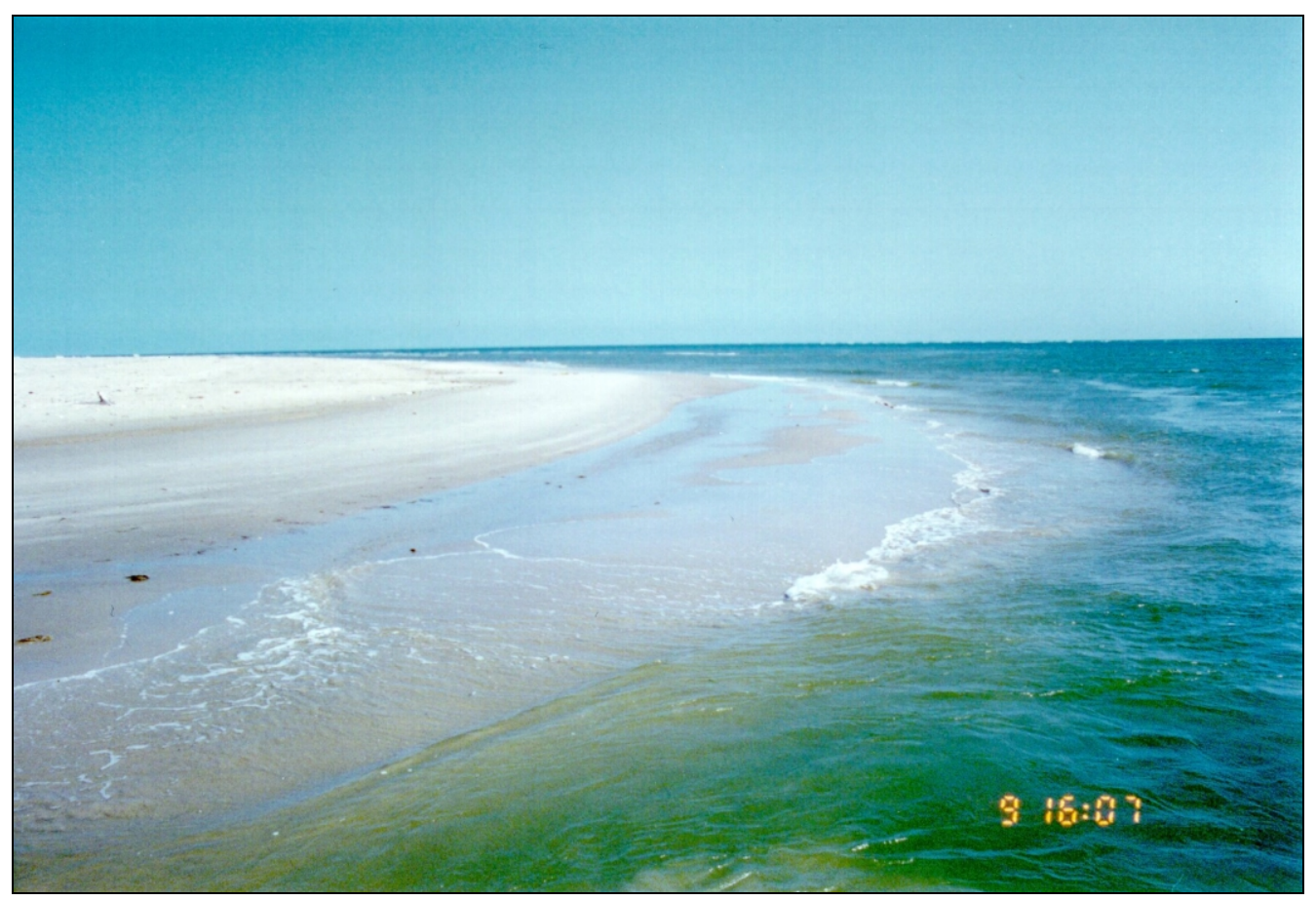

Figure 6. Distal end of Delcros Point, looking gulfward (September 1997)

\section{Matagorda ship channel}

The MSC is one of eight Federal channels of Texas that exit to the Gulf of Mexico (Figure 1). Considerations leading to construction of the MSC are given in the U.S. Army Engineer District, Galveston (1992) and in Simmons and Rhodes (1966). Quoting USAED, Galveston (1992), "To secure a 12-ft-channel depth across the bar, a single jetty was begun in 1881 at the south side of the pass, designed to extend 7,600 ft from Matagorda Island. However, in 1888 the project was abandoned. In 1948, the controlling depth was approximately $9 \mathrm{ft}$." According to Simmons and Rhodes (1966), "In 1949, a channel with a controlling depth of $17 \mathrm{ft}$, width of $135 \mathrm{ft}$, and length of 3,000 ft was dredged across the outer bar at Pass Cavallo as an emergency measure to relieve the restricted navigation conditions. The channel was completed on 9 September 1949 , but shoaled rapidly to a controlling depth of $10 \mathrm{ft}$ by 2 November 1949 and to a controlling depth of $8 \mathrm{ft}$ in March 1952." No further attempts were made to dredge Pass Cavallo.

It can be concluded that the significant width of Pass Cavallo made infeasible the possibility of economically maintaining a reliable channel and that the cost of constructing jetties to constrict the wide area would similarly be infeasible. Prior to cutting the MSC, Pass Cavallo was approximately 8,000 ft wide. Presently, aerial 
photography and bathymetric surveys show it as approximately 2,000 ft wide. If Pass Cavallo were to close, the discharge through the MSC would increase, and the channel would further scour until the equilibrium cross-sectional area was reached.

The MSC was authorized by Congress in 1958 for a channel $36 \mathrm{ft}$ deep (mlt) (38 ft deep on the outer bar) and $300 \mathrm{ft}$ wide. WES conducted a study in a fixed-bed movable model under the sponsorship of the Galveston District to determine the hydrodynamic properties and consequences of alternative locations for the cut in Matagorda Peninsula. In support of the Federal study, measurements of the water level and current in the bay were made in the late 1950 s by the main local interest, the Aluminum Company of America (ALCOA). ALCOA is still a major user of the MSC, which approaches its plant at Point Comfort, as well as Port Lavaca, in Lavaca Bay. The physical model study is documented in a comprehensive report prepared by Simmons and Rhodes (1966), and additional aspects of the project are described by Galveston District personnel (Rhodes and Boland 1962; Weiser and Armstrong 1962).

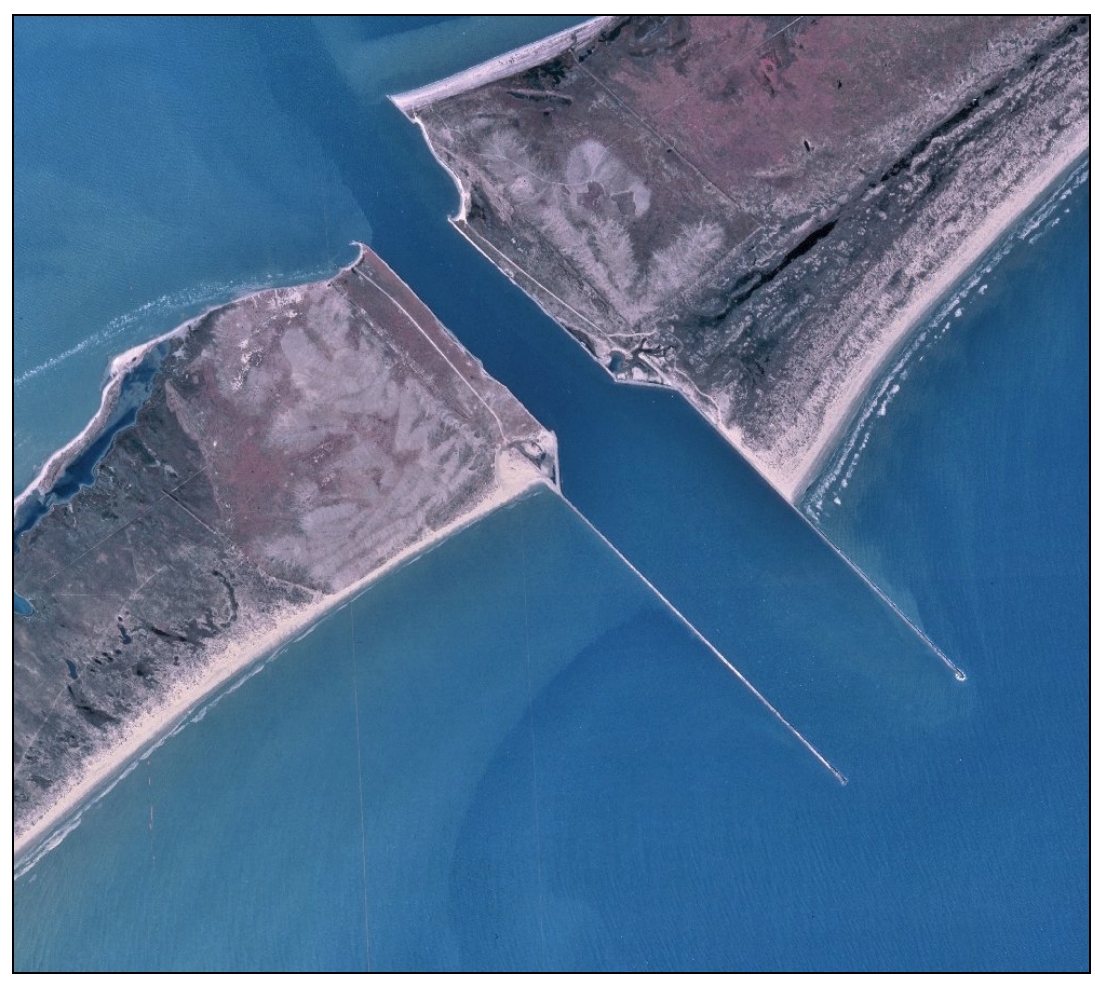

Figure 7. Matagorda Ship Channel, January 1995

Inlet dredging through Matagorda Peninsula and the associated jetty construction was initiated in 1962, with the land cut opened in September 1963. The deep-draft MSC was placed 18,000 ft northeast of Delcros Point at Pass Cavallo. As predicted in the physical model, the current was strong and within a few months after opening, the entrance channel had scoured below the design depth. The entrance was revetted in a bottleneck shape (Figure 7) and is $800 \mathrm{ft}$ wide in the neck and 2,000 ft wide at the gulfward jetty section. Presently, depth in the channel entrance runs from more than $100 \mathrm{ft}$ just north of the neck, decreasing to between 50 and $60 \mathrm{ft}$ for more than a mile gulfward of the 
entrance. The inlet gorge is self-scouring and, since construction, no dredging has been required at or seaward of the MSC entrance.

\section{Gulf Intracoastal Waterway}

The Gulf Intercoastal Waterway (GIWW) is a major water artery that runs along the inland coastal waters of Texas for 435 miles. The first navigable segment of the GIWW in Texas was completed in 1853 (Texas Department of Transportation 1994) and connected West Galveston Bay and the Brazos River, which lie to the north of Matagorda. Thereafter, the GIWW in Texas was constructed in a series of segments, and the earlier waterways were typically $9 \mathrm{ft}$ deep by $100 \mathrm{ft}$ wide.

The present design dimensions of the GIWW are 500-ft width at the top, 125-ft width at the bottom, and 12-ft depth (to mlt for the case of Texas). Legislation to maintain the entire waterway to its present dimensions was passed by Congress in 1942. In Texas, the GIWW is dredged to 14-ft depth, which includes $1 \mathrm{ft}$ of advance dredging and $1 \mathrm{ft}$ of over-dredging (allowance for operational practicality and inaccuracy in dredging).

Atturio, Basco, and James (1976) studied the shoaling characteristics of the GIWW from Port Arthur to Brownsville (380 miles) by evaluating dredging records in 5,000-ft segments along U.S. Army Corps of Engineers (USACE) waterway stations. Among their conclusions are as follows:

a. The average shoaling rate over the entire reach was 10.5 in. per year.

$b$. Shoaling rates in open-bay areas were on average 3 in. per year greater than in land-cut areas.

c. The combination of dredged-material mounds, or fetch greater than 5 miles, with water depths less than $6 \mathrm{ft}$ (surrounding bay depth) increased average shoaling rates to 5 in. per year.

$d$. The placement of dredged material in mounds on the windward side of the waterway increased the average shoaling rate of open-bay areas by 7 in. per year.

$e$. In bay areas with long fetches and depths less than $3 \mathrm{ft}$, it was found that windward placement of dredged material reduced the shoaling rate as compared to neighboring sections.

f. Hurricanes did not appear to have catastrophic consequences for the inland waterway.

In a study on the cause of chronic shoaling in the Lower Laguna Madre (see Figure 1), Militello and Kraus $(1994,1995)$ found that redirection of the tidal and windgenerated flow in the large lagoon moved opposite to the circulation inferred from the predominant wind direction. At this high-shoaling area, they recommended placing the dredged-material islands upwind rather than downwind. Their study showed that the cause of increased sediment shoaling in a waterway may not be intuitively obvious and, together with modest field measurements, an application of a numerical model of the hydrodynamics can be helpful for inferring sediment paths and the driving mechanisms controlling the shoaling. 


\section{Problem Statement - Relocation of the GIWW}

Authorization for the present dimensions of the GIWW in Matagorda Bay is contained in U.S. Congress (1939). It is believed that the original waterway exited the land cut opposite Palacios Bay and proceeded to Port O'Conner in a much more northerly route than that occupied at present. This original route would have been the most direct and would have taken advantage of deeper water in the north portion of the bay. The GIWW in Matagorda Bay was relocated in 1944 in support of military activities at Camp Hulen, which was located near the city of Palacios. The relocation of the waterway to the south was probably done on local discretionary authority. Authorization to relocate the channel back to its pre-1944 position is contained in U.S. Congress (1962).

Presently, the GIWW crosses the MSC about 13,000 ft northward of the bayward side of the MSC entrance, and there is substantial ship and barge traffic at that intersection. Significant shoaling as well as swift currents are also present because of the close proximity of the intersection to the MSC entrance. The current has been reported by the Matagorda Bay Pilots Association to be exceptionally difficult on flood tide, which they estimate reaches 7 knots (approximately $3.5 \mathrm{~m} / \mathrm{sec}$ ). According to a 1994 letter sent to the Galveston District by the U.S. Coast Guard (USCG), there were 44 groundings and 382 aids-to-navigation discrepancies near the intersection in $1994 .{ }^{2}$ The combination of rapid shoaling, strong wind, and strong tidal current greatly increases the likelihood of grounding by towing vessels. Because of the strong current flowing through it, the MSC may be one of the few locations along the coast of Texas where tidal force dominate wind force. However, wind-induced currents, as well as the wind acting on high profiles of ships and empty barges, are also significant factors for navigation in all Texas coastal waters, including at the MSC-GIWW intersection.

The GIWW section located northeast of the MSC-GIWW intersection that runs from sta 600+00 to 615+00 requires maintenance dredging each year, and barge groundings occur frequently along this stretch. Sundown Island, an artificial island created from dredged material, lies near the intersection, east of the MSC and south of the GIWW, and the high-frequency dredging section runs along the north side of the island. The island is a successful and prominent "Beneficial Uses of Dredged Material" site that serves as habitat for the endangered brown pelican. The island is prone to erosion, and it is only through near-annual nourishment and shore protection over some of its perimeter that it remains. The mechanism of the erosion is examined in the present study. It will be shown in this report that material eroded from the island is a significant contribution to shoaling in the GIWW.

The Galveston District, the USCG Marine Safety Office, the Matagorda Ship Pilots, and the waterway towing industry have raised the possibility of moving the GIWW northeastward. The new intersection of the MSC and GIWW would be located about $7,000 \mathrm{ft}$ northward of the present intersection and about 20,000 $\mathrm{ft}$ from the bayward side of the MSC entrance. Potential benefits to relocating the GIWW northward are as follows:

\footnotetext{
${ }^{1}$ Personal communication, 2 December 1998, Mr. Larry Robinson, Pilot, Matagorda Bay Pilots Association. Mr. Robinson has been piloting ships in Matagorda Bay since 1981. He stated that the current in the MSC has become stronger over the years, which he attributes to the gradual closure of Pass Cavallo.

${ }^{2}$ Personal communication, 1994, USCG.
} 
a. Northward relocation will provide safer navigation by increasing the distance between the MSC-GIWW intersection, thereby putting it in area of weaker alongchannel and cross-channel currents.

$b$. The relocated GIWW will not receive the significant contribution to sediment shoaling experienced at the present location. Weaker currents across the relocated GIWW will reduce the sediment shoaling rate as compared to the high rate at the present location of the GIWW.

c. Once the sediment-transport processes are known, rebuilding of a "New Sundown Island" might be accomplished to create a more stable bird island that will require less maintenance because it would be in an area of weaker currents. The island would be placed at a location where it would not erode into the GIWW, as is the case at present.

The northward location would require minimum dredging because of the existing depths of the natural bay bottom to the north.

No study has been undertaken to develop objective information for moving the GIWW or for considering other alternatives to reduce dredging frequency. The problem addressed in this DMS application is to determine the causes of shoaling at the present MSC-GIWW intersection and to provide guidance for optimal placement of dredged material at the alternative location of the GIWW. This information enters the decision process for judging the economic and environmental feasibility of moving the GIWW northward to its pre-1942 location or for comparison to other possible alternatives.

\section{Objectives and Procedures of this Study}

The objective of this study is to determine the cause of chronic shoaling in the GIWW near the MSC-GIWW intersection in Matagorda Bay and to recommend a solution that will reduce the frequency and cost of dredging, while improving navigation safety. The objective is to be met by application of DMS concepts and methodology.

The procedure employed in this first DMS application is as follows:

a. Make site visits, review the existing literature, and discuss the physical processes with those possessing local knowledge. Persons consulted were staff of the Construction and Operations Division of the Galveston District, surveyors from the Corpus Christi Field Office of the Galveston District, pilots of Matagorda Bay Pilots Association, and Mr. Chester Smith, who is the Sundown Island warden for the National Audubon Society.

$b$. Make limited-duration measurements of the current and water level in the vicinity of the MSC, Pass Cavallo, and the MSC-GIWW intersection to understand the circulation pattern at the study site and to calibrate the numerical hydrodynamic model established for Matagorda Bay under DMS guidelines.

c. Analyze dredging records for the study site and interpret them in light of information obtained in Items $a$ and $b$ through classification according to the DMS Manual (Kraus et al., in preparation).

$d$. Establish and calibrate a numerical hydrodynamic model for the depth-averaged two-dimensional circulation in Matagorda Bay and run the model with the existing condition and for the alternatives. 
e. Synthesize information and results from Items $a-d$ and make recommendations for reduction of channel shoaling.

This report documents the results of this DMS application. Chapter 1 gives the problem statement, overview of the study site, and study objectives. Chapter 2 contains a review of the dredging records and gives qualitative observations of shoaling in the problem area of the GIWW. Procedures and results of the circulation modeling are presented in Chapter 3, which also includes discussion of the tide, circulation, and wind at Matagorda Bay. Chapter 4 presents conclusions and recommendations.

\section{Units of Measurement}

In discussion of dimensions and quantities originally reported in the literature in American Customary (non-SI) units, those units are retained. A table of conversion factors from non-SI to SI units is given on page viii. Oceanographic and meteorologic measurements and calculations, such as water current and wind velocity, are given in SI units. 


\section{Channel Shoaling}

In this chapter, the shoaling rates are analyzed for the high-frequency dredging section adjacent to the MSC-GIWW intersection and to Sundown Island. The analysis is based on Galveston District dredging records. Inferences about sediment paths are made by inspection of aerial photographs and reconnaissance surveys of Sundown Island.

\section{Review of Dredging Records}

The Galveston District provided maintenance dredging records dated from 1965 to 1995 that include listings of dredging frequency and amount of material dredged for maintenance by location according to District stationing. The area experiencing greatest navigation discrepancies and dredging is located at and around the MSC-GIWW intersection, and the studied reaches were selected according to their proximity to this intersection. The stretch covered by the records for the MSC extends from the Matagorda Peninsula south of the channel to Point Comfort to the north. The stretch for the GIWW extends across Matagorda Bay.

The analyzed records comprise 3.4 miles of the GIWW and 1.9 miles of the MSC. Records of the GIWW were analyzed from sta $600+000$ to $618+000$ (east to west). The MSC stretch from sta $11+000$ to $21+000$ was studied (south to north). Both reaches include the MSC-GIWW intersection. The studied stretch of the GIWW was divided into 2,000-ft-long segments, and the MSC stretch was divided into 1,000-ft-long segments for analysis. This division into equal lengths allows more reliable comparison of volume distributions.

\section{Dredged volume}

Figure 8 plots the volume of material dredged from the GIWW stretch under study. The MSC-GIWW intersection is located between sta 616+000 and 617+000. The quantity of material dredged increases significantly as distance to the intersection decreases. The amounts of dredged material and distance to the intersection have a high correlation coefficient of 0.91 , statistically significant at 99 percent confidence level.

Volumes of most of the material dredged from the MSC section under study are displayed in Figure 9. The intersection of the GIWW with the MSC is located at sta $616+000$. Again, the figure shows a substantial increase in volume of dredged material at and northward of the intersection with the GIWW. 


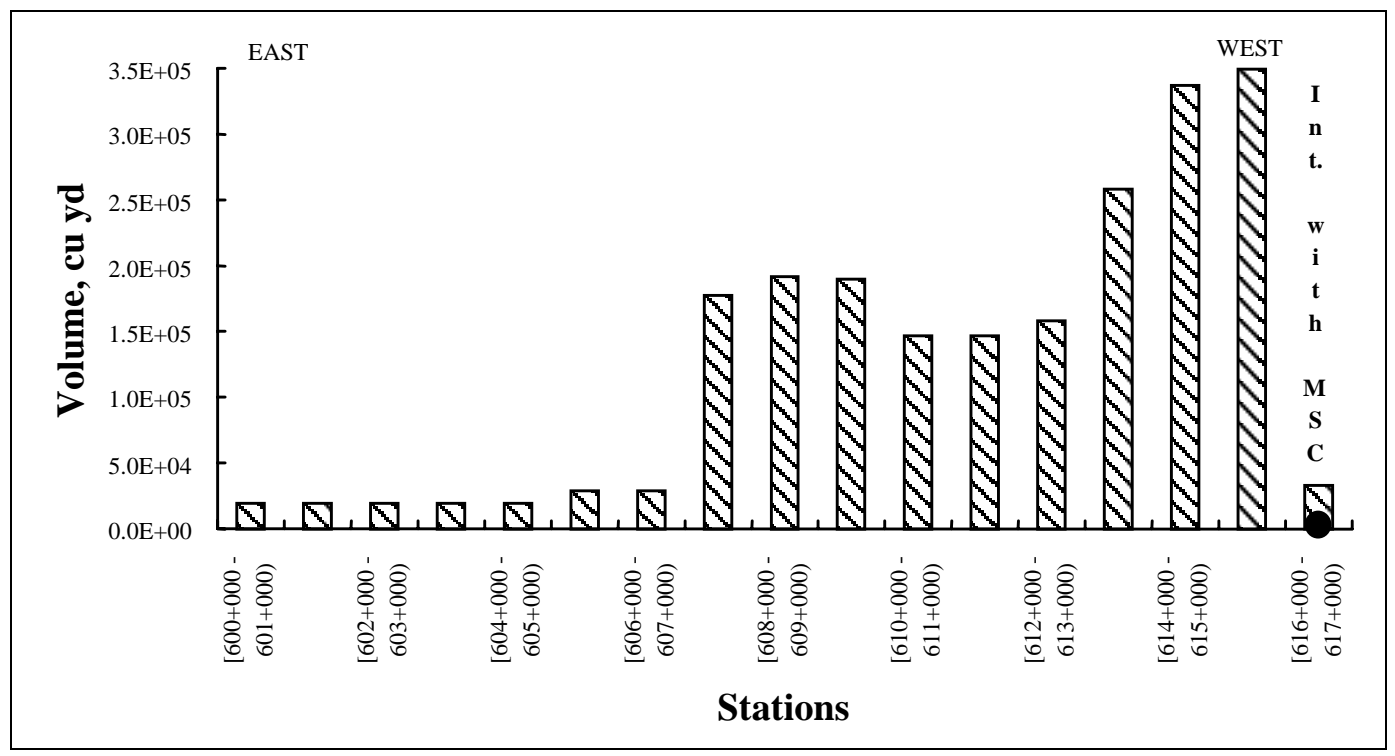

Figure 8. Volume of material dredged for maintenance from the GIWW (1969-1995)

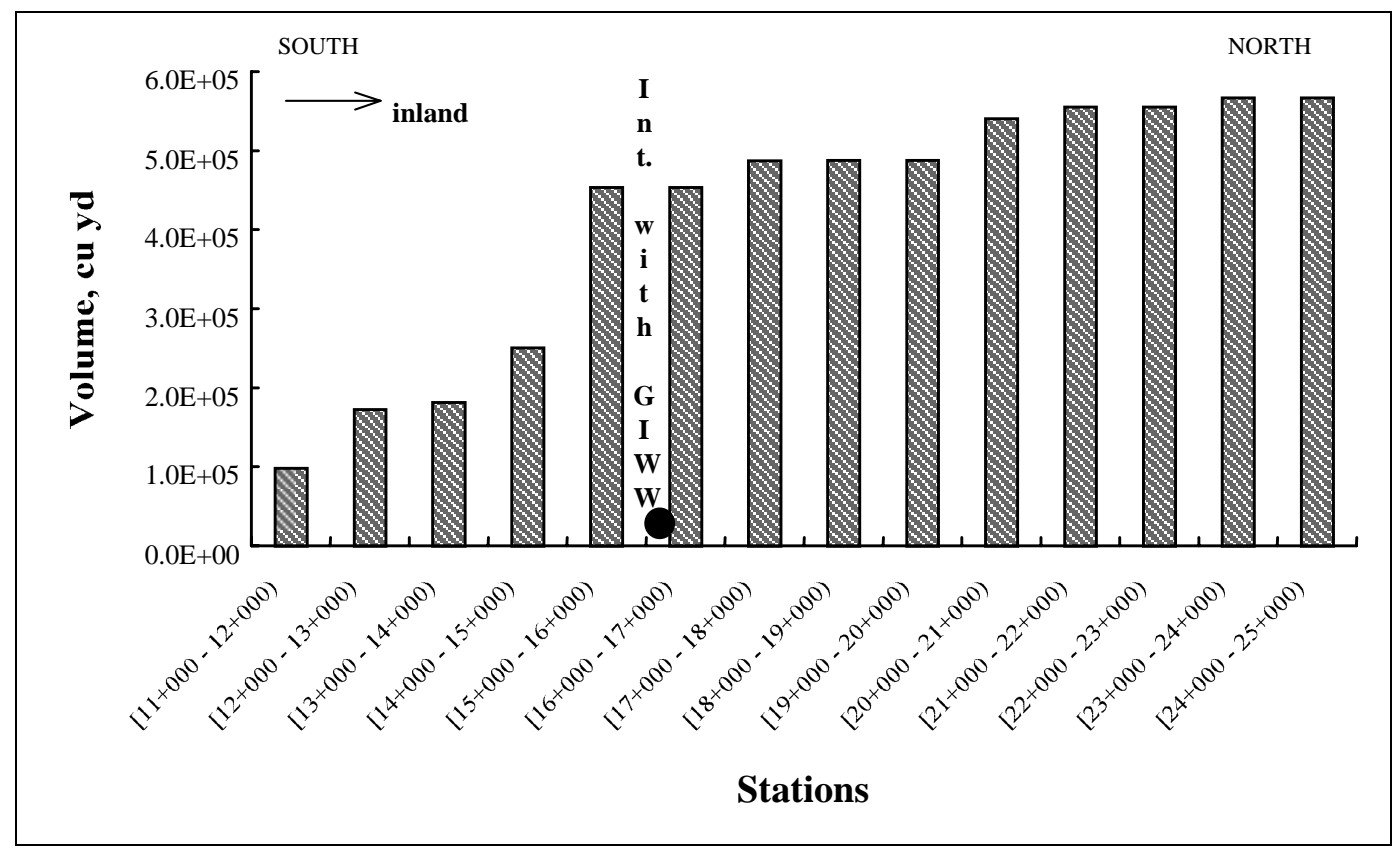

Figure 9. Volume of material dredged for maintenance from the MSC (1965-1994)

Figures 10 and 11 show the cumulative volumes dredged for maintenance in the GIWW and MSC, respectively. The closest section of the GIWW to the intersection (sta $612+000-616+000$ ) is the one exhibiting most rapid shoaling over the years. Instead of being uniform or a linear function of time, the cumulative volume of this stretch increases at a greater rate. The best-fit power function to this curve is: 


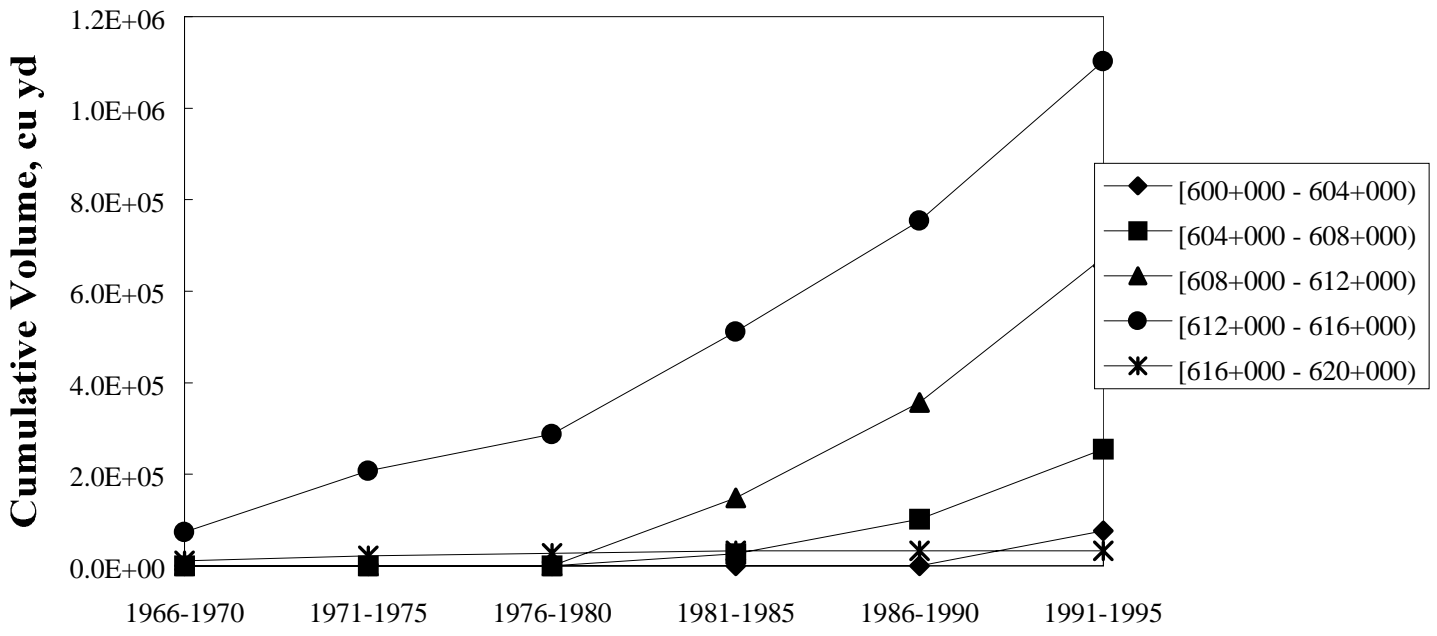

Elapsed Time (years)

Figure 10. Cumulative volume of material dredged for maintenance from the GIWW

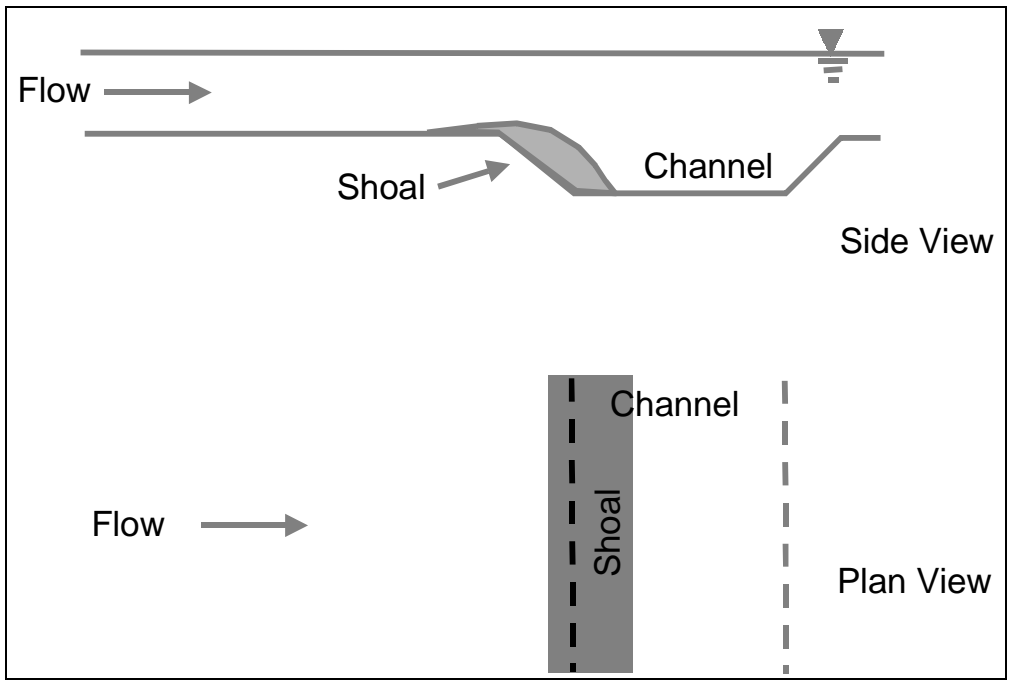

Figure 11. Idealized channel infilling pattern by a current with predominant flow direction

$$
V=70,468 t^{1.46}
$$

where

$V=$ cumulative volume $(\mathrm{cu} \mathrm{yd})$

$t=$ elapsed time (years) (counting in 4-year increments; that is, $t=1$ means 4 years, $t=2$ means 8 years, etc.) 
This power function describes the existing situation whereby the increasing sediment shoaling or dredging volume will require increased O\&M cost with time.

Figure 12 indicates how the segments after the intersection (sta 15+000 - 21+000) with the GIWW have cumulatively yielded larger amounts of material dredged. Figure 13 breaks down the cumulative volume dredged for maintenance from the GIWW into sections for the years in which most of the dredging has been performed. The years between 1986 and 1995 experienced the most dredging activity. This observation is consistent with the increase in dredging frequency and cost noted by the Galveston District.

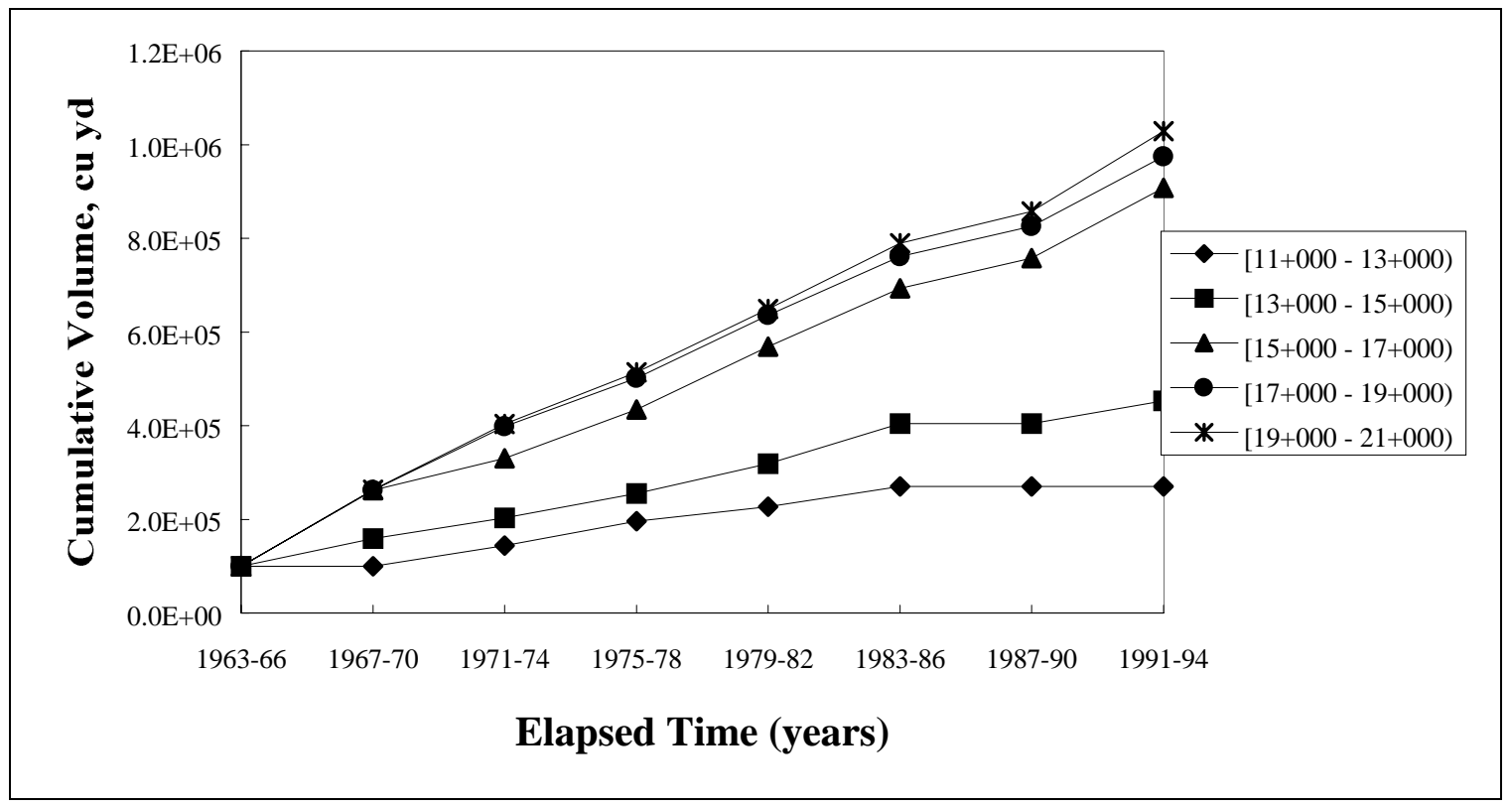

Figure 12. Cumulative volume dredged for maintenance from the MSC

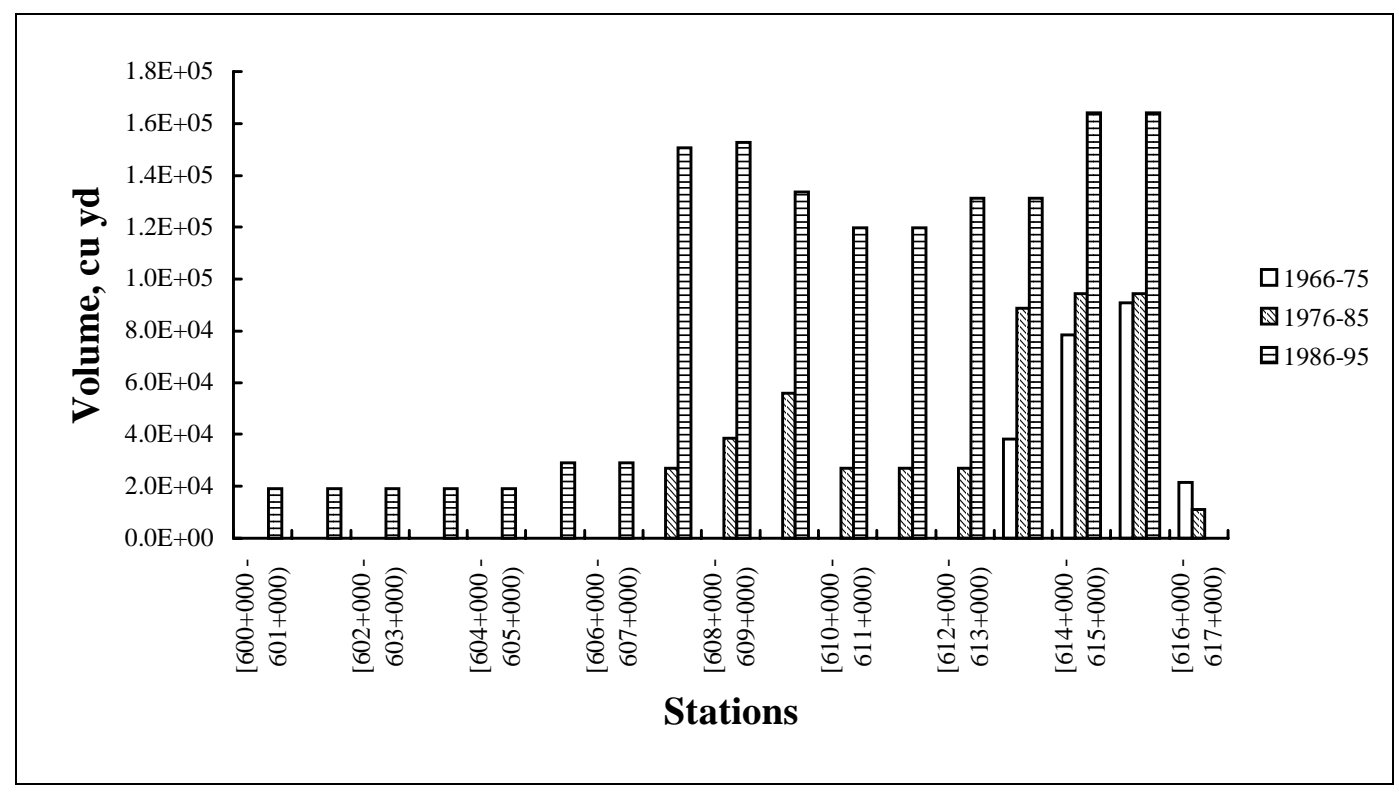

Figure 13. Volume of material dredged for maintenance from the GIWW 
Figure 14 depicts the dredging history for the MSC for the same time interval as in Figure 13 for the GIWW. This MSC segment was dredged the most in the first decade after the MSC entrance was cut. Maintenance dredging declined somewhat in the subsequent 10 years, and the amount of material dredged increased slightly after 1984 .

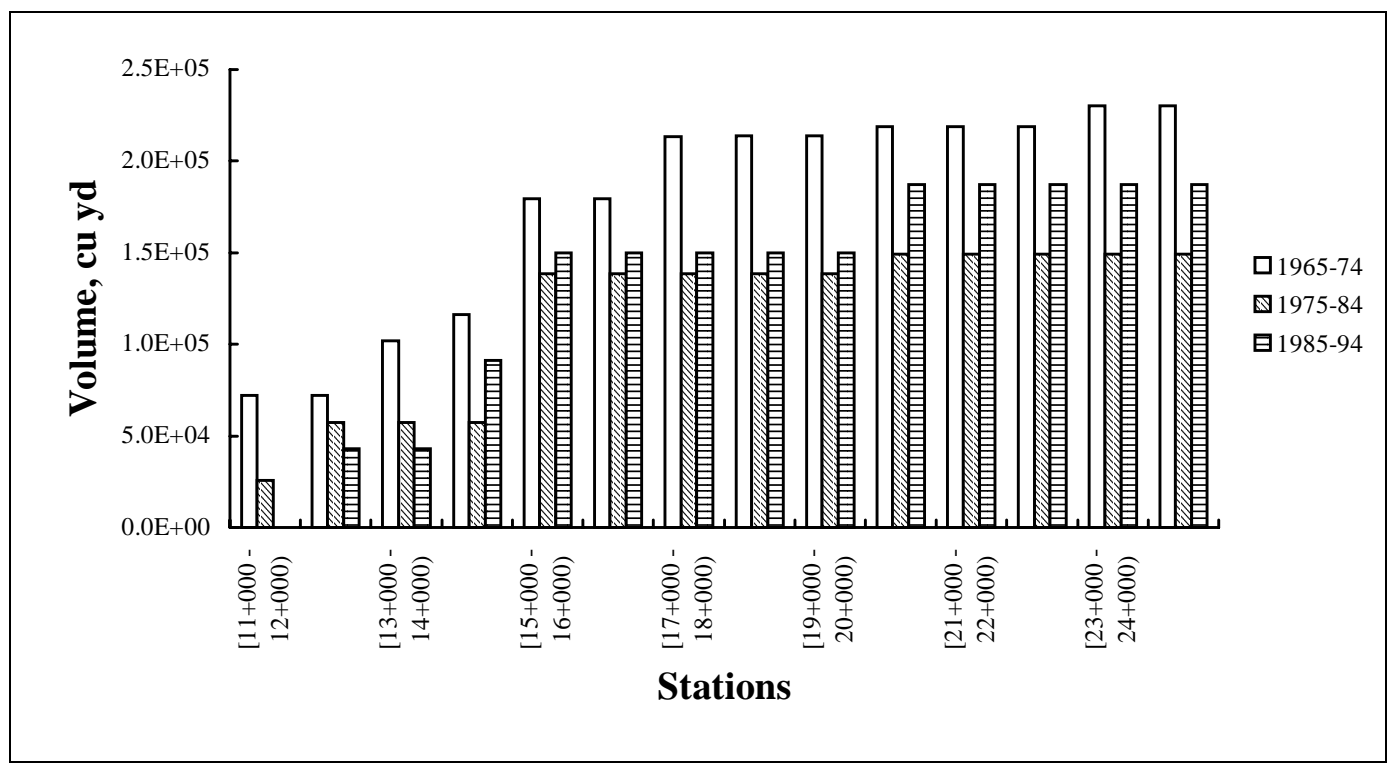

Figure 14. Volume of material dredged for maintenance from the MSC

\section{Channel cross section}

Condition surveys were examined for the MSC and GIWW channel segments discussed in the preceding section. It was found that the MSC tended to accumulate sediment in approximately equal amounts on both sides of the channel center line, with little change in depth in the middle of the channel. It can be reasoned that the motion of the keel and propellers of ships traversing the MSC tend to sweep sediment away from the bottom of the channel. Approximately equal amounts of deposition on either side of the center line indicate that the crosscurrent is balanced in direction; there was no strongly preferential direction of the crosscurrent.

The condition surveys of the GIWW showed that the sediment accumulated predominantly on the south side, the side nearest Sundown Island. The pattern of accumulation is consistent from a characteristic or "symptom" identified in the DMS Manual, as depicted in Figure 11. Sediment is shown entering a channel from one side, as transport by the water flow. If the sediments are in the sand size range and do not remain in suspension or are easily suspended, then the bank will fill to reduce channel width and, ultimately, channel depth.

\section{Sundown Island}

Sundown Island serves as a beneficial uses site for dredged material and forms a portion of the Galveston District's Disposal Area 116A. It is an unconfined, partially-emergent disposal area and subject to chronic erosion by waves and currents, especially during strong winds and storms, when the water level in the bay 
becomes elevated. The emergent area of Sundown Island has been variously estimated as between 15 and 50 acres, depending on the state of erosion and subsequent fill. The island was formed of material removed in cutting of the MSC during 1962 to 1963, and it may have been placed in its location as suggested by Simmons and Rhodes (1966) to reduce the crosscurrent along the MSC that was observed in the physical model. Material dredged from the GIWW in the vicinity of the island is placed on the island during permitted environmental windows. From 1983 to 1998, Galveston District records show that approximately 2.6 million cu yd have been placed on the island, all originating from the GIWW segment between sta $600+000$ to $616+000$.

A high-altitude photograph of Sundown Island and the MSC taken in 1991 is given in Figure 15. The two jetties of Port O'Conner, through which the GIWW passes, are seen on the left side of the photograph. This photograph indicates a process of erosion of Sundown Island consistent with the dredging records and observations of the morphology of the island itself. Sediment is removed from the island by waves, especially during times of high water and fronts out of the northwest, which would create waves moving toward the northeast corner of the island. The flood current entering the bay then transports northward the sediment mobilized from the platform and foreshore of the island. The sediment is then deposited into the GIWW. In the DMS Manual, this transport and deposition process is termed "horizontal expansion," as depicted in Figure 16, and is discussed further in Chapter 3.

Boat reconnaissance of Sundown Island made in May and September 1997, indicated that it is situated on a broad shallow platform of sediments consisting primarily of sand. The platform tends to be skewed to the northeast, approaching the GIWW at an angle. Older and more stable portions of the island are located in its center. It has been reported that vertical cuts appear in the island as it erodes, and these cuts tend to be on the northeast side, which is the side facing the longest fetch in the bay with respect to the location of the island.

Sundown Island is a significant natural resource for bird nesting, because its location far from shore in the bay hinders mainland predators from reaching it. Bird species that nest on the island include brown pelicans (endangered species), herons, egrets, ibises, roseate spoonbills, gulls, terns, and black skinners (Texas Department of Transportation 1994). Figures 17 and 18 show the perimeter of Sundown Island, as seen from the MSC entrance upon entering the bay. Much of the perimeter of the island is of relatively low relief and susceptible to erosion by waves. The tidal and wind-generated current can then easily move the mobilized sediment.

If the erosion and sediment-transport processes are as described in the preceding paragraphs, then a numerical model of circulation in the bay will reveal a strong flood current around the perimeter of Sundown Island. The model and calculation results are described in the next chapter. 


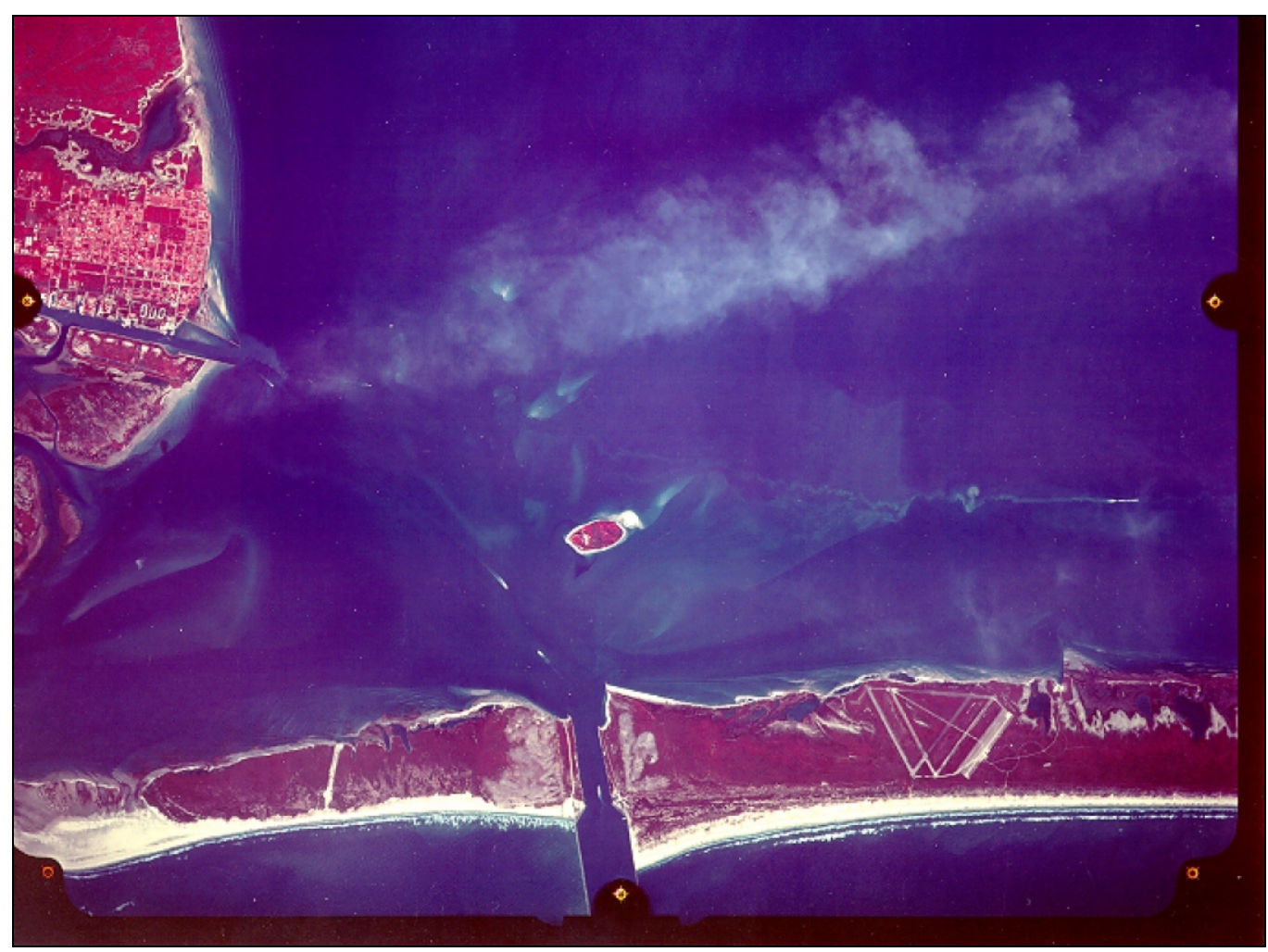

Figure 15. High-altitude, infra-red photograph (1991) of the MSC, Sundown Island, and Port O'Conner on the left (west) side

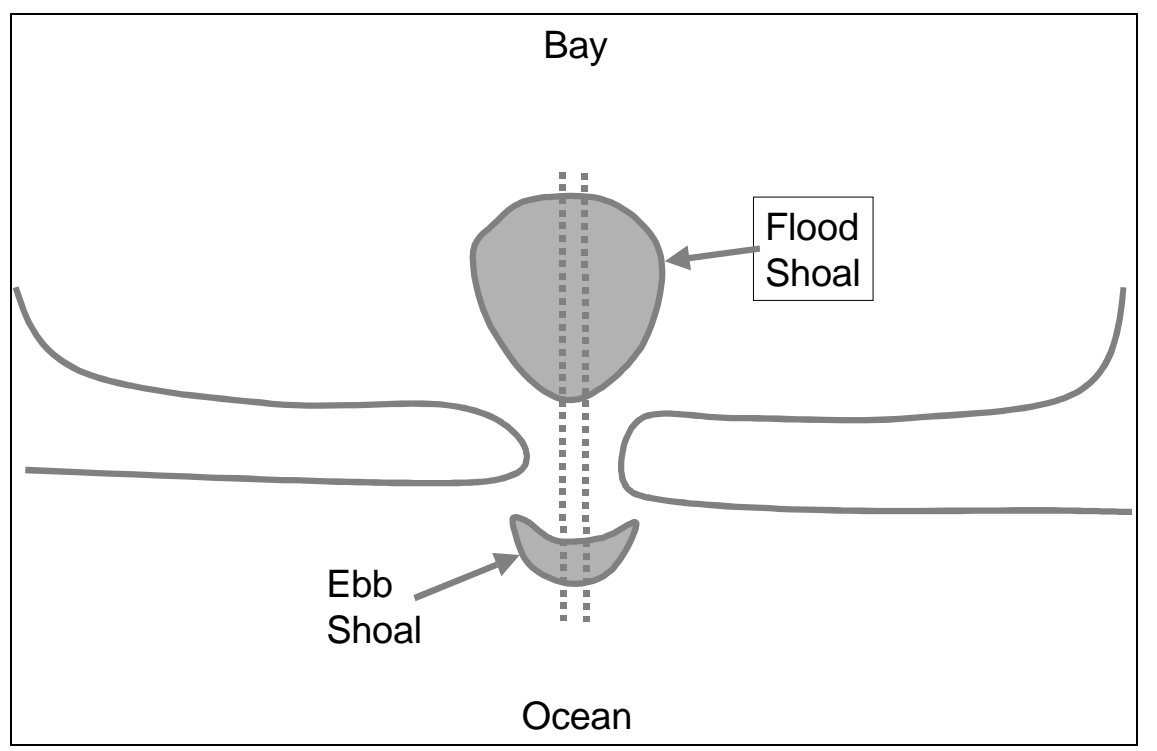

Figure 16. Sketch of sediment deposition and flood shoal development by horizontal expansion 


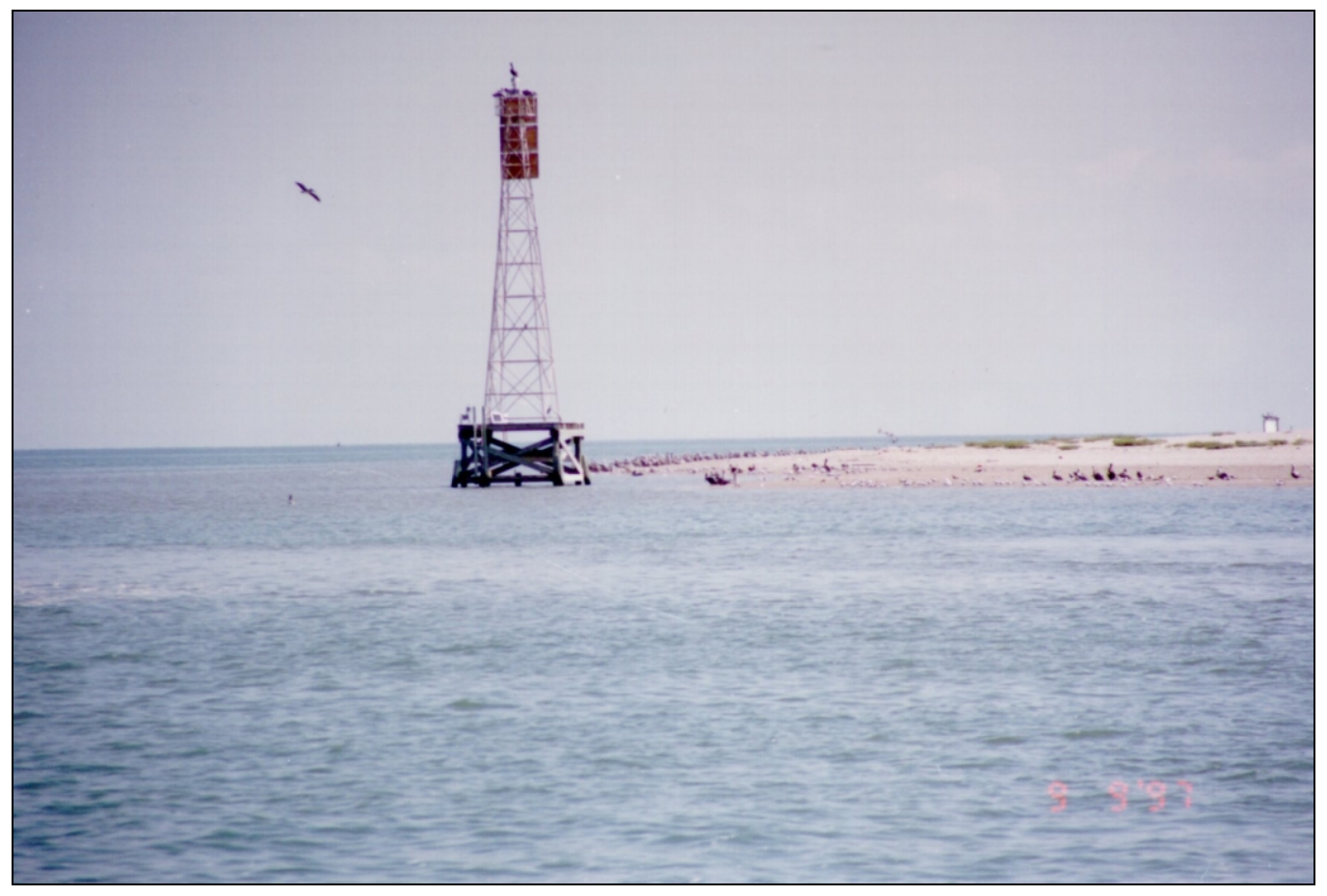

Figure 17. Southwest corner of Sundown Island and channel range marker, as seen from the MSC upon entering the bay (May 1997)

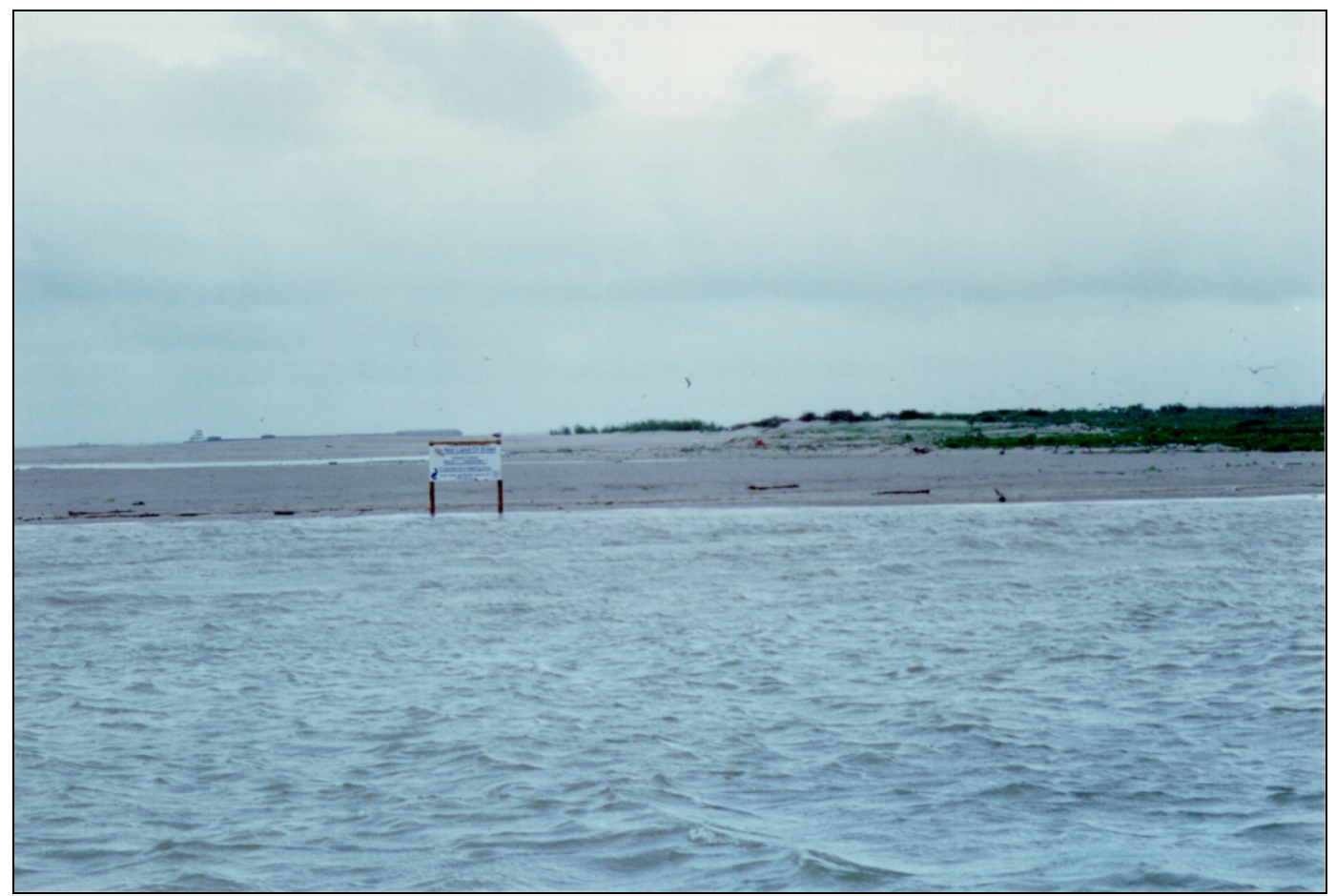

Figure 18. Portion of northeast perimeter of Sundown Island, with barge tow in the GIWW, far left (May 1997) 


\section{Circulation Modeling}

This chapter presents a numerical modeling study of the circulation patterns in Matagorda Bay, with focus on the current in the vicinity of the MSC-GIWW intersection. The objective of the modeling is to infer sediment paths and their relative magnitudes. The hydrodynamic model and its solution scheme are described, together with the numerical grid representing the study area. Calibration of the model is presented for which calculated water-surface elevations and current velocities are compared to measurements. The model is then modified to represent the relocated GIWW, and comparisons of currents computed with the existing and proposed channel configurations are made.

\section{Hydrodynamic Model}

The $\underline{\text { ADvanced }}$ CIRCulation (ADCIRC) numerical model was chosen for simulating the long-wave hydrodynamic processes in the study area. By specifying the tidal-elevation signal at the coastal boundary together with the wind-induced shear stresses over the model domain, the ADCIRC model can simulate tidal- and windinduced circulation in Matagorda Bay. The ADCIRC model was developed in the USACE Dredging Research Program as a family of two- and three-dimensional finite element-based models (Luettich, Westerink, and Scheffner 1992). Model attributes include the capability of the following:

a. Simulating tidal circulation and storm-surge propagation over large computational domains while simultaneously providing high resolution in areas of complex shoreline and bathymetry. The targeted areas of interest include continental shelves, nearshore areas, and estuaries.

$b$. Representing the pertinent physics of the equations of motion. These include tidal potential, Coriolis, and all nonlinear terms of the governing equations.

c. Calculating reliably and efficiently over time intervals ranging from months to years.

In two dimensions, the model formulation is based on the depth-averaged shallowwater equations for conservation of mass and momentum. The formulation assumes that water is incompressible, and that the pressure is hydrostatic. Rather than directly solving the Navier-Stokes and continuity equations, ADCIRC employs the Generalized Wave Continuity Equation (GWCE) for computing water-surface elevations and velocities. The GWCE-based solution scheme eliminates several problems associated with those finite-element schemes that solve the primitive forms of the continuity and momentum 
equations, including spurious modes of oscillation and artificial damping of the tidal signal. Forcing functions include time-varying water-surface elevation, wind shear stress, and atmospheric pressure gradient. The Coriolis force is included in the GWCE. Also, the study area can be described in ADCIRC through either a Cartesian (flat earth) or spherical coordinate system. For representing Matagorda Bay, the grid was defined in the spherical coordinate system.

The ADCIRC model is based on a finite-element algorithm for solving the defined governing equations over complicated bathymetry encompassed by irregular sea and coastal boundaries. This algorithm allows for flexible spatial discretization over the computational domain while retaining high stability. The advantage of this flexibility in developing a computational grid is that larger elements can be specified in open-ocean regions where less resolution is needed, and smaller elements can be specified in the nearshore and estuary areas where finer resolution is required to resolve hydrodynamic details in channels and around islands.

\section{Numerical Grid}

A study area is defined by means of an unstructured grid composed of triangular elements. Water depths are specified at the vertices, referred to as nodes, of each element composing the grid. The water-surface elevations and the horizontal velocities are computed at the nodes. Figure 19 shows the numerical grid, with the existing GIWW position, developed for this study. Figure 20 displays the grid in the vicinity of the MSC entrance.

The grid encloses Matagorda Bay entirely and incorporates Lavaca, Carancahua, Tres Palacios, Chocolate, Keller, and Espiritu Santo Bays. The alongshore open-ocean boundary is situated approximately $65.2 \mathrm{~km}$ in the seaward direction from Matagorda Peninsula. Lateral open-ocean boundaries are positioned 91.7 and $69.5 \mathrm{~km}$ to the northeast and southwest, respectively, from the MSC.

The grid consists of 20,320 elements and 11,575 nodes, and elemental areas ranged from $1.02110^{3}$ to $1.3110^{8} \mathrm{sq} \mathrm{m}$. The largest element lies on the Gulf boundary, whereas the smallest resides in the GIWW at the channel's northeast entrance. Generally, smaller elements are specified for resolving the various dredged channels in the study area, with larger elements being placed in areas with relatively modest depth gradients and in the open bay and Gulf.

Bathymetry data specified in the grid were obtained from three sources. The general source was the NOS bathymetric database, which was accessed to define water depths for those nodes residing in the open-ocean portion of the grid. Depths contained in this database are defined relative to the Gulf Low Water Datum and were subsequently converted to msl (by adding $1.05 \mathrm{ft}$ ). Depths assigned to grid nodes were found by interpolating the three nodes contained in the database that encloses a given grid node. Nodal depths are interpolated with an algorithm that weights each sounding or data point inversely proportional to its distance from that node.

NOAA Chart 11319 served as the second source and provided the depths for nodes located in Matagorda Bay and in adjacent, smaller bays such as Lavaca Bay. Depths were digitally extracted from this chart and processed in the same manner as those extracted from the NOS database. 


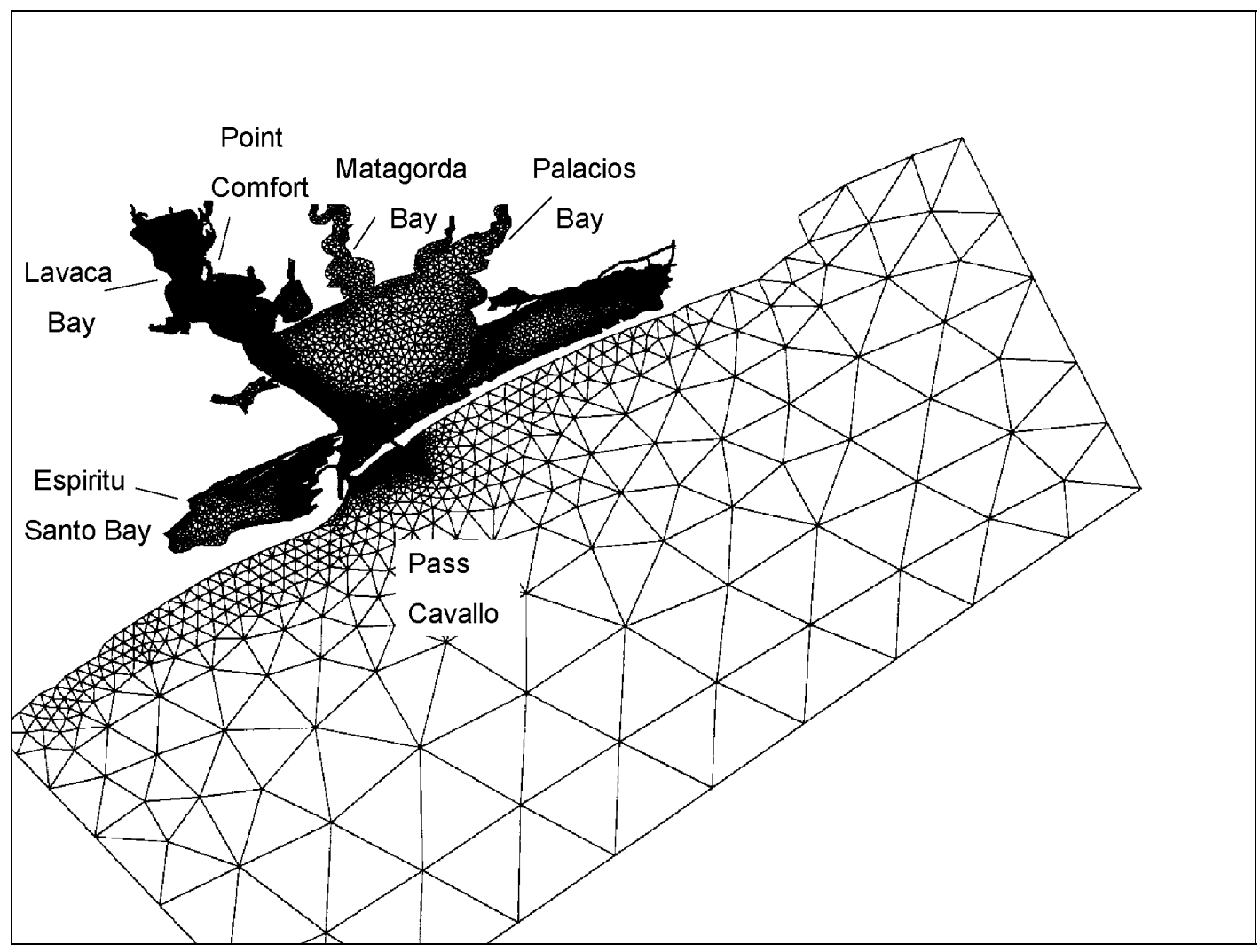

Figure 19. Numerical grid including the offshore, Matagorda Bay, and communicating bays

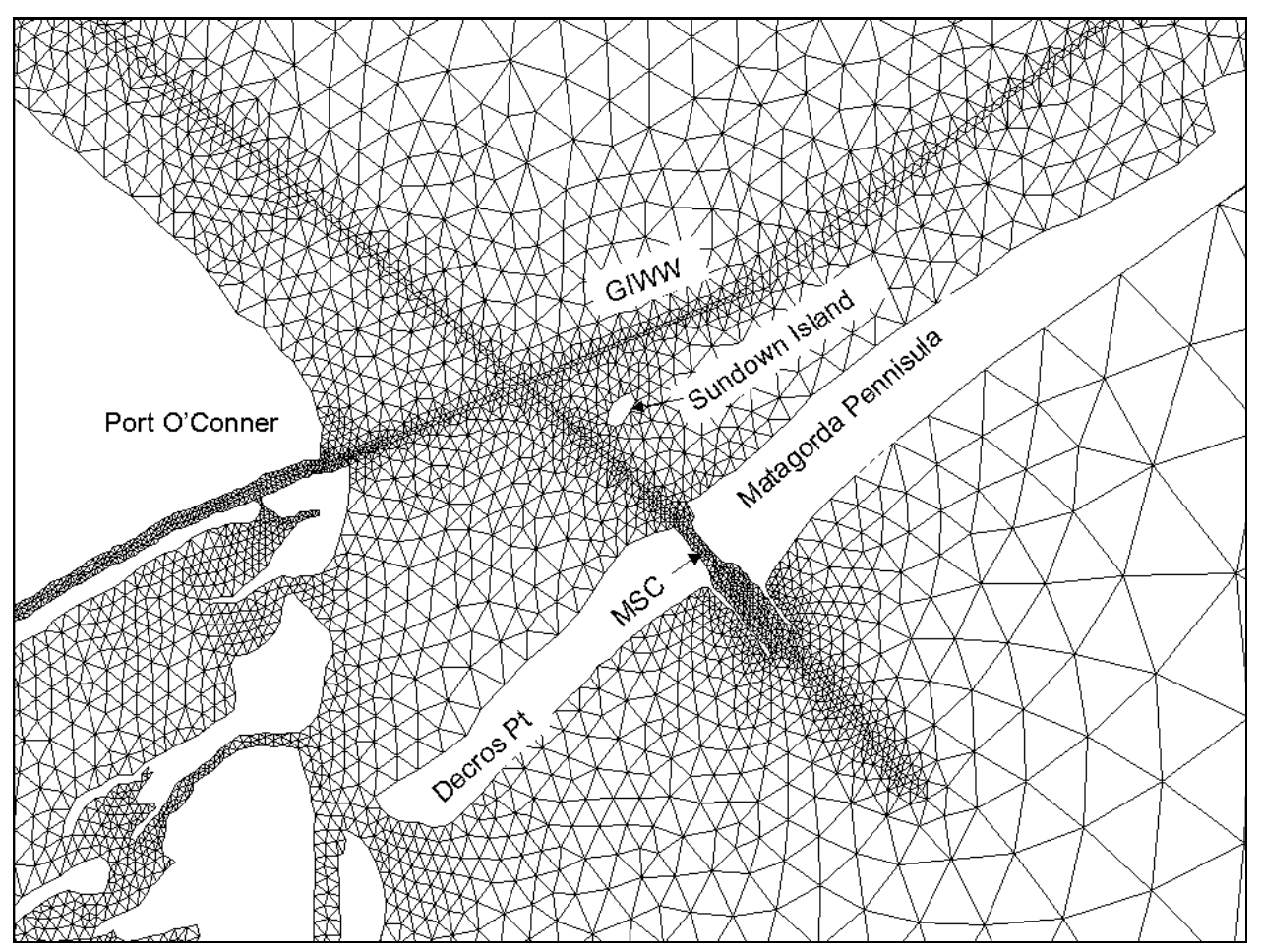

Figure 20. Numerical grid in vicinity of the MSC-GIWW intersection 
A bathymetric survey conducted by the Galveston District and the DMS Work Unit in September 1997 was the third source of data and provided the bathymetry for those nodes composing Pass Cavallo and the MSC entrance. Both of these areas are geomorphically active. As discussed in Chapter 1, Pass Cavallo is tending to close because of the presence of the MSC entrance, whereas the entrance is deepening because of the strong current flowing through it. Thus, the bathymetry data were collected to represent present-day width and depth of Pass Cavallo, as compared to anachronistic information on the NOS charts, and to better represent the MSC entrance. Depths at Pass Cavallo and the MSC entrance must represent present conditions to allow water to flow through the inlets to accurately model the circulation and water level in the bay.

Forcing mechanisms specified in the model were tide, wind, and the Coriolis force. A time series of water-surface elevations was assigned to each node composing the open gulf boundary. Serving as boundary conditions, these water levels induce tidal circulation in the model. Time series of wind speed and direction are processed in the model by converting the wind speed into shear stress, and shear stress components are then computed with the wind direction.

\section{Measurements}

Time series of measured water-surface levels and wind-speed and direction data were obtained from a worldwide Web site maintained by the Texas A\&M University-Corpus Christi, Conrad Blucher Institute, which archives data collected through the Texas Coastal Ocean Observation Network (TCOON). The Texas General Land Office, the Texas Water Development Board, and the Galveston District sponsor this network. Stations at which time series of measured water-surface levels are available include East Matagorda Bay, Lavaca Bay, Port Lavaca, Galveston Pleasure Pier, Bob Hall Pier (Corpus Christi), and Rawlings Bait Camp (located in the Colorado River Navigation Channel between East Matagorda Bay and Matagorda Bay). (The Galveston and Bob Hall stations are operated by the NOS.) Data on water level are provided at 6-min intervals and are measured with respect to each station's staff zero. All data were subsequently converted to local msl for defining depth in the model.

The time series of water-surface elevation collected at the Galveston Pleasure Pier served to drive the open gulf boundary in the model. The model requires that each node composing an elevation-specified boundary have assigned to it a continuous series of elevations input at equal time intervals and at identical times. The Galveston gauge time series contained four gaps in the data string, with the longest gap being $18 \mathrm{~min}$. To form a complete or continuous time series, missing data entries were estimated via linear interpolation, where each missing entry was computed from measurements recorded immediately prior to and after that particular gap.

The measured elevations implicitly contain tidal wave shoaling produced as waves enter shallower water. Shoaling increases the amplitude of the tidal signal measured at the nearshore station as compared to that expected at the offshore boundary of the grid located in deeper water. Wave shoaling contributions to the signal must be removed from the time series of the forcing data because the model computes shoaling. Sensitivity simulations were conducted, by which the elevations were multiplied by a correction factor (which is less than unity), and comparisons were made between the measured and computed water-surface elevations at the Port Lavaca station. Applying an iterative approach to determine the optimal corrections, the time series of water-surface elevation 
for each of the gulf boundary nodes were assigned according to the following. For those nodes along the lateral boundaries, the nodes located at the land-water interface (or shore) as well the next node removed from the shore, the water-surface elevations were not adjusted. Elevations assigned to the third node removed from the shore were multiplied by 0.98 . Similarly, elevations assigned to the fourth, fifth, and sixth nodes removed from shore were multiplied by $0.96,0.94$, and 0.92 , respectively. Elevations assigned to all remaining gulf boundary nodes were multiplied by 0.90 .

The strong sea breeze and fronts experienced along the Texas coast dominate the astronomical tidal forcing and significantly alter the circulation and water level in the shallow bays and estuaries. Harwood (1973) noted that typical strong winds can contribute as much as $1 \mathrm{ft}$ of change in water level, as compared to a typical tidal range of $0.8 \mathrm{ft}$ in the bay. Kraus and Militello $(1996,1999)$ measured a 2-ft, wind-induced waterelevation change in East Matagorda Bay, and 1-ft changes occurred weekly. The time series of wind speed and direction recorded at the East Matagorda Bay station were input to the model. (Wind direction is measured relative to magnetic North.) This station was chosen instead of the Lavaca Bay station because data for the calibration period in 1997 were available in part at 6-min intervals, as opposed to hourly data for the Lavaca Bay station. Data at 6-min intervals were available for the period Year Day (YD) 258 (15 September) through YD 294 (21 October), and hourly data were available during the remaining study period. For input to the model, hourly values were interpolated linearly to achieve a time series with uniform 6-min intervals between data points.

Field measurements were made to obtain currents for calibrating and evaluating the accuracy of the hydrodynamic model. This program consisted of sustained and synoptic monitoring, which for the sustained portion of the program, two current meters were deployed in the vicinity of the MSC-GIWW intersection (Figure 21). One meter was placed adjacent to the MSC, and the other was situated adjacent to the GIWW. Instruments were affixed to existing pilings located along the channels. Measurements were collected at 15-min intervals over the period 9 September through 2 October.

For the synoptic portion, Acoustic-Doppler Current Profilers (ADCP) were mounted on two boats and measured currents on transects at certain times during two 2-day periods. The first period was 10 and 11 September, and the second period was 30 September and 1 October. Measurements of the current through the water column were made along 18 transects. Two of the transects crossed Pass Cavallo, and another two crossed the inland side of the MSC entrance. In the calibration procedure, calculated discharges will be compared to the measured discharges at one transect at Pass Cavallo and at one transect at the entrance.

Five passes were conducted along the MSC inlet and Pass Cavallo transects on 10 September. Time intervals between each pass ranged between 1 and $2 \mathrm{hr}$. An additional seven passes were made on 1 October, at roughly 1-hr intervals.

Two rivers, the Colorado and Lavaca Rivers, empty into Matagorda Bay. The Colorado River is the larger of the two rivers and discharges into Matagorda Bay through the Colorado River Diversion Channel, located at the eastern end of the bay. Since about 1935, the Colorado River had emptied directly into the Gulf of Mexico. Beginning in 1992, the bulk of the river flow was diverted through the diversion channel. A minor amount of water volume can pass through navigation locks on the GIWW. This quantity of water is limited to the amount of water used in operating the locks themselves. For the period of 1960 through 1982, the Colorado River had a mean annual discharge volume of 1,720,600 acre-ft (Mueller and Matthews 1987), as measured at the USGS-operated 
gauge located at Bay City, Texas. Its maximum and minimum annual discharge volumes were $3,812,800$ and 344,000 acre-ft, respectively

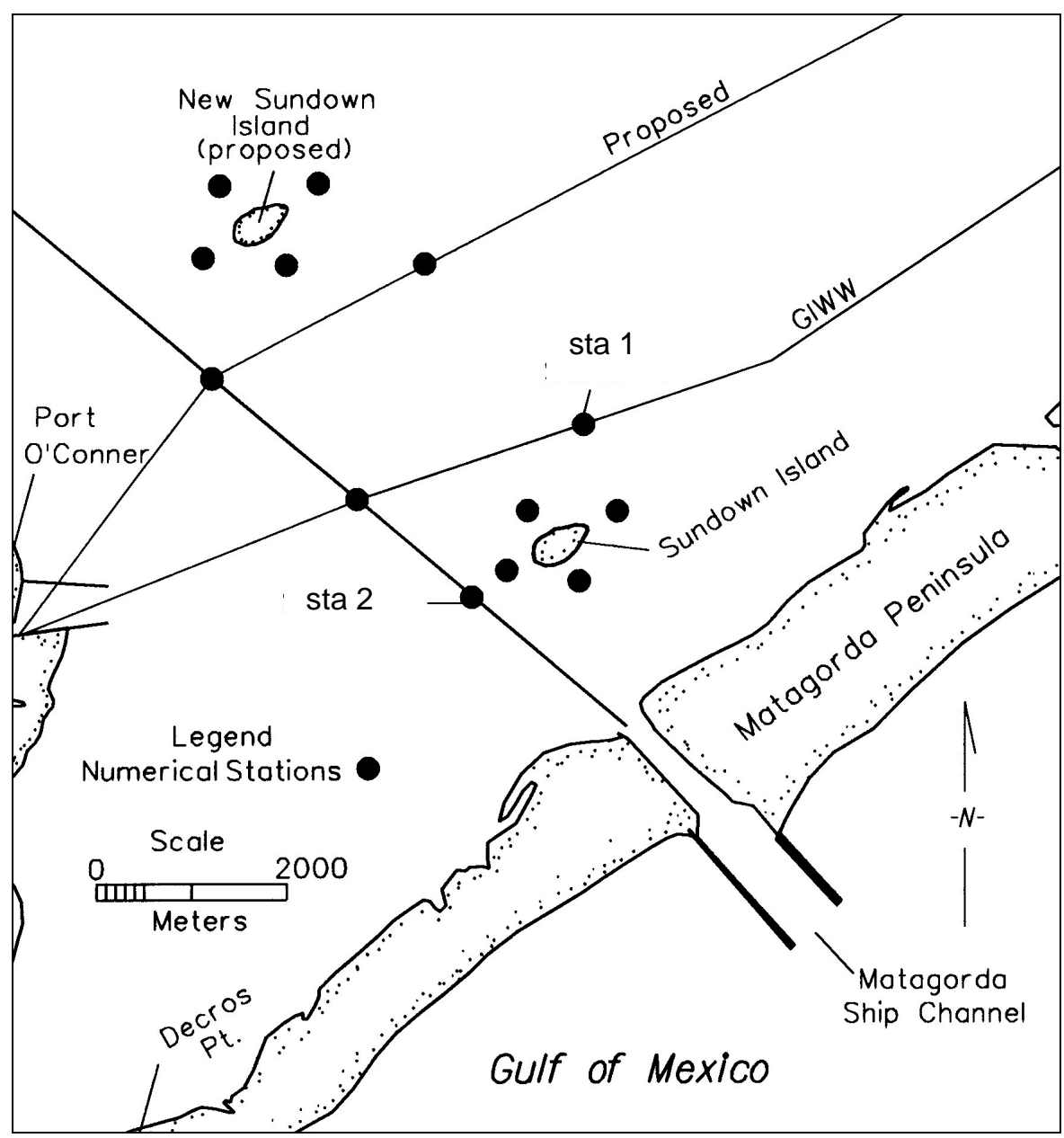

Figure 21. Locations of deployed current meters and numerical gauges

Lavaca River enters Lavaca Bay at its northeast corner, and, prior to 1980, had an annual discharge volume of 795,900 acre-ft (Mueller and Matthews 1987). The maximum and minimum annual discharge volumes were 2,023,900 and 133,900 acre-ft, respectively. In 1980, the Palmetto Bend Dam, forming Lake Texana, was constructed on the lower Navidad River, which is a major tributary to the Lavaca River. The dam reduced the discharge volume of Lavaca River by 92,000 acre-ft annually.

Harwood (1973) investigated whether the inflow of the Lavaca and Colorado Rivers increases the ebb flow in Matagorda Bay by increasing the water-surface gradient from the bay to the open gulf. After examining stream gauging records and estimating that the total discharge from the two rivers was 10,000 cfs, Harwood (1973) concluded that, except during major floods, the combined river flows add less than $0.1 \mathrm{ft}$ to the watersurface elevation in a $24-\mathrm{hr}$ period (the diurnal tidal period). Because the mean tidal range at Port Lavaca is about $0.8 \mathrm{ft}$, for the present study, river inflows to the bay were judged to make a minimal contribution to the circulation within the bay. Therefore, the 
rivers were omitted from the model setup. However, if a more thorough study of the entire bay is needed, river discharges to the bay should be represented.

\section{Calibration of Model}

During the process of establishing a numerical model to represent a given study area, calibration is performed to ensure it adequately predicts hydrodynamic conditions. Accuracy of a model is determined by the accuracy of the boundary and forcing conditions, representation of the geometry of the study area (i.e., bathymetry and landand-water interface), and to a lesser extent, by the values of certain parameters, principally the bottom-friction coefficient. A satisfactory comparison between calculations and measurements in the calibration procedure gives confidence that the model adequately simulates hydrodynamic processes. Calibration exercises were conducted via hindcast simulations of September 1997, for which measurements of the current and water level were made as part of this project.

\section{Procedure}

Calibration was performed primarily through adjusting the bottom-friction coefficient, which was specified globally throughout the model domain. For the DMS application, no attempt was made to modify the value of the friction coefficient according to location. Simulations were performed by varying the bottom-friction coefficient between 0.0020 and 0.0050 to determine a first estimate. A simulation was conducted for each coefficient, and its accuracy was determined by comparing calculated water-surface elevations to those measured at the Port Lavaca water-level station.

With this estimate serving as a basis, the model was run over a range of values with a narrower range of coefficients specified for optimizing the calculated water-surface elevations. Coefficients chosen for this stage ranged from 0.0030 to 0.0050 , and the appropriateness or accuracy of each coefficient was again determined by comparing calculated water-surface elevations to those measured at the Port Lavaca station.

Finally, the model was run with only two coefficients, 0.0035 and 0.0040 , and their accuracy was judged by comparing calculated velocities to velocities measured in the MSC and GIWW. The optimum value of the global bottom friction coefficient was found to be 0.0040 .

\section{Calibration period conditions}

The calibration procedure previously discussed was conducted over a 14-day period beginning on YD 243 (31 August 1997) at 0000 Greenwich Mean Time (GMT) and ending on YD 257 (13 September) at 0000 GMT. The model was run with a 4-s timestep. Uniform, time-varying wind velocities were applied over the entire model domain, and water level forcing was specified at the open gulf boundary. Once the optimum bottom friction coefficient value was determined, the model was run for the 31-day period beginning on YD 243 at 0000 GMT and ending on YD 274 (1 October) at 0000 GMT.

Coastal wind speeds measured at the East Matagorda station (Figure 22) for the period YD 246 through 263 show a periodicity with maximum wind speed ranging from about 5 to $8 \mathrm{~m} / \mathrm{sec}$. The hour at which these peak winds occur ranges from 1900 to $0000 \mathrm{hr}$ GMT, or 1300 to $1800 \mathrm{hr}$ Central Standard Time (CST), respectively. 


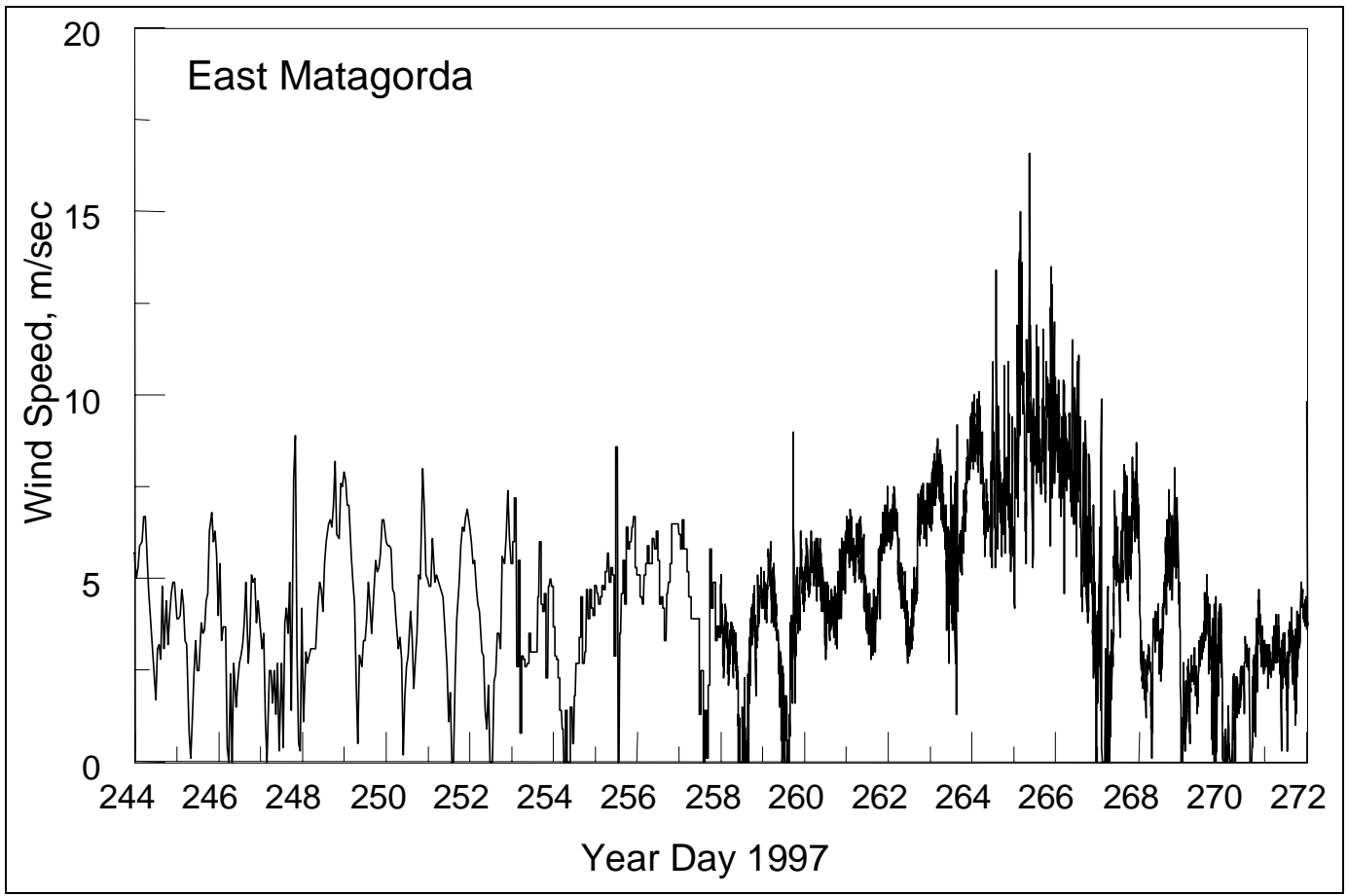

Figure 22. Time series of wind speed measured at the East Matagorda station

Conversely, minimum wind speeds are experienced at approximately 0800 GMT, or 0200 CST. From YD 245 through 250, the maximum wind speeds are associated chiefly with northerly winds (Figure 23). (Wind direction is defined by the standard meteorological convention so that an angle of " 0 " defines a wind blowing from north to south, and that angles increase in the clockwise direction to a maximum of $360 \mathrm{deg}$, which again is north) The near-vertical discontinuities seen in this figure result from the wind shifting from the north-northwest to north-northeast (e.g., wind direction from $350 \mathrm{deg}$ to $10 \mathrm{deg}$ ) or vice versa.

Measured water-surface elevation at the Galveston Pleasure Pier (Figure 24) shows a distinct set down for this period, which should be expected given the east-west orientation of the gulf coastline in the vicinity of the pier, together with the northerly peak daily winds experienced in the region. This same phenomenon was experienced at Lavaca Bay (Figure 25) where the tidal range was reduced to approximately $0.15 \mathrm{~m}$ for the period of YD 247 at 1200 GMT to YD 248 at 1200 GMT. (The tidal range is typically about $0.30 \mathrm{~m}$ at this station.)

For YD 251 through 253, wind direction at the time of peak measured wind speed correspond to an east-southeasterly wind. Water level in Lavaca Bay during this period show a moderate rise with peak maximum and minimum of 0.35 and $0.20 \mathrm{~m}$, respectively. Water level at the Galveston station also appears elevated with a peak water level of $0.45 \mathrm{~m}$.

From YD 254 through 261, it appears the tide is the dominating force, as opposed to wind, governing water level in the bay. Water elevation measured over this time span at the Galveston station varied from -0.30 to $0.40 \mathrm{~m}$. The measured water level at he Port Lavaca station varied from -0.02 to $0.40 \mathrm{~m}$.

\footnotetext{
${ }^{1}$ All water elevations specified for the model are referenced to mean sea level.
} 


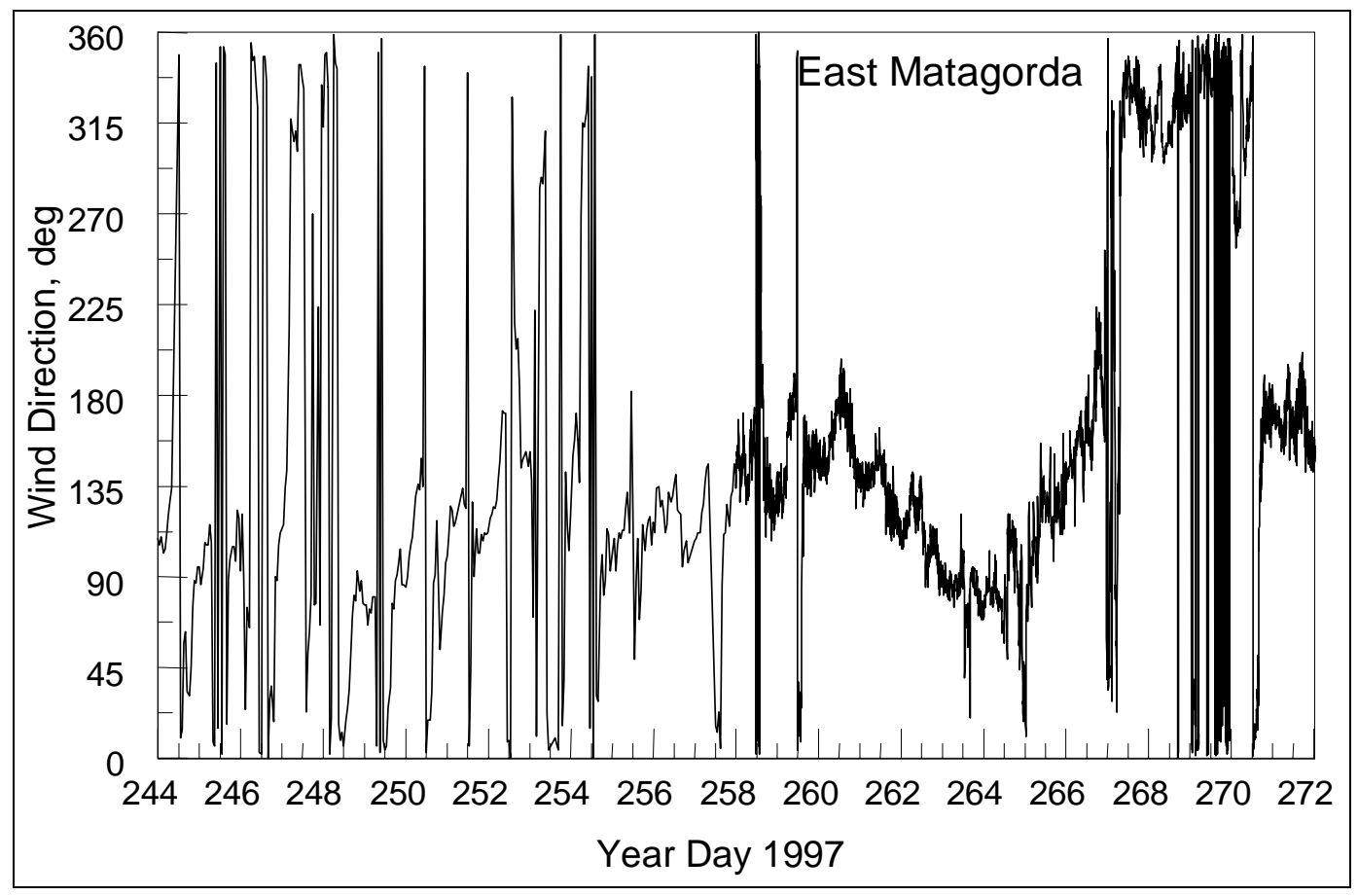

Figure 23. Time series of wind direction measured at the East Matagorda station

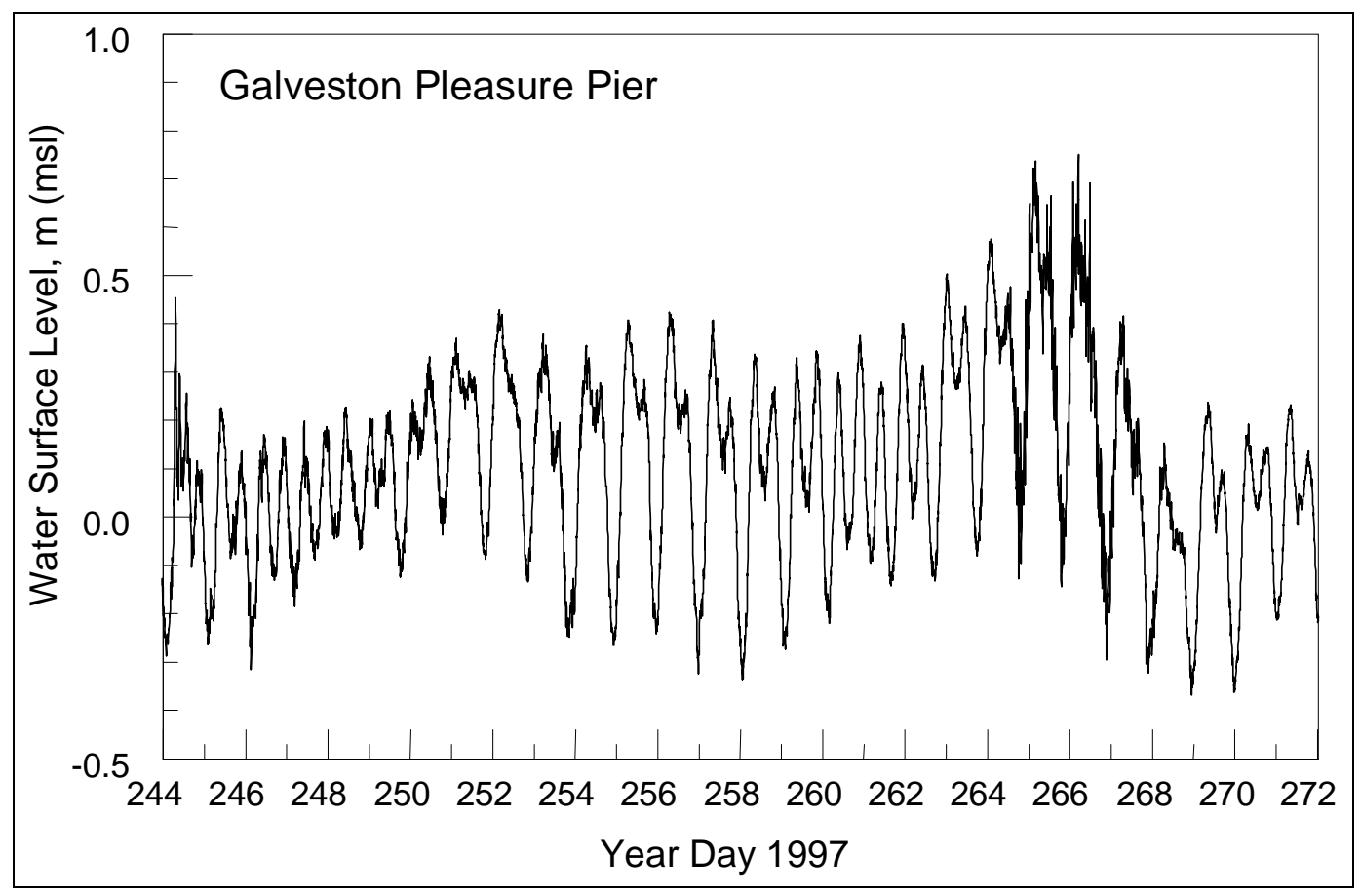

Figure 24. Time series of water-surface elevation measured at Galveston Pleasure Pier 


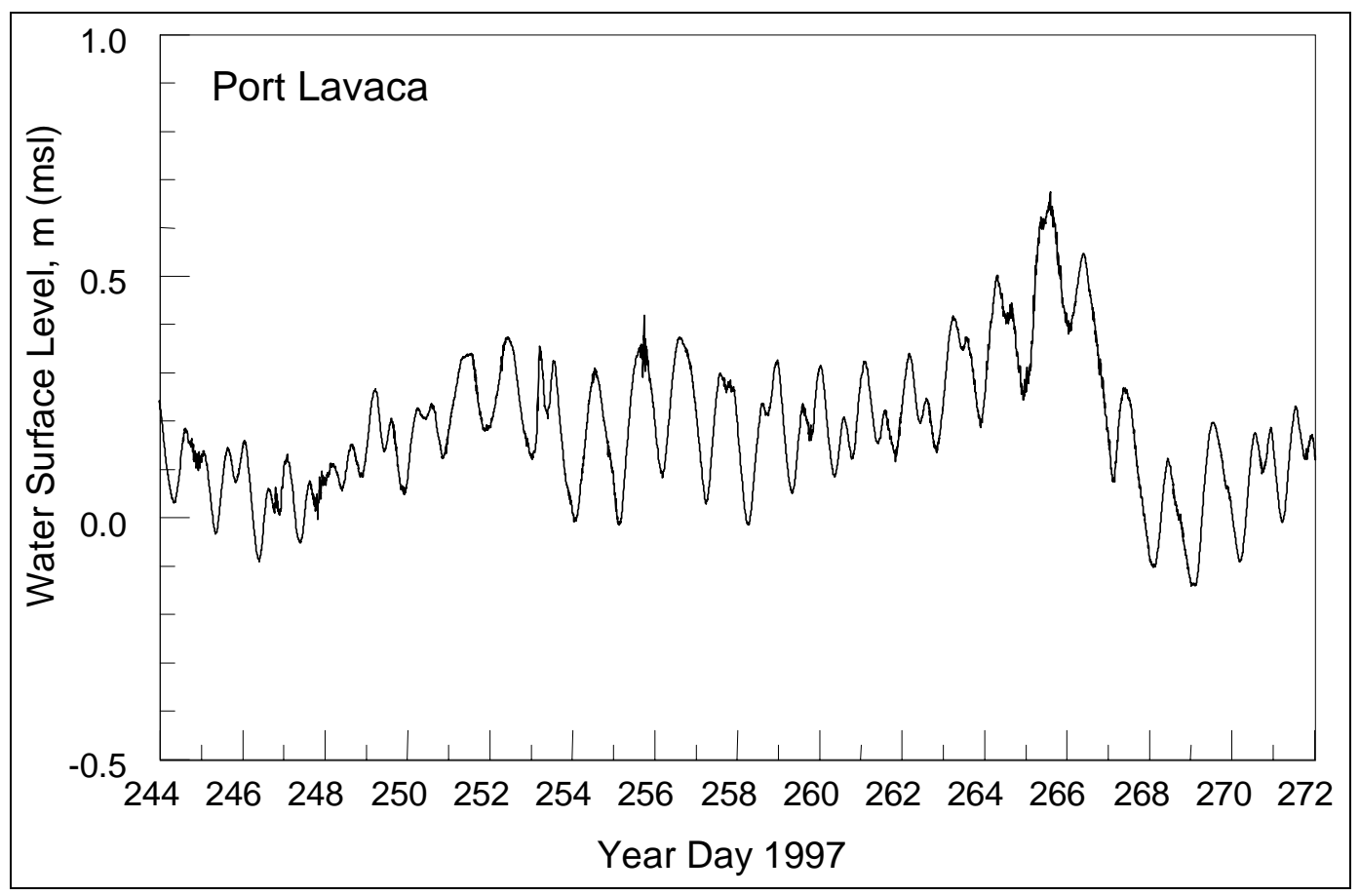

Figure 25. Time series of water-surface elevation measured at Port Lavaca station

Beginning on YD 262 and extending through 266, wind speed increased from daily peak speeds of $6 \mathrm{~m} / \mathrm{sec}$ for the first 3-week period to a maximum speed of $17 \mathrm{~m} / \mathrm{sec}$ on YD 265. Minimum daily wind speed of $5 \mathrm{~m} / \mathrm{sec}$ on YD 264 and 265 are about the same as the peak speed for the initial 3-week period. Wind direction for the period YD 262 through 266 shifted from the east to the south. The strong wind together with its southerly direction induced water level at both the Galveston and Port Lavaca stations to increase to 0.74 and $0.70 \mathrm{~m}$, respectively, which are the highest maximum water-surface elevations recorded during the 1-month modeling period.

The wind remained strong through YD 267, then slowly began to diminish. Wind direction, however, shifted from the south to the north, resulting in a pronounced drop in the water level at both the Galveston and Port Lavaca stations. The minimum water level at the Port Lavaca station was about $0.10 \mathrm{~m}$. Consequently, over the 4-day period of YD 265 through 269, wind speed and its corresponding direction resulted in a maximum water-level range of $0.8 \mathrm{~m}$, or approximately three times the typical tidal range in the bay.

\section{Discussion of calibration results}

For this DMS application, the model adequately reproduces both the phase and magnitude of the water velocity measured by the current meter in the GIWW, which is sta 1 (Figure 26). Typically, calculated velocity was within $5 \mathrm{~cm} / \mathrm{sec}$ of the measurements. Notable discrepancies occur from YD 265 through 267, during a strong wind, for which calculated velocity exceeded the measured by as much as $11 \mathrm{~cm} / \mathrm{sec}$, or $40 \mathrm{~cm} / \mathrm{sec}$ for the model versus $29 \mathrm{~cm} / \mathrm{sec}$ for the current meter. 


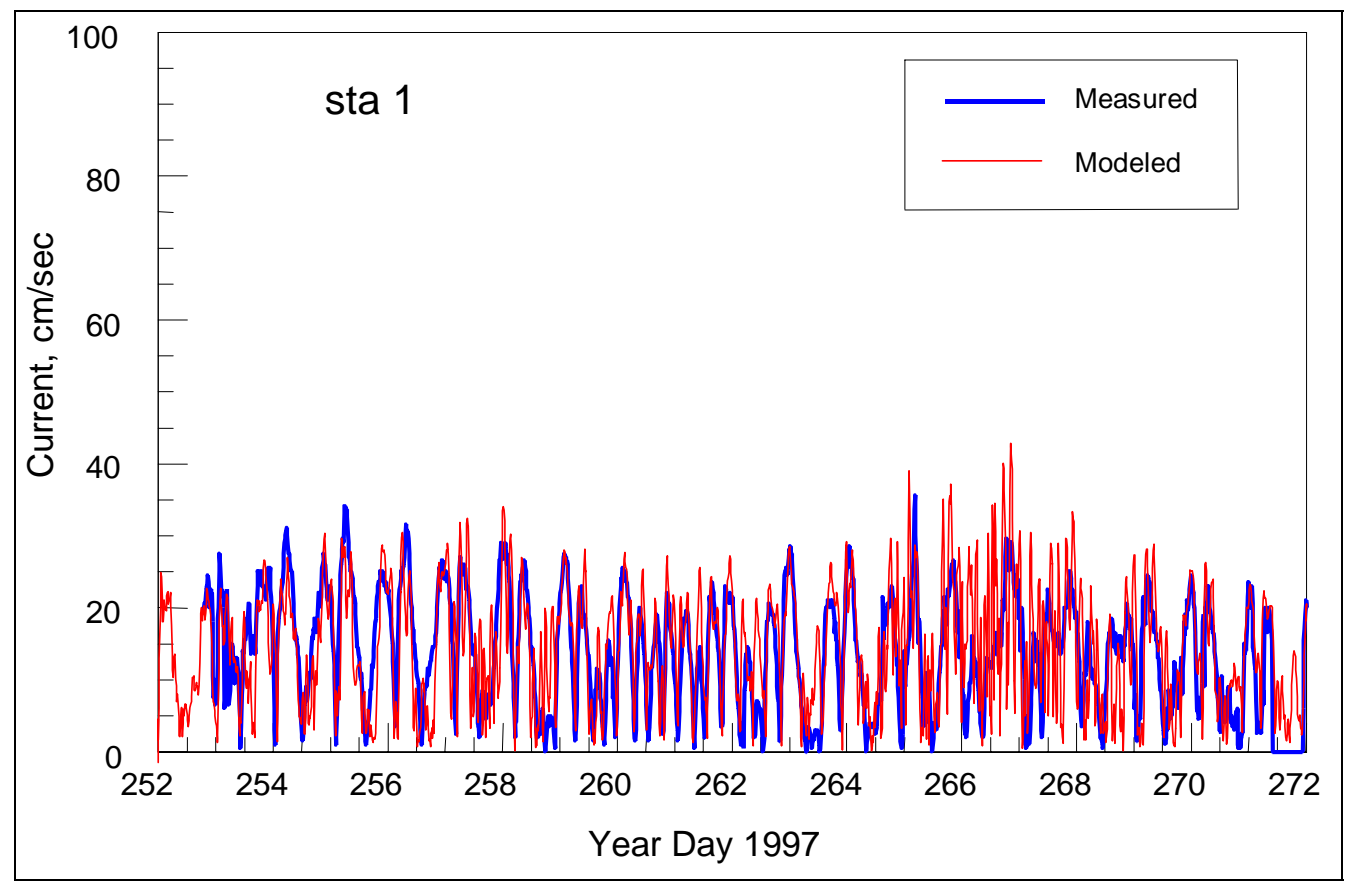

Figure 26. Comparison of calculated and measured velocities at sta 1

At sta 2, shown in Figure 27, calculated velocity matched the measured current in phase, but overestimated the peak magnitude by as much as 50 percent during some periods (e.g., YD 253 at 1800). During other periods, such as YD 255 at 0600, the calculated peak velocity matched the measured velocities to within $4 \mathrm{~cm} / \mathrm{sec}$. Inspecting currents at sta 2 together with both the wind directions recorded at the East Matagorda station and the water-surface elevations recorded at the Galveston Pleasure Pier, it appears that the model overestimates water velocity if the wind is blowing in the same direction as the current. For example, the model over-predicts water velocity during ebb flow when the wind is from the north. During periods when the wind direction differs by more than 50 deg from the current direction, the calculated velocities nearly match the measurements.

The matching of calculated and measured velocity for these transient wind events is difficult because the current meter measures at a point in the water column, whereas the model calculates an average over a relatively large grid area (approximately 1,000 sq m). A second cause for these discrepancies at sta 2 can be attributed to driving the model with water-surface elevation and wind measured at sites outside the study area. Galveston Pleasure Pier and East Matagorda Bay stations are located about 70 and 20 miles, respectively, to the northeast from the MSC entrance. Given these relatively large distances, the wind-induced setup and setdown contained in the time series of watersurface elevation measured at the Galveston station may not be synchronous with the wind measured at East Matagorda. Thus, the forcing imposed on the model is not synchronous with the current measured at sta 2.

Calculated water-surface elevation was compared to measurements at the Port Lavaca station, shown in Figure 28. The model replicates the phase of the tidal signal, and the calculated elevations are generally within $0.05 \mathrm{~m}$ of the measurements. The maximum discrepancy between the calculated and measured water-surface elevations occurs at YD 266 at 1200, or when the wind is blowing at $135 \mathrm{deg}$ (i.e., from the 


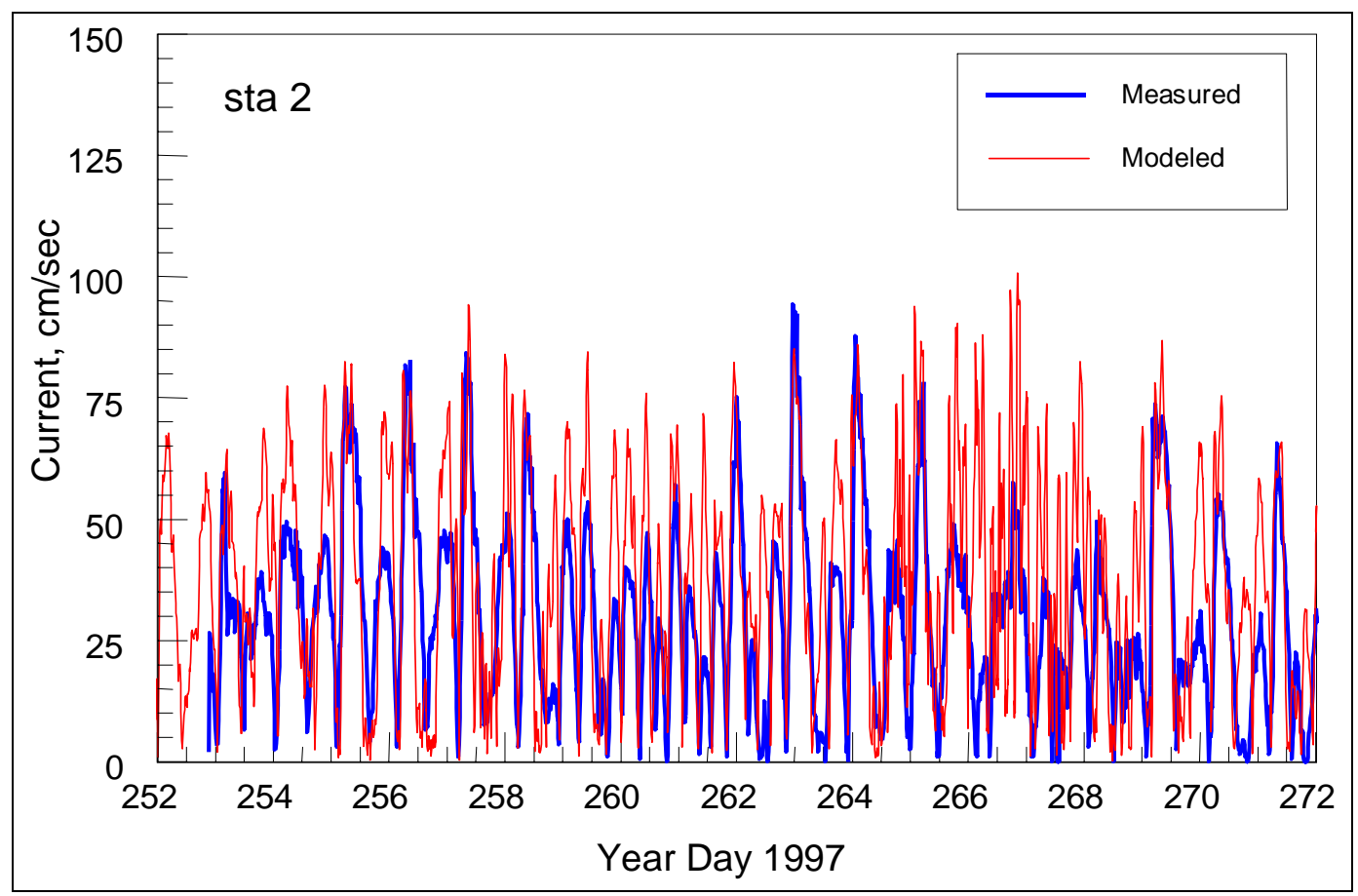

Figure 27. Comparison of calculated and measured velocities at sta 2

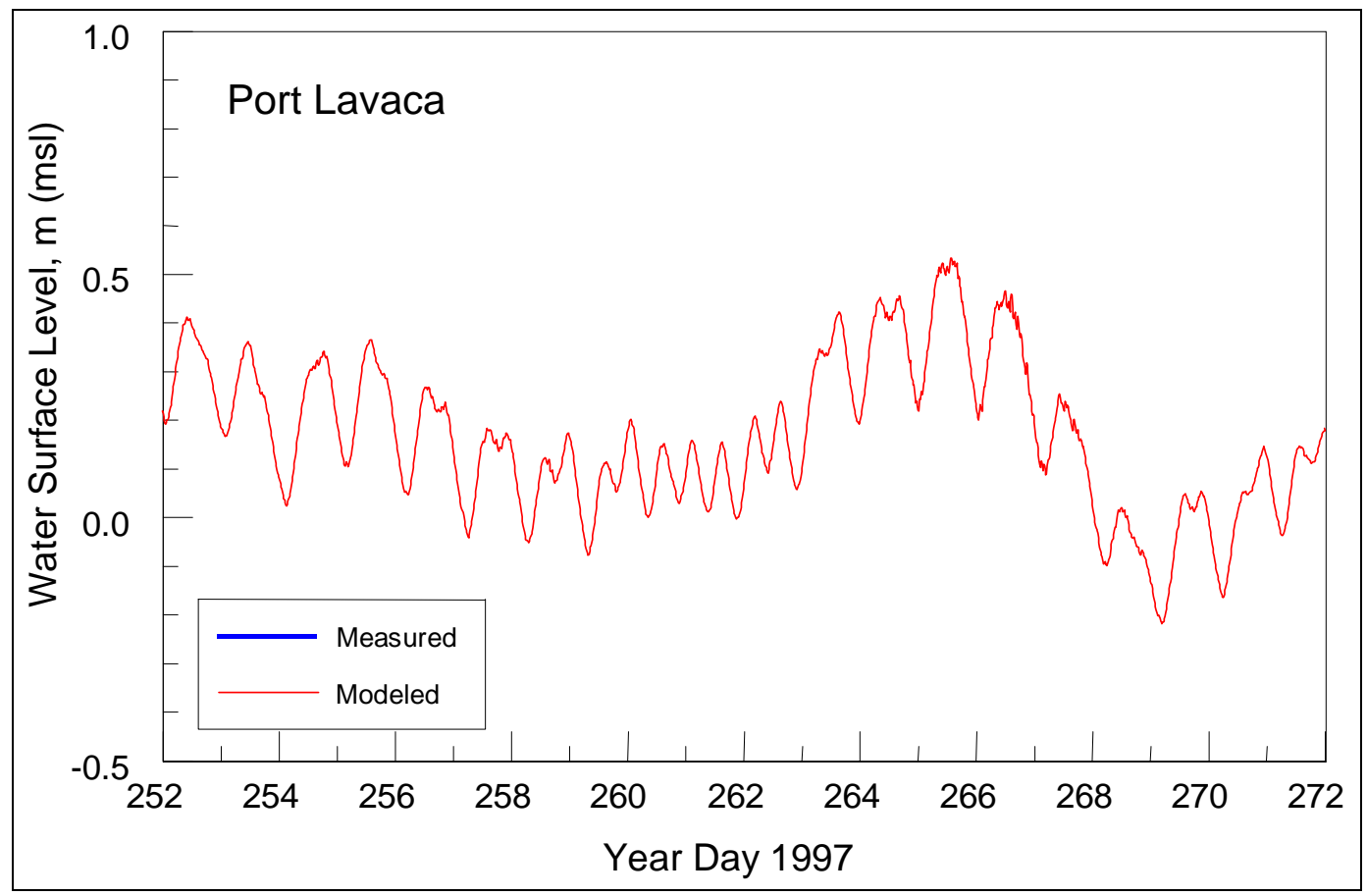

Figure 28. Comparison of calculated and measured water-surface elevations at Port Lavaca station (East Matagorda winds specified in model) 
southeast). At this time, the model underpredicted the measured elevations by $0.17 \mathrm{~m}$. Furthermore, the model tends to underpredict water level whenever winds are blowing to the northwest, such as the period YD 257 through 263. For those periods when the winds are blowing from a different direction, such as the north (e.g., YD 267 through 272), the model reproduces the water-surface elevation well.

Model predictions were also examined by driving it with the hourly winds measured at the Lavaca Bay station (as opposed to the winds measured at the East Matagorda station). Calculations with the model forced by the local winds are presented in Figure 29. The comparison between calculated and measured water levels improved substantially for the period YD 255 through 269. Furthermore, the model accurately reproduced the water-surface elevations throughout the strong wind event. Discrepancies were less than $0.06 \mathrm{~m}$ during this event, demonstrating that the bay is highly responsive to the local wind speed and direction. The conclusion is that for the frequently winddominated circulation of the Texas shallow bays and estuaries, local wind measurements at high frequency (6- or 10-min averages) are needed to simulate the velocity and watersurface elevation with reliability (Kraus and Militello 1995, 1999).

To measure the ebb and flood flows exiting and entering Matagorda Bay, discharge measurements were taken with the ADCP across the inland sides of the MSC entrance and Pass Cavallo. Ebb flow measurements were collected on YD 253 (10 September), and flood flows were collected YD 274 (1 October). Comparisons between calculated and measured discharges are presented in Figures 30 through 33. (Positive discharges represent ebb flows, and negative discharges represent flood flows in these figures.)

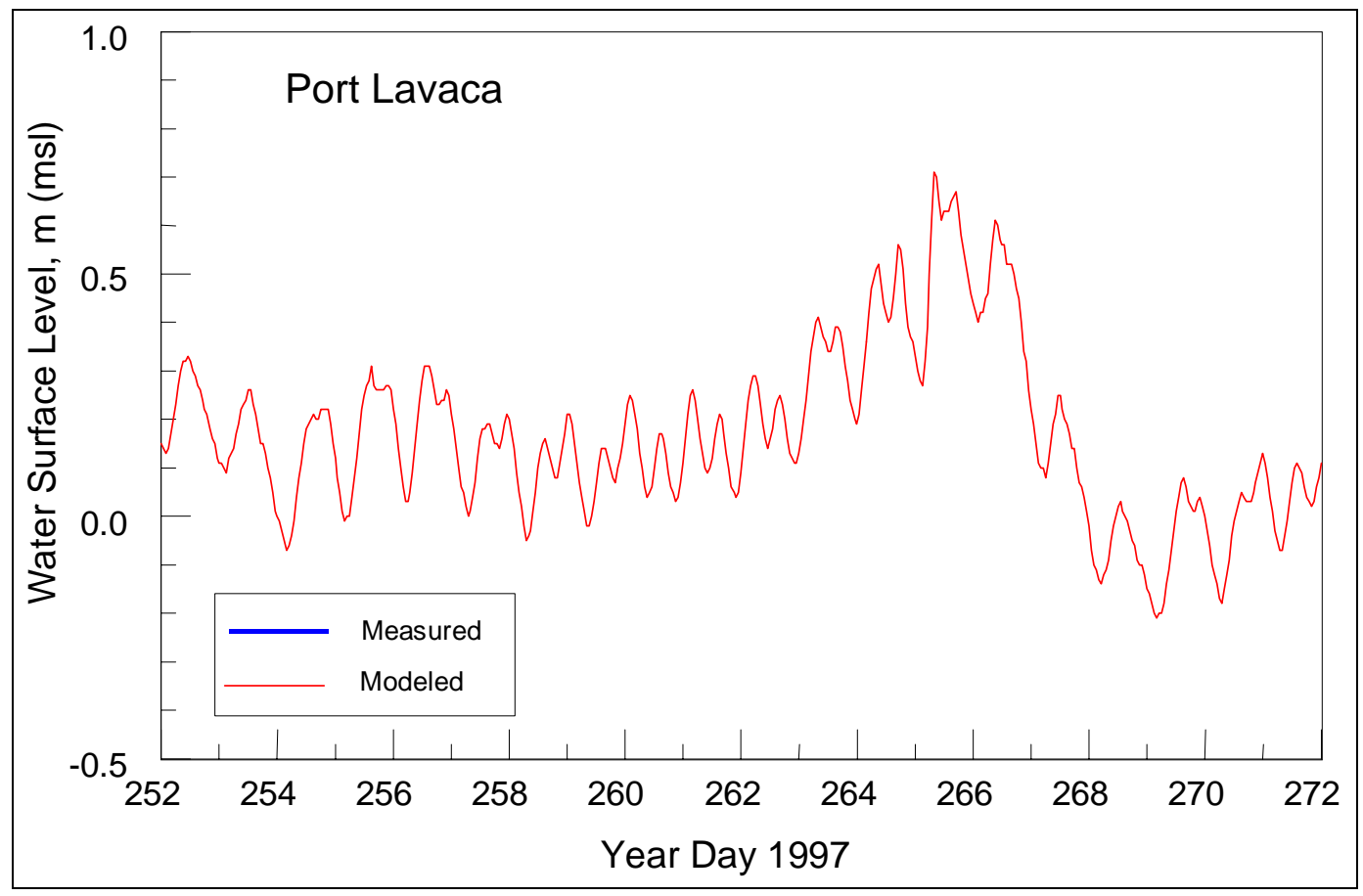

Figure 29. Comparison of calculated and measured water-surface elevations at Port Lavaca station (Lavaca Bay winds specified in model) 


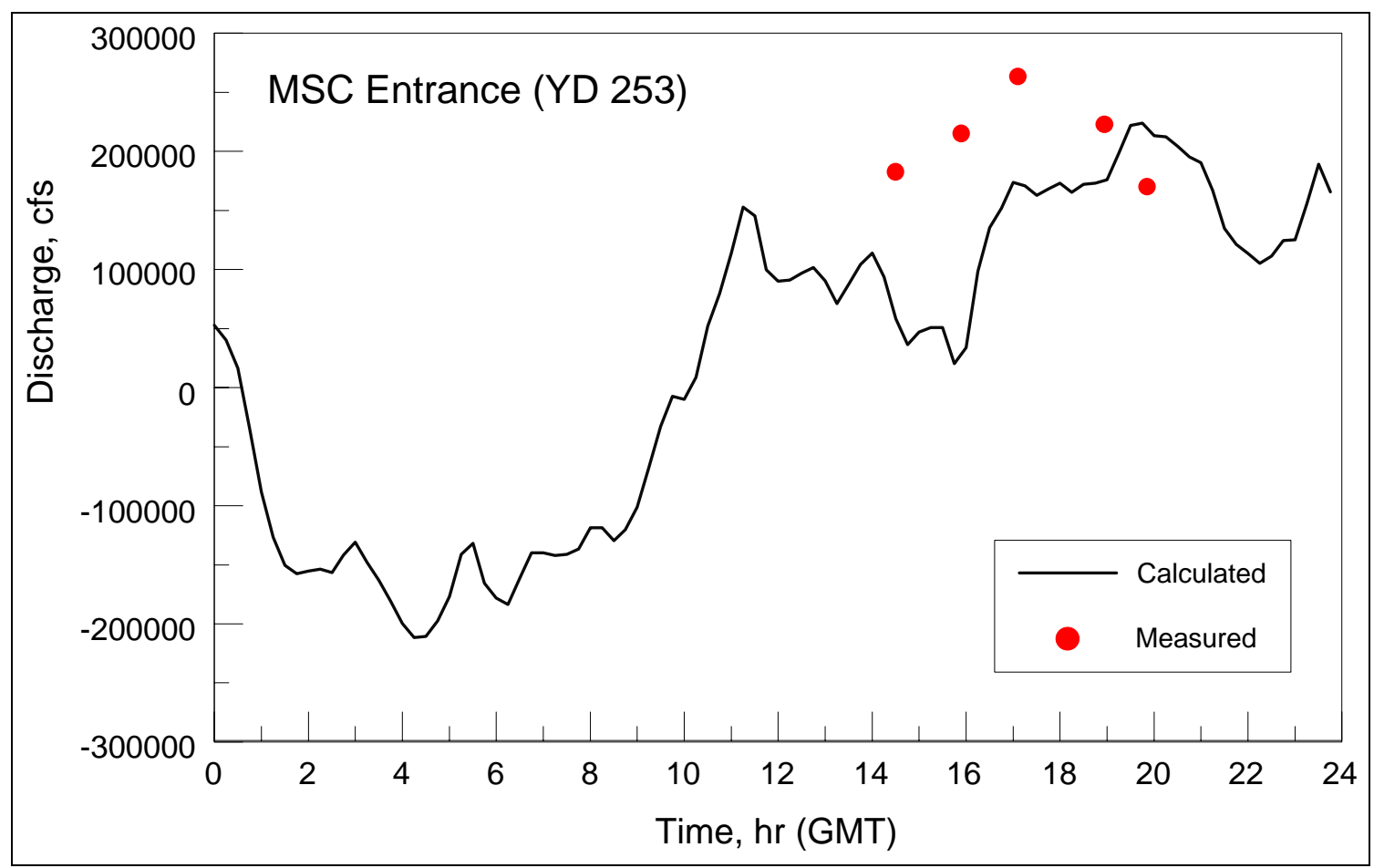

Figure 30. Comparison of calculated and measured discharges at MSC entrance for YD 253

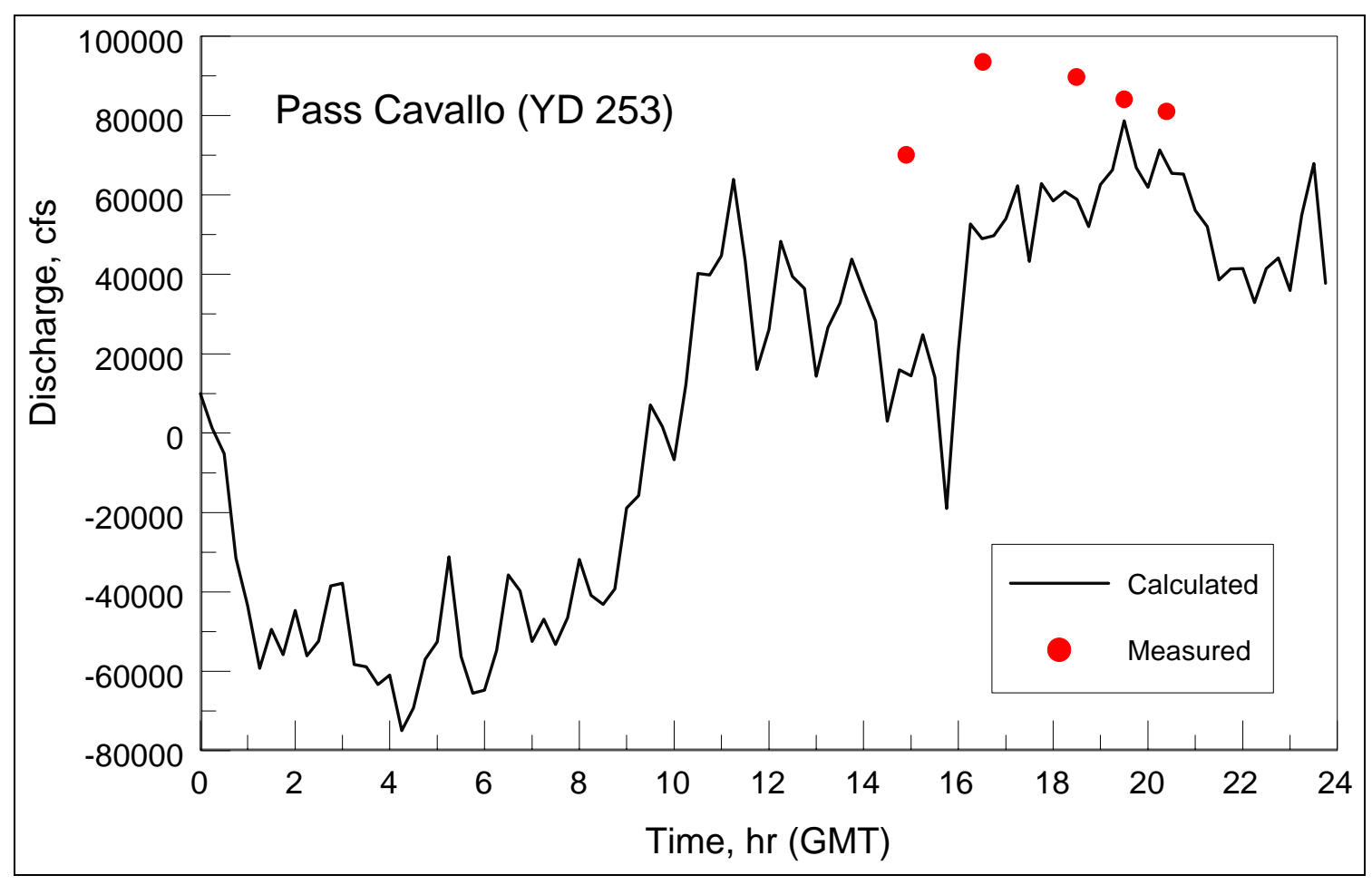

Figure 31. Comparison of calculated and measured discharges at Pass Cavallo for YD 253 


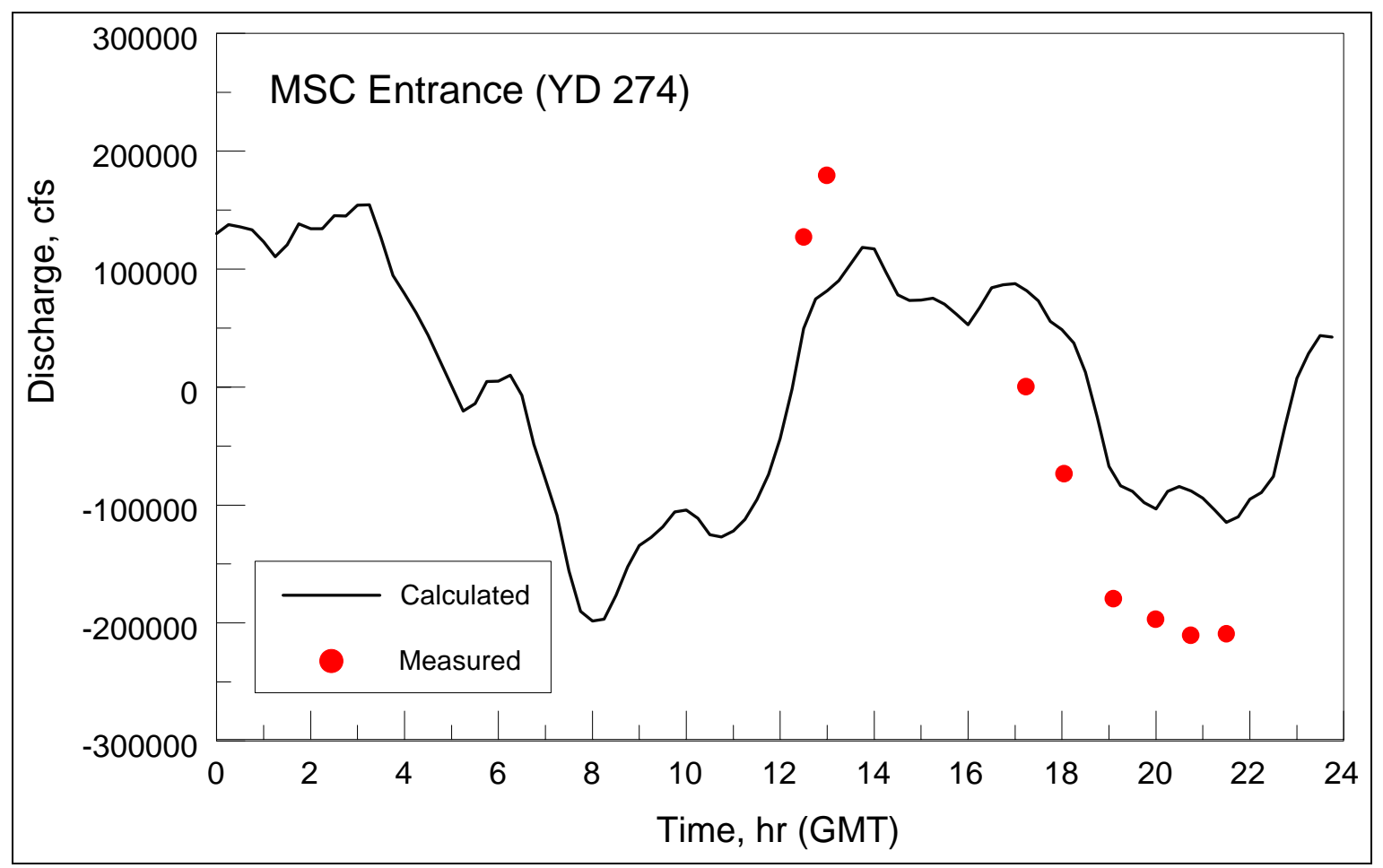

Figure 32. Comparison of calculated and measured discharges at MSC entrance for YD 274

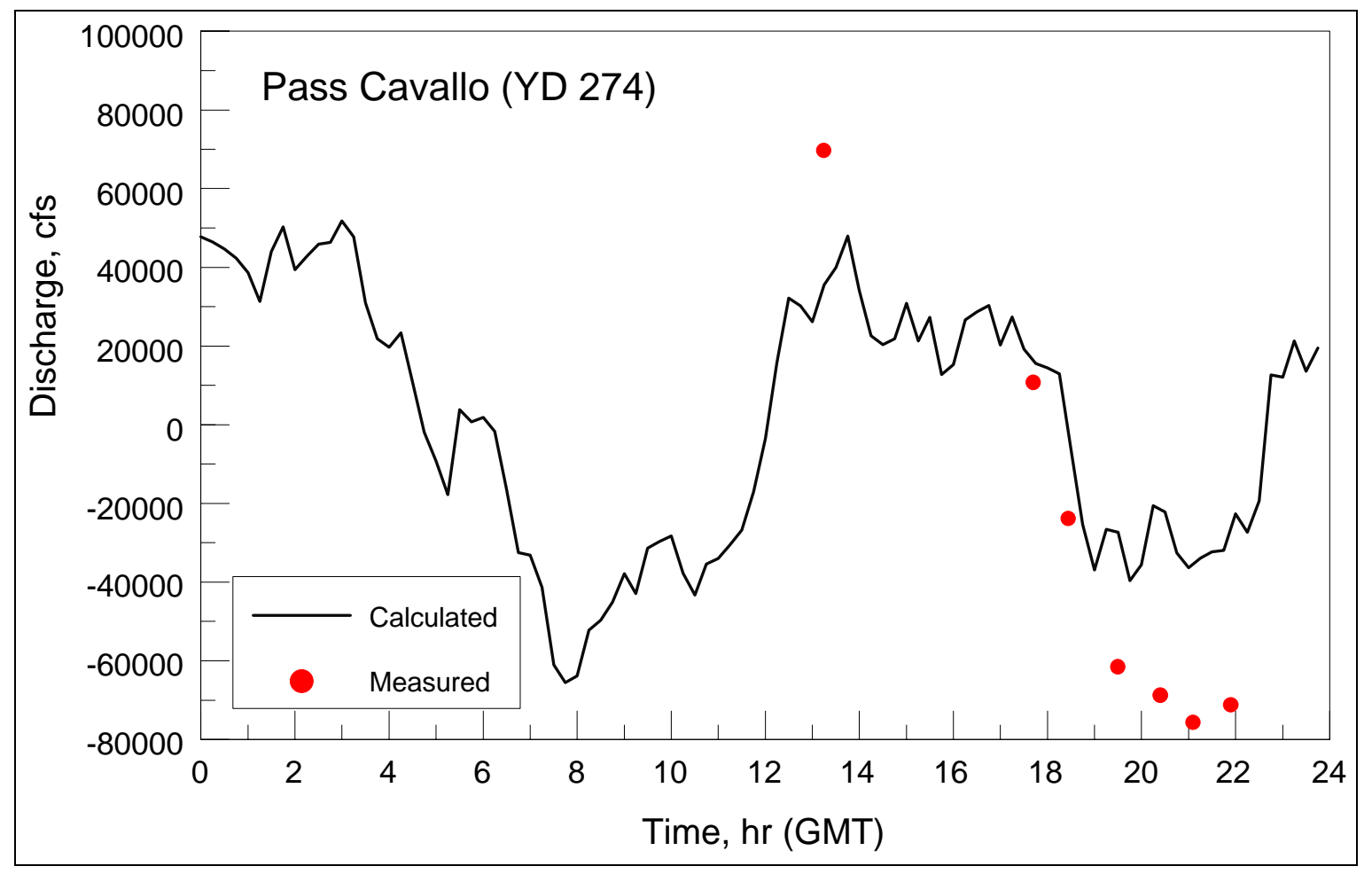

Figure 33. Comparison of calculated and measured discharges at Pass Cavallo for YD 274 
On YD 253, five passes (and corresponding measurements) were made along the transect crossing the MSC entrance. Measured discharges ranged from 170,179 to 263,370 cfs over the 7.5-hr sampling period. Calculated discharges varied from 36,220 to 223,842 cfs over this same period. For Pass Cavallo, where five passes were made, measured discharges ranged from 70,025 to $93,410 \mathrm{cfs}$, and the calculated discharges varied from $-18,957$ (i.e., flood flow) to 78,611 cfs.

On YD 274, discharges measured at the MSC entrance ranged from 179,186 to $-210,470 \mathrm{cfs}$, and the calculated discharges varied from 118,286 to $-114,690 \mathrm{cfs}$. For Pass Cavallo, measured discharges ranged from 69,639 to $-71,250 \mathrm{cfs}$, and calculated discharges varied from 47,967 to $-36,944 \mathrm{cfs}$.

Values of the maximum discharge measured at the MSC entrance agree well with those estimated by Harwood (1973) for Pass Cavallo prior to the cutting of the MSC. If peak discharges of 90,000 and 240,000 cfs are taken as representative of Pass Cavallo and the MSC entrance, respectively, in their present (1998) state, then the volume of water now flowing through Pass Cavallo is only 30 percent of that at the MSC Entrance.

At a given time, discharges for either ebb or flood currents were underpredicted by as much as 48 percent, although there is agreement between trends and magnitudes for the calculations and the measurements. One source of discrepancy is lack of detailed bathymetric data for the ebb and flood shoals at Pass Cavallo. Another source of discrepancy between calculations and measurements concerns driving the open boundary with water-surface elevation collected at the Galveston Pleasure Pier while specifying the wind measured at the East Matagorda station. Ideally, the model should be driven with data collected in closer proximity to the study area.

\section{Implementation of Alternative}

As discussed in Chapter 1, this study focuses on the feasibility of relocating a section of the GIWW northward within Matagorda Bay. Presently, barges and other watercraft traversing the GIWW experience strong currents in the vicinity of the MSC-GIWW intersection during periods of strong winds and peak tidal floods. Furthermore, at its present location, the GIWW near the intersection is subject to extensive shoaling because of the strong crosscurrent. As discussed in Chapter 2, Sundown Island, constructed and maintained through dredging operations, has been identified as a major source of sediment deposited into the GIWW near the intersection. Its position relative to the MSC, on the south side of the GIWW, and its close proximity (1,300 ft) to the waterway, makes the island highly susceptible to erosion induced by the strong currents experienced in this area.

To assess the consequences of relocating the GIWW and possible reduction of sediment shoaling of the waterway by erosion of an artificially created bird island, the bathymetry grid of the circulation model was modified to represent the proposed alignment. A one-month simulation was then made with the calibrated model, and time series of water velocity computed at several complementary locations at the existing and proposed GIWW alignments were saved and processed. These time series were analyzed and compared in assessing and qualifying the potential reduction in shoaling at the relocated channel. The complementary stations for the calculated currents allow comparisons for equivalent geometric locations for the existing and relocated waterway and island. 


\section{Adaptation of Calibrated Model}

The grid constructed for the existing Matagorda Bay condition was adapted to represent the proposed GIWW alignment. The existing-condition grid was modified by increasing nodal resolution in the vicinity of the proposed channel and by positioning additional nodes to depict this channel. The modified grid thereby contains an accurate channel in both alignment and width. Channel depths assigned to these nodes are consistent to those composing the existing GIWW (with respect to displacement away from the MSC) for areas that are shallower than the channel. For areas where the proposed channel depth is equal to or less than the ambient conditions, the ambient depths were used.

Because the existing GIWW can be expected to eventually fill with sediment, this channel was removed from the grid, and nodal positions were adjusted in this region to allow elemental sizes to approximate neighboring elements. Depths assigned to these new nodes correspond to the ambient bathymetry in the surrounding area. For similar reasons, the existing Sundown Island was removed from the new grid to represent a longterm perspective.

The existing and proposed GIWW locations are presented in Figure 34. The MSCGIWW intersection for the existing channel is located at approximately $96 \mathrm{deg} 21.9 \mathrm{~min}$ W long, $28 \mathrm{deg} 27.3 \mathrm{~min} \mathrm{~N}$ lat. The proposed intersection is located at $96 \mathrm{deg} 22.9 \mathrm{~min}$ W long, 28 deg 28.0 min $\mathrm{N}$ lat. Figure 35 presents the grid in the vicinity of the proposed MSC-GIWW intersection. This grid consists of 21,940 elements and 12,382 nodes (as opposed to 20,320 elements and 11,575 nodes for the existing-configuration grid).

Each hindcast simulation began on YD 243 (31 August 1997) at 0000 GMT and ended on YD 273 (1 October) at 0000 GMT. The model was run with a 4-s time-step. The wind input over the entire model domain and the tidal-elevation forcing imposed at the gulf open boundary were identical to those of the calibration for simulating the existing and proposed GIWW configurations.

Based on dredging records, extent of the flood shoal at Pass Cavallo, and qualitative observations on site and of aerial photography, it was hypothesized in Chapter 2 that Sundown Island is a significant source of sediment being deposited in the GIWW. Sediment is being eroded and entrained by waves striking the island from the northeast; therefore, flood currents entering through the MSC entrance can readily transport this sediment towards the GIWW, where it is subsequently deposited. Calculated tidal-flood currents (with the existing-configuration grid) in the vicinity of the project area are displayed in Figure 36, which plots velocities at 1 September at 0600 GMT. Arrows indicating current magnitude and direction are displayed at each grid node, and the MSC and GIWW can be observed in the figure by the close proximity of those nodes and their alignment composing the channels. 


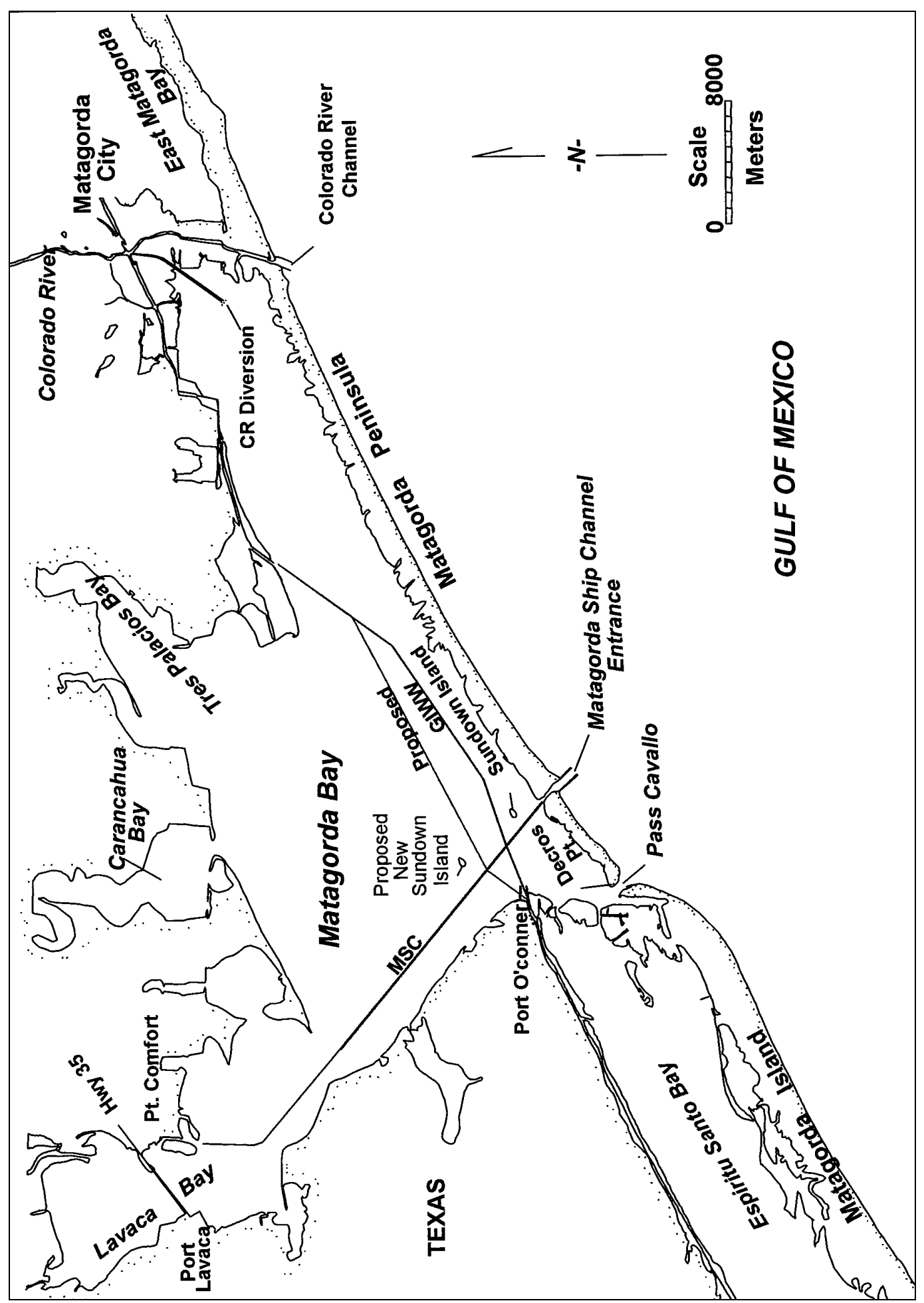

Figure 34. Location map of existing and proposed GIWW 


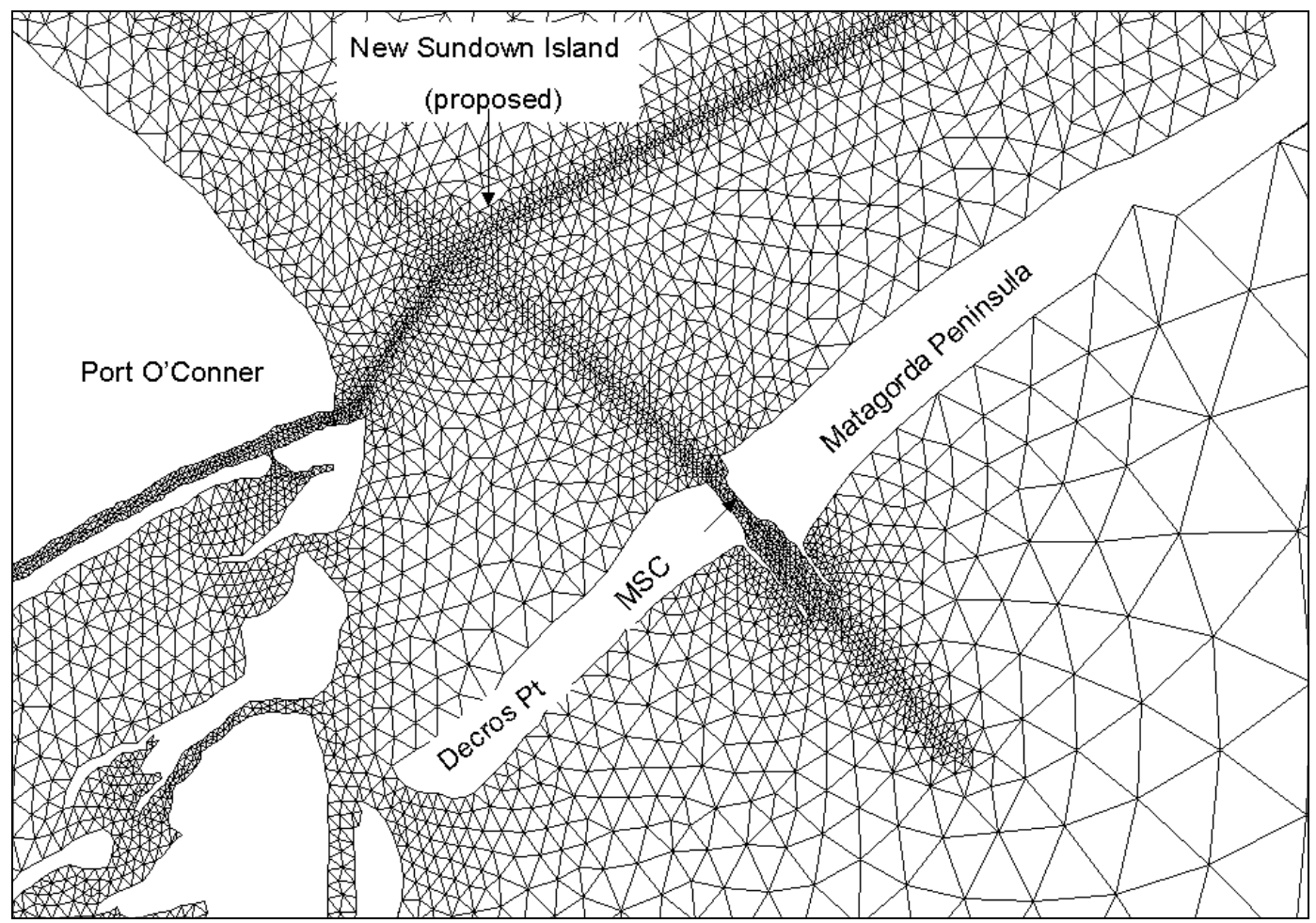

Figure 35. Numerical grid in vicinity of proposed (relocated) GIWW

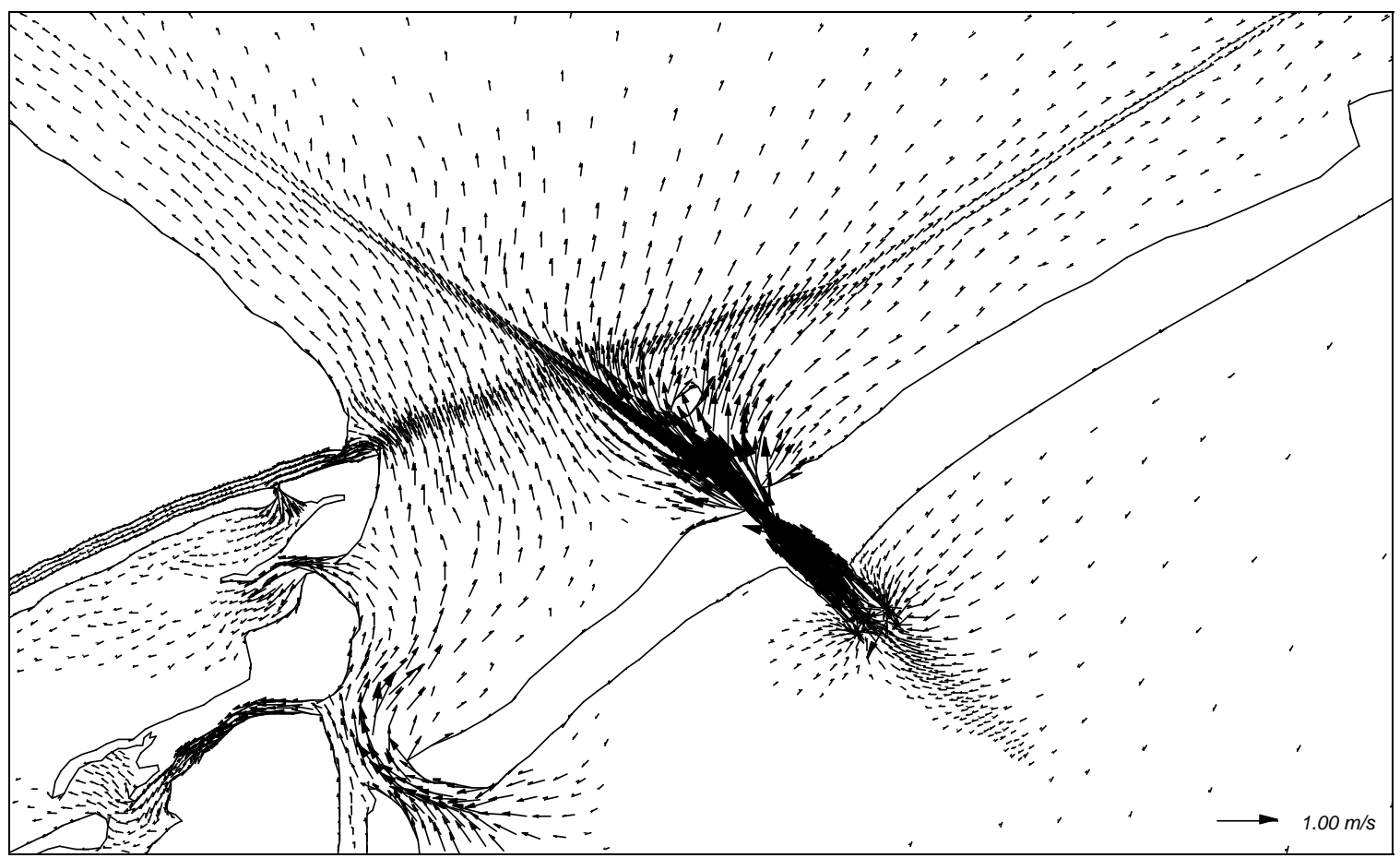

Figure 36. Current vector map for existing GIWW 
Entering the open bay through the MSC entrance, tidal-flood currents exceed $2.5 \mathrm{~m} / \mathrm{sec}$. These currents progressively weaken as they propagate to the northwest, along the MSC, to about $0.3 \mathrm{~m} / \mathrm{sec}$ approximately 2 miles inland from the entrance. This weakening is in great part a consequence of the tidal jet spreading laterally over an increasingly widening area as the jet moves into the bay. The lateral extent of this jet is greater for the eastern side of the MSC than for the western side. The shallower water on the western side (compared with the eastern side) impedes intrusion of the jet into the western side. Also, the flood current at Pass Cavallo enters the bay at a northeasterly heading and tends to deflect or displace the MSC current to a northwesterly heading.

The eastern lateral extent of the tidal jet is deflected further eastward by Sundown Island, subjecting the island to strong currents. The jet is divided into two portions, with one portion flowing south of the island and towards the east-northeast and the other flowing between the island and the MSC and towards the northeast. Consequently, the western and southern faces of the island are exposed to the strongest currents and can be expected to experience the greatest sediment transport potential. Weaker currents, with headings towards the north-northeast, are shown along the northern side of the island; because this area is sheltered from the tidal jet, sediment deposition is likely to occur in this area.

Figure 37 presents a vector map of the current for the relocated GIWW alternative route. (To facilitate comparison of current patterns between existing- and proposedchannel configurations, this figure covers the identical spatial area, and with the same vector scaling, as Figure 36.) The current is reduced on the western side of the bay; without Sundown Island obstructing the jet, less water is diverted to the west of the location of the island. Without Sundown Island, the heading of the jet changes to the northeast of the MSC. Under the existing-configuration conditions, the jet is divided into northwestern and northeastern currents; if Sundown Island is allowed to erode, the jet will have a northwestern heading, reducing the current moving towards the northeast. In addition, the current in the vicinity of the proposed Sundown Island is weaker than that in the vicinity of the existing island.

To quantify and compare the current in the vicinity of the relocated GIWW and proposed Sundown Island, time series of the current were saved at 12 locations in Matagorda Bay (Figure 21). Locations were chosen so that computed velocities at six sites under the proposed GIWW configuration can be compared with their complementary or equivalent site with respect to the existing GIWW location.

One complementary pair of time series was computed at the existing and proposed MSC-GIWW intersection. A second pair was chosen to depict equivalent currents with respect to sta 1 , the location where currents were measured during the calibration period using a current meter placed in the GIWW. For the existing configuration, the current was computed at the actual meter position; an equivalent position, relative to the distance from the station to the MSC-GIWW intersection, was selected for the proposed configuration at the relocated waterway.

The remaining four complementary sites surround the existing and the proposed Sundown Islands. One pair of sites is located off the western extent of the islands, and a second pair was specified at the eastern extent of each island. The fifth pair was placed midway between the island and the channel, and the sixth pair lies on the opposite side of the island from the channel. 


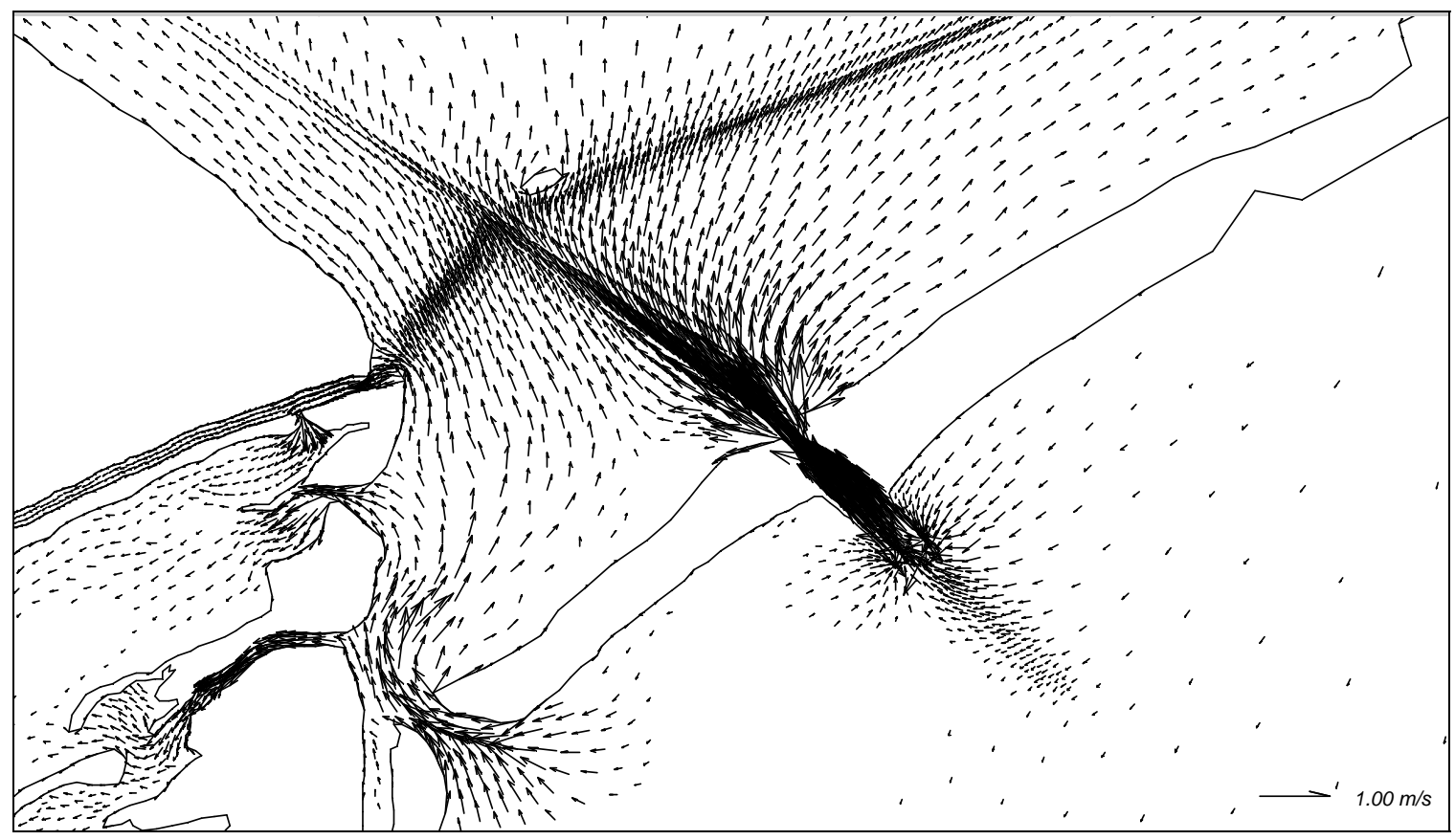

Figure 37. Current vector map for proposed GIWW relocation

Comparing time series of currents calculated at the western island locations, the average peak current at the existing island was about $50.0 \mathrm{~cm} / \mathrm{sec}$, whereas the average peak current at the proposed island was $17.5 \mathrm{~cm} / \mathrm{sec}$, or $32.5 \mathrm{~cm} / \mathrm{sec}$ weaker (Figure 38). The differences in currents are presented in Figure 39, which were computed by subtracting, for each entry in the time series, the existing-configuration current from the proposed-configuration current; negative values of the current contained in this plot correspond to the existing-condition current being greater than the proposedconfiguration current. The current is reduced because the water flows over an increasingly wider area. Time-averaged currents at these locations were $22.7 \mathrm{~cm} / \mathrm{sec}$ for the existing site as opposed to $13.3 \mathrm{~cm} / \mathrm{sec}$ for the numerical station.

Comparing time series of currents computed at the MSC-GIWW intersection, presented in Figure 40, the average-peak current at the existing intersection was about $30.0 \mathrm{~cm} / \mathrm{sec}$, whereas the average-peak current at the proposed intersection was $20.0 \mathrm{~cm} / \mathrm{sec}$, or about $20 \mathrm{~cm} / \mathrm{sec}$ less. Weaker currents at the proposed site can be expected because it is situated about $13,000 \mathrm{ft}$ from the bay side of the MSC entrance, or approximately $7,000 \mathrm{ft}$ to the north-northwest from the existing intersection. Timeaverage currents at the existing and proposed sites were 20.3 and $15.3 \mathrm{~cm} / \mathrm{sec}$, respectively, and differences in currents are presented in Figure 41. The MSC is an efficient conduit for water flow because of its depth. The predominant component of the current in the MSC is along its axis, which plays a major role for moving sediment into the channel.

For the pair of stations residing between the GIWW and the islands, the average-peak current north of the existing island was about $35.0 \mathrm{~cm} / \mathrm{sec}$, whereas the average-peak current for the complementary site south of the proposed island was $17.5 \mathrm{~cm} / \mathrm{sec}$, or $17.5 \mathrm{~cm} / \mathrm{sec}$ weaker (Figure 42). Differences in current are presented in Figure 43. 


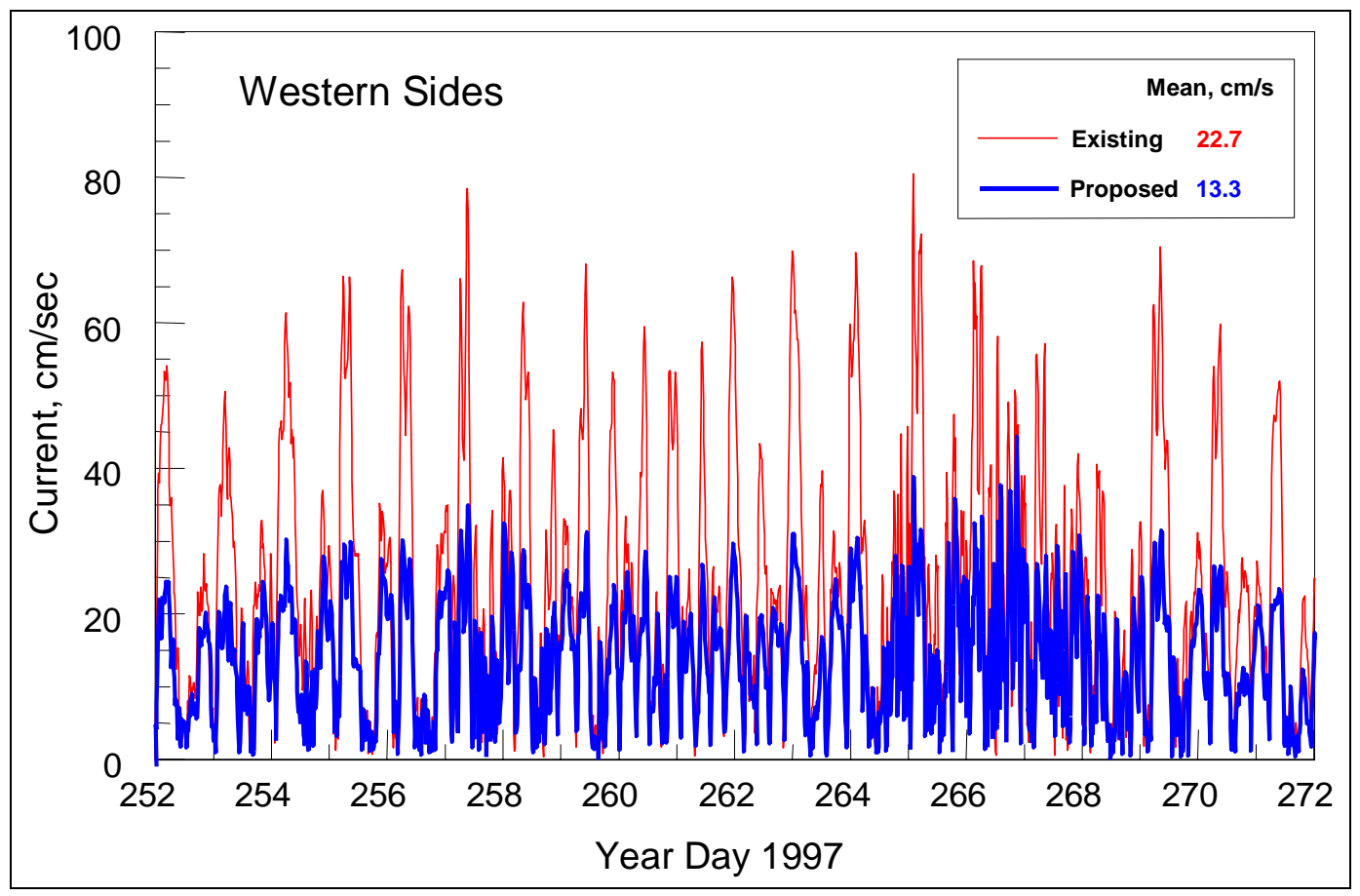

Figure 38. Comparison of currents at the western sides of Sundown Islands

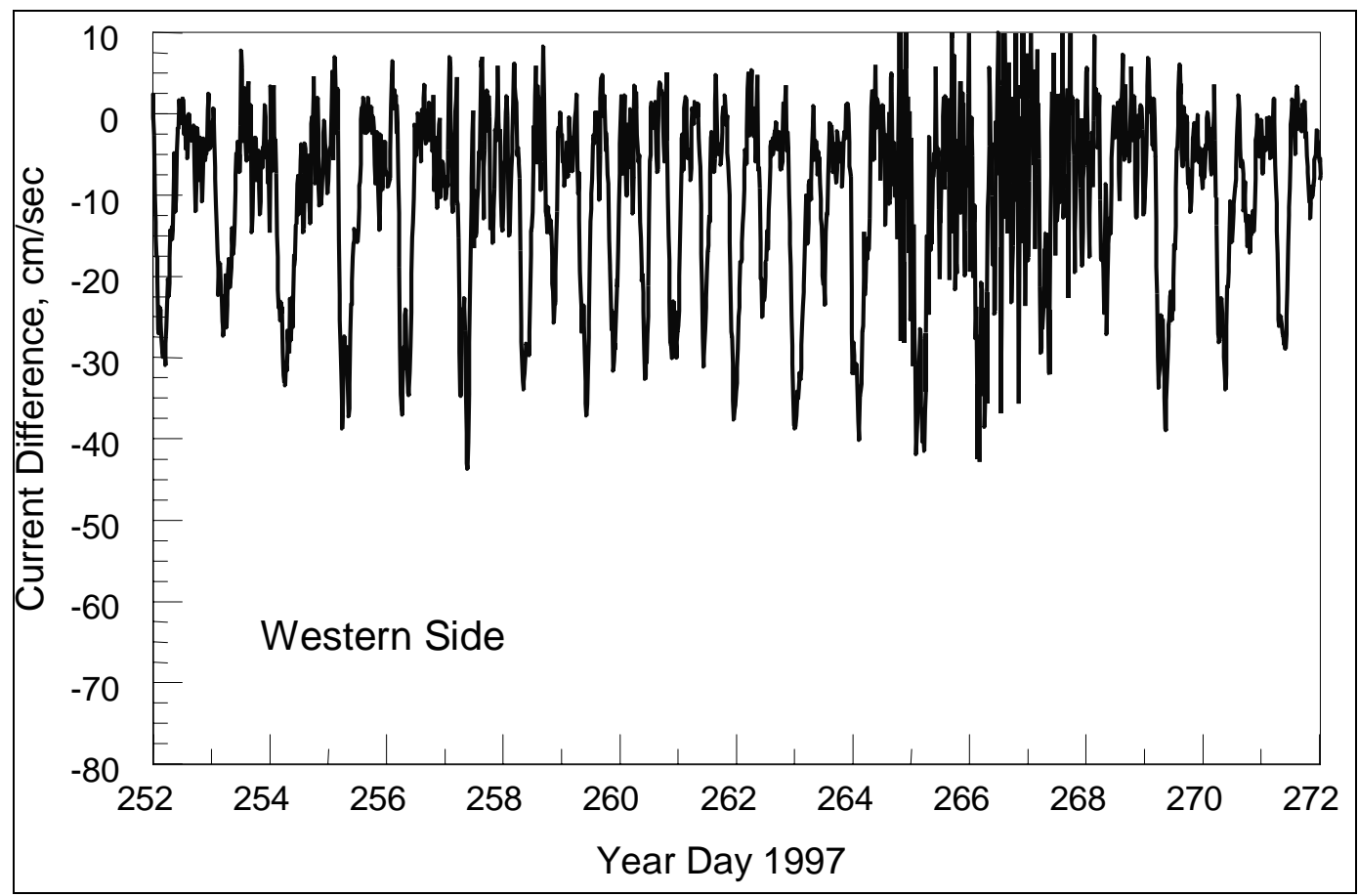

Figure 39. Time series of current differences calculated at western side 


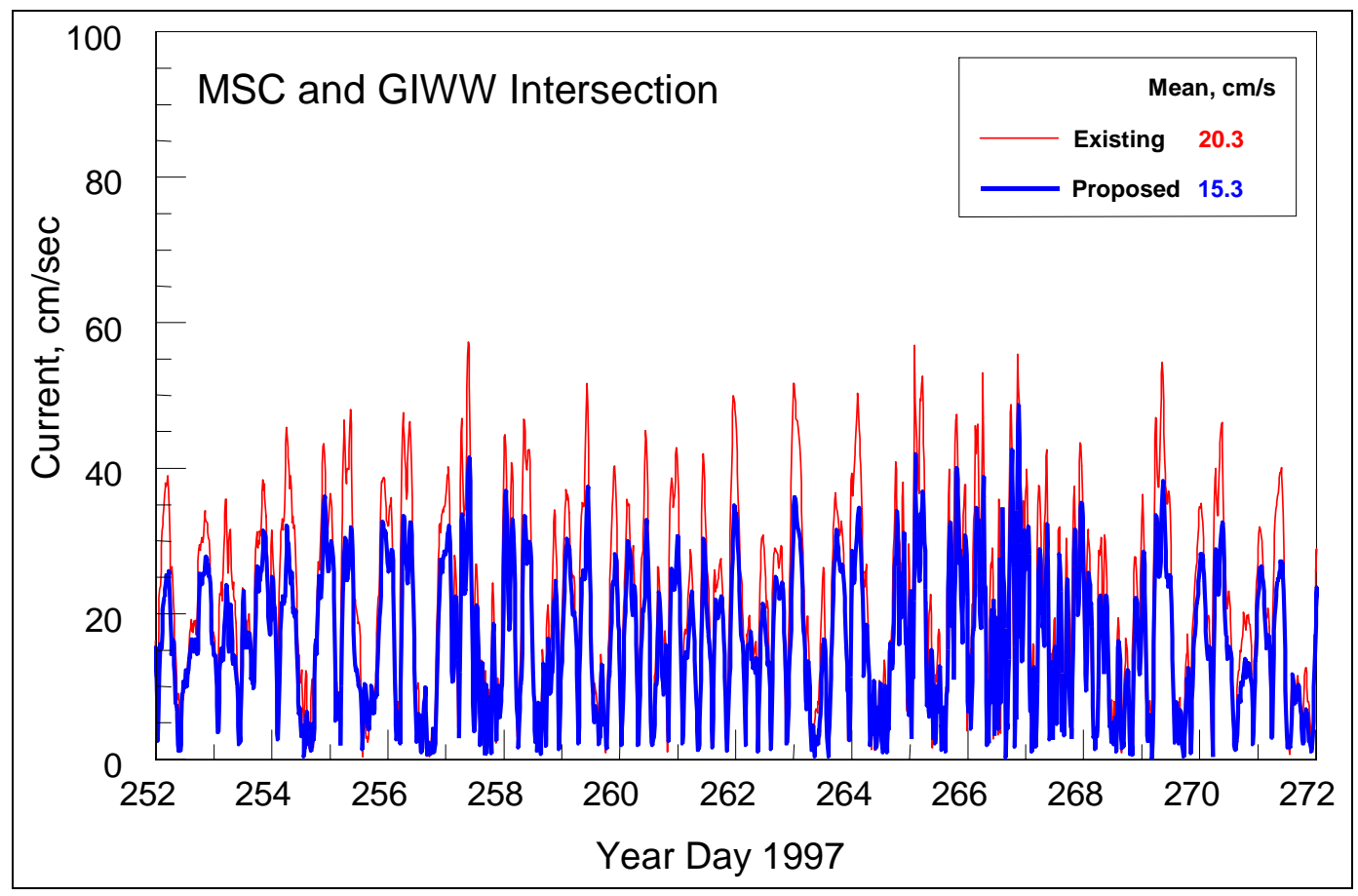

Figure 40. Comparison of currents at the MSC-GIWW intersection

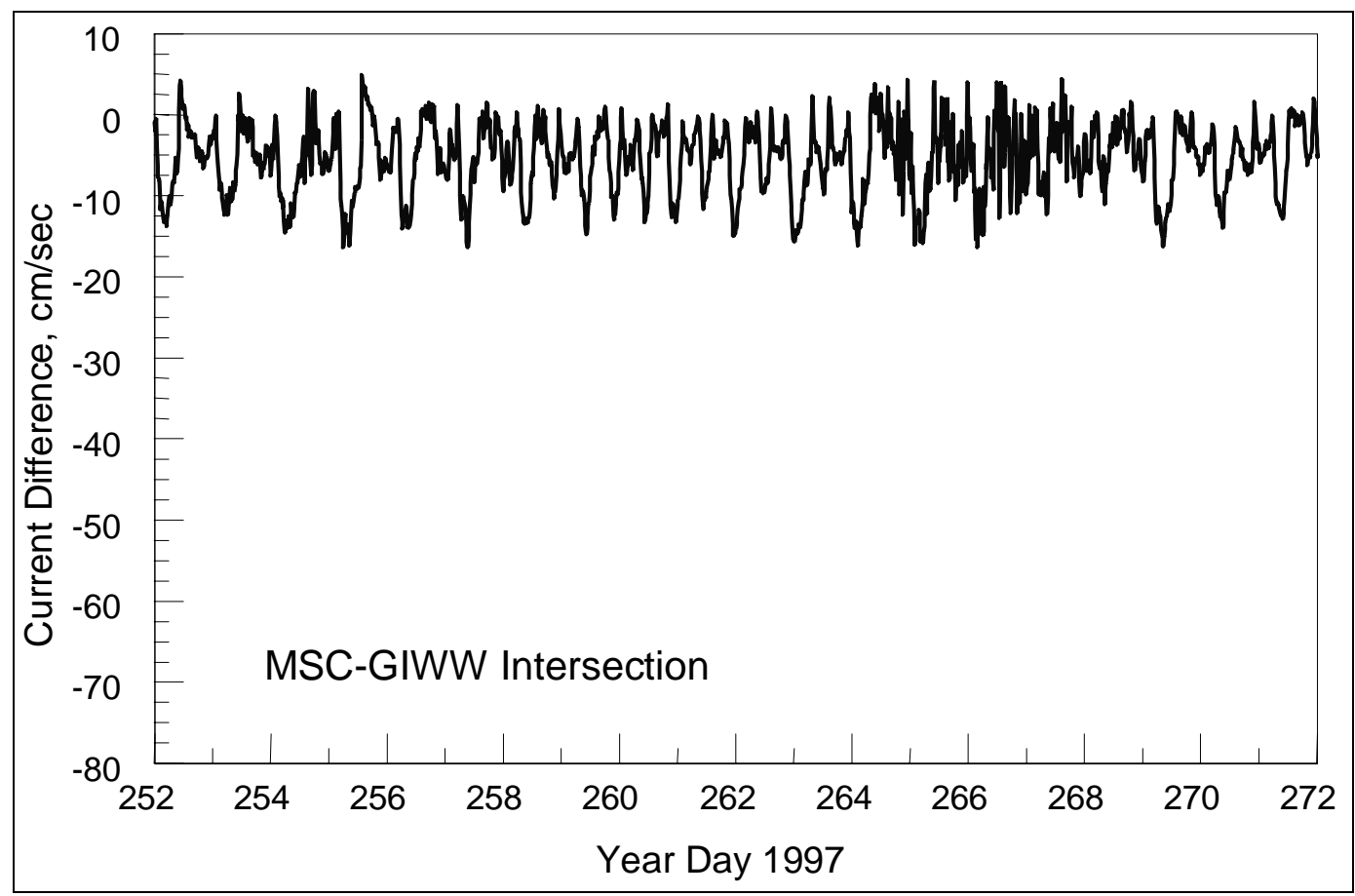

Figure 41. Time series of current differences calculated at the MSC-GIWW intersection 


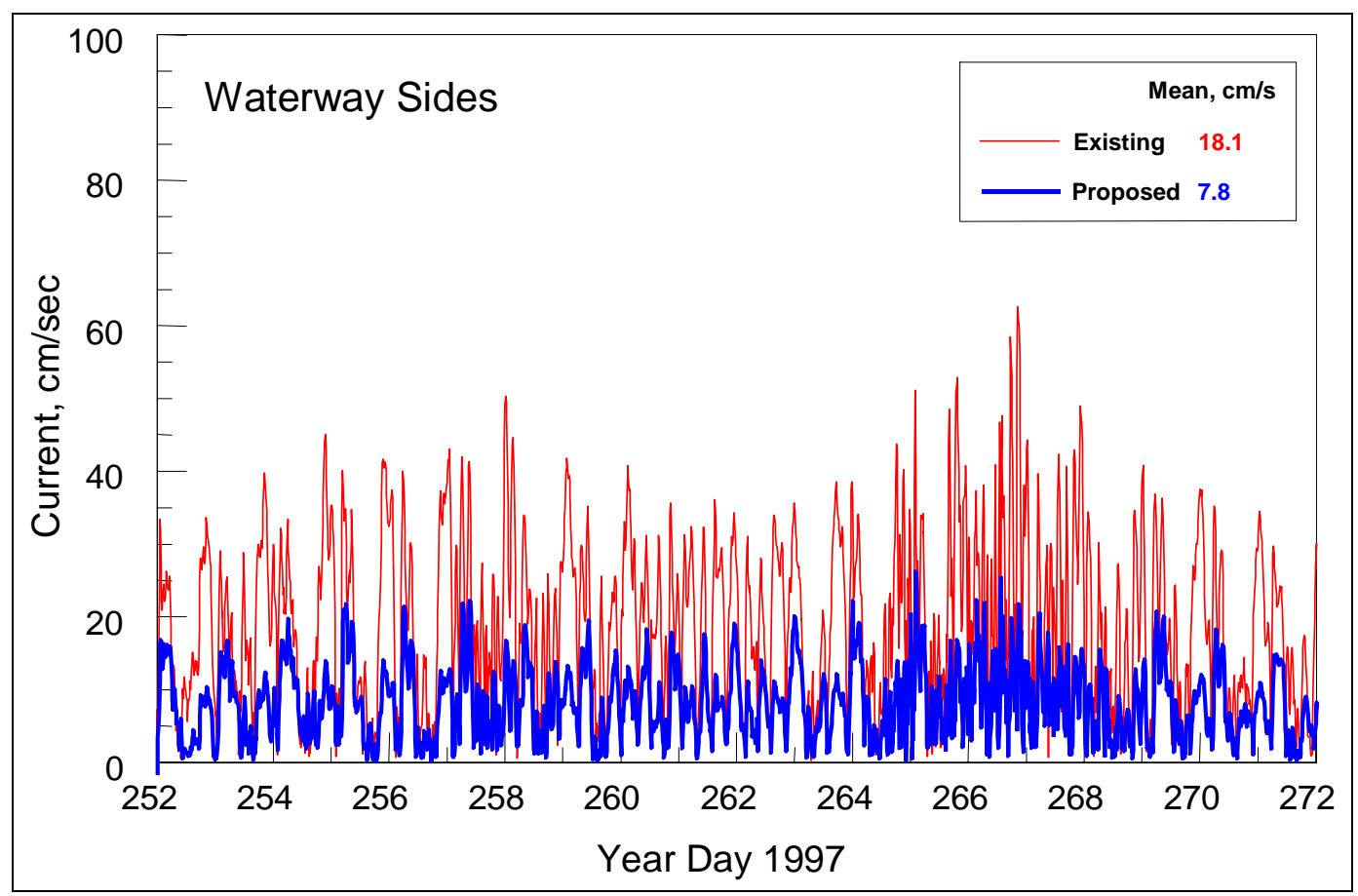

Figure 42. Comparison of currents at the waterway sides of Sundown Islands

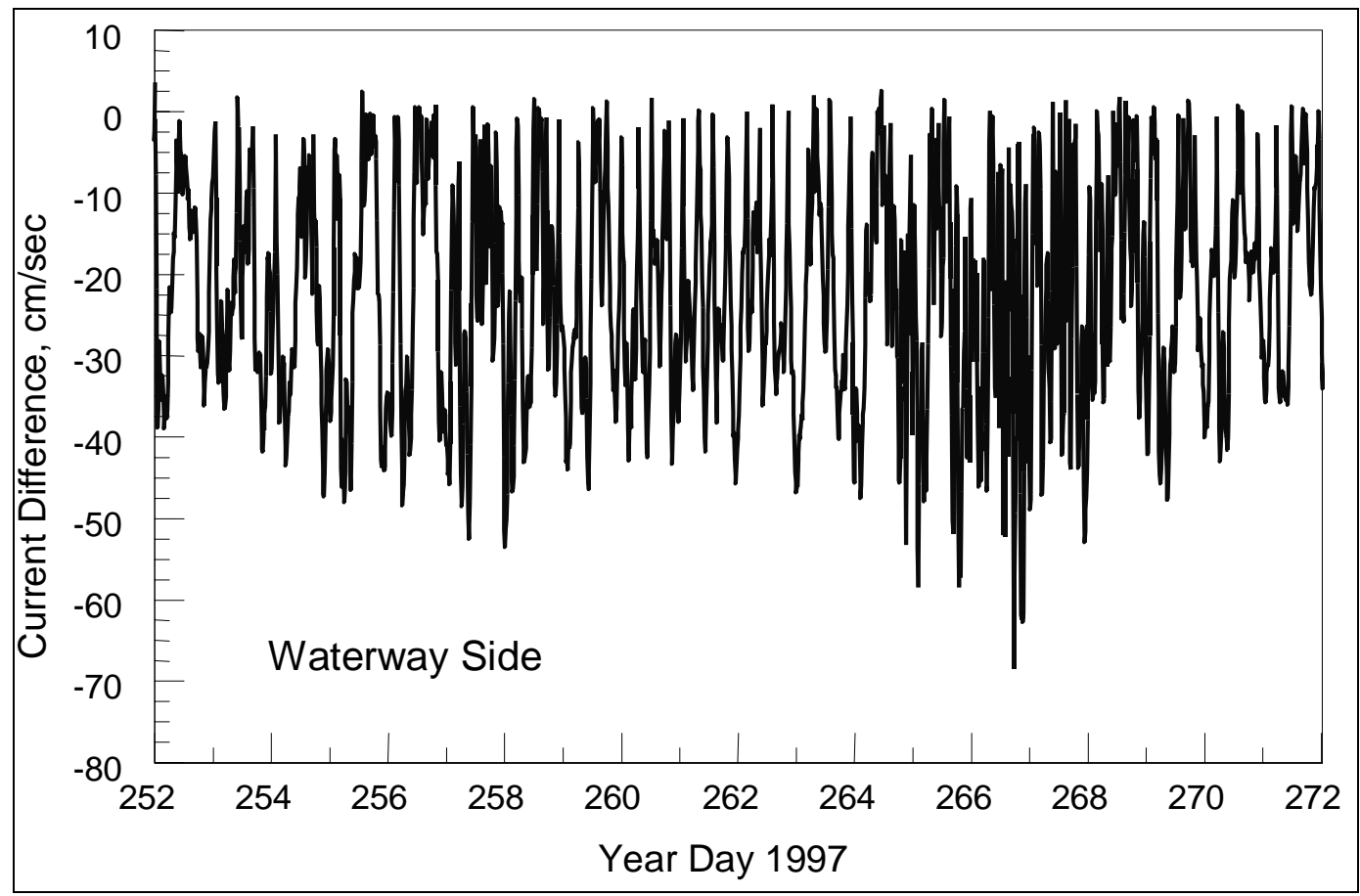

Figure 43. Time series of current differences calculated on the waterway side of Sundown Island 
Similar observations can be made with the pair of stations with positions corresponding to the sta 1 current meter location, where the average-peak current at the actual site was approximately $25 \mathrm{~cm} / \mathrm{sec}$, versus $15 \mathrm{~cm} / \mathrm{sec}$ at its complementary site in the proposed GIWW (Figure 44). Time-averaged velocities at these locations were $13.7 \mathrm{~cm} / \mathrm{sec}$ for the existing sta 1 site as opposed to $10.8 \mathrm{~cm} / \mathrm{sec}$ for the numerical station.

At the eastern island locations, the average-peak water velocity computed off the existing island was approximately $35 \mathrm{~cm} / \mathrm{sec}$ (Figure 45). The average-peak current experienced at its complementary site at the proposed Sundown Island was approximately $25 \mathrm{~cm} / \mathrm{sec}$, or $10 \mathrm{~cm} / \mathrm{sec}$ less than at the existing island. Time-averaged velocities at these locations were $18.5 \mathrm{~cm} / \mathrm{sec}$ for the existing site as opposed to $12.8 \mathrm{~cm} / \mathrm{sec}$ for the numerical station.

The last pair of sites lie on the opposite side of their respective islands from the waterways. The peak current computed south of the existing island was approximately $60 \mathrm{~cm} / \mathrm{sec}$, whereas peak velocity was approximately $12 \mathrm{~cm} / \mathrm{sec}$ at its complementary station located south of the proposed island (Figure 46). Time-averaged velocity for the existing site was $18.1 \mathrm{~cm} / \mathrm{sec}$, whereas the average velocity for the proposed site was $7.8 \mathrm{~cm} / \mathrm{sec}$.

Implications of these calculations are very favorable for relocating the GIWW northward to its pre-1942 route. The sediment transport rate, whatever type of formula applied, is a nonlinear function of the magnitude of current velocity. A typical value would be velocity raised to the power of three, or velocity cubed. From the above figures, current velocity at complementary points adjacent to the GIWW indicate a decrease in peak current of more than half, giving an estimated reduction in the transport rate by the crosscurrent of one-eighth. In general, the magnitude of the crosscurrent along the relocated route of the GIWW is significantly less than at the present location of the GIWW near the corresponding MSC-GIWW intersection. Thus, based on calculations of the current, the sediment transport rate and shoaling rates in the relocated GIWW will be approximately an order of magnitude less than at the present location. 


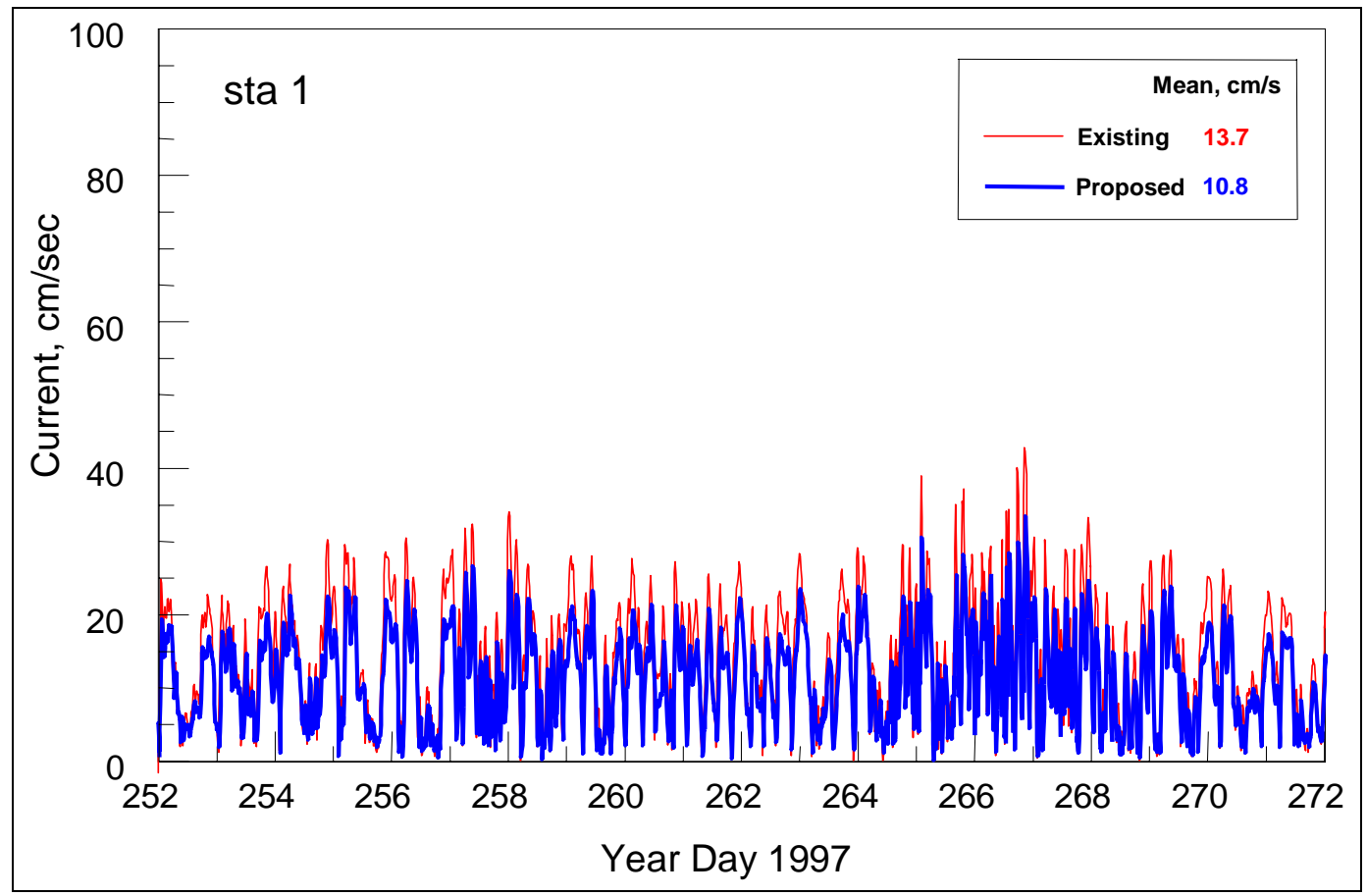

Figure 44. Comparison of currents at sta 1

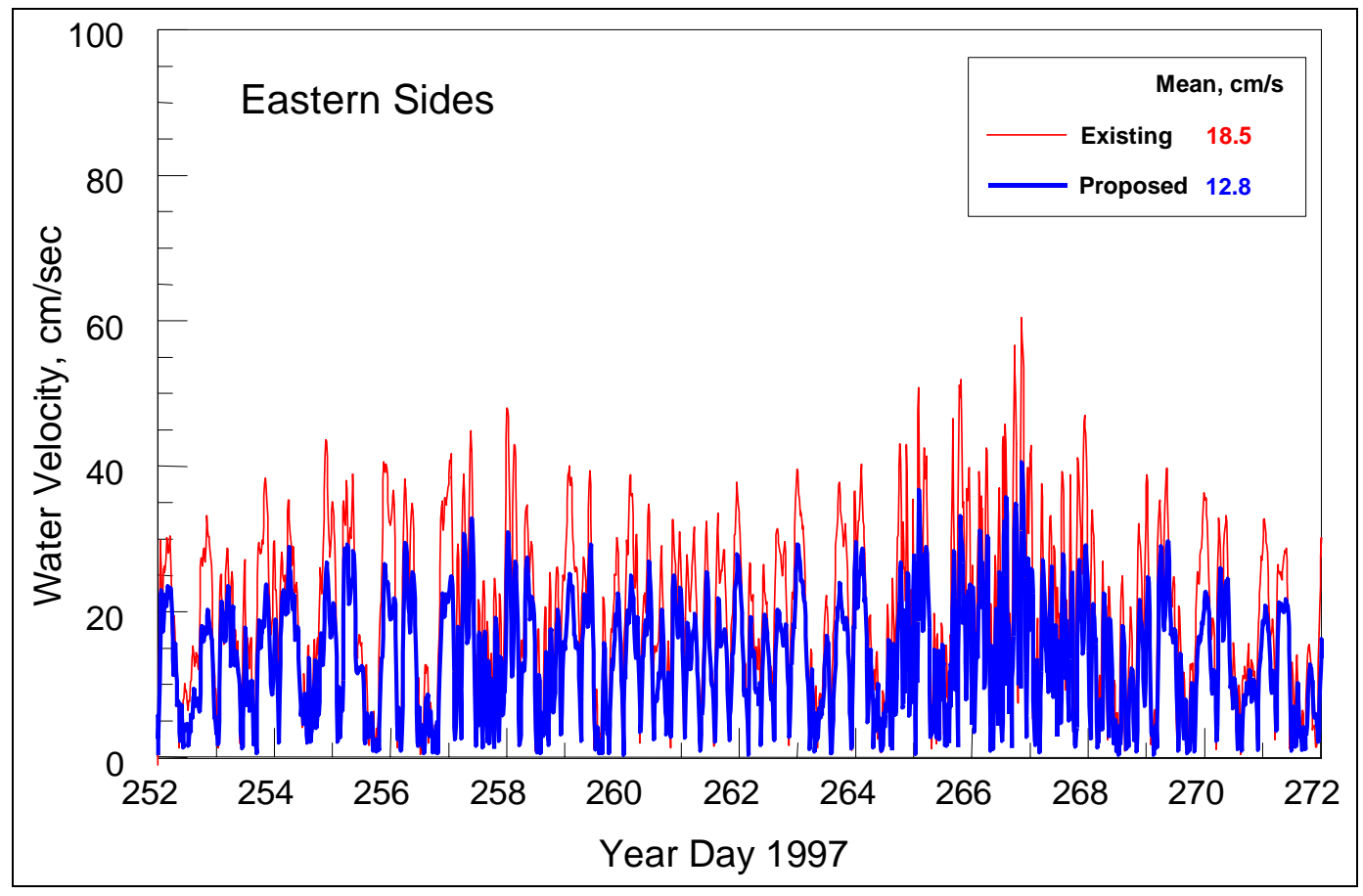

Figure 45. Comparison of currents at the eastern sides of Sundown Islands 


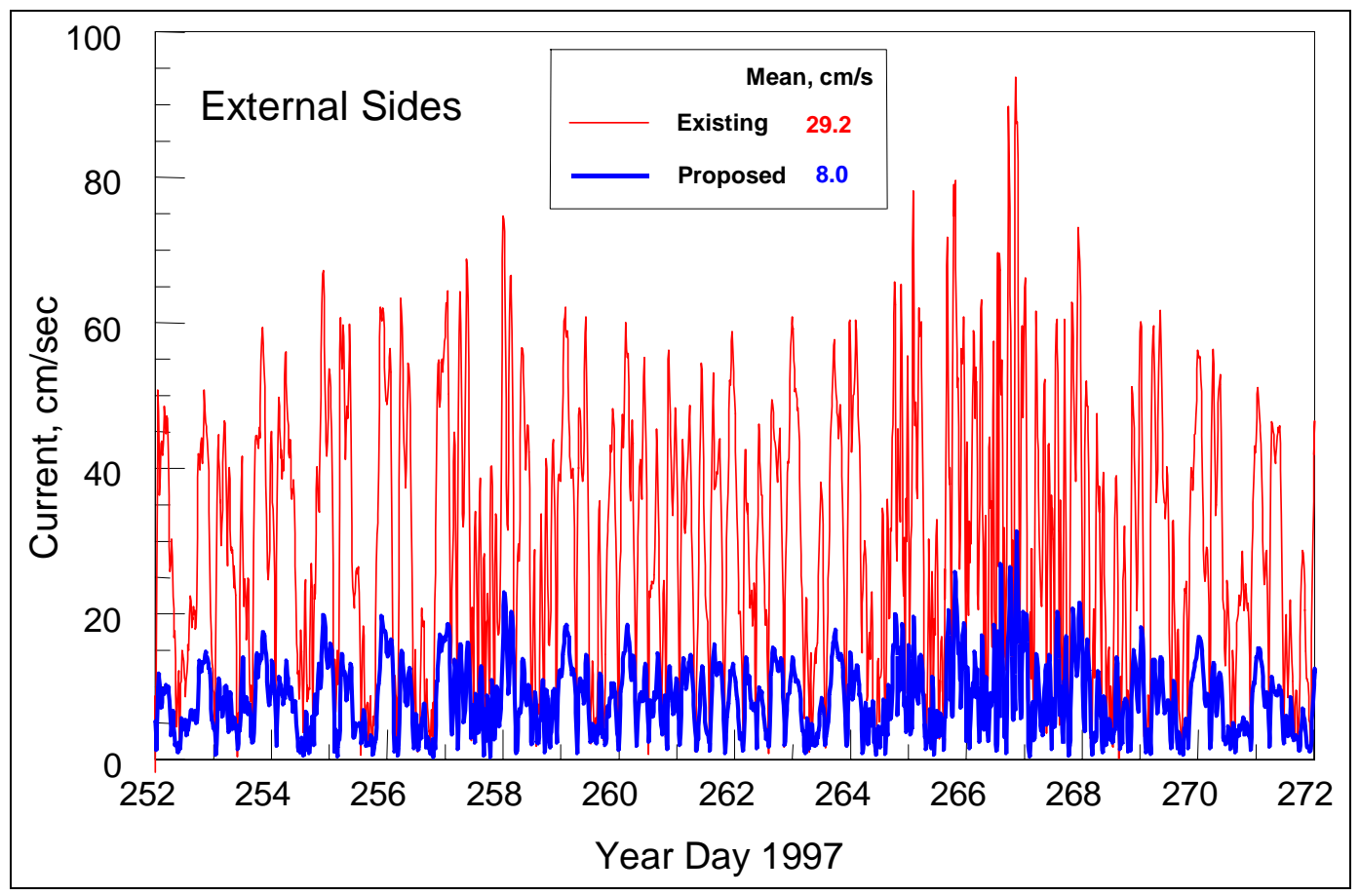

Figure 46. Comparison of currents at the external sides of Sundown Islands 


\section{Summary and Recommendations}

This chapter summarizes study findings on the cause of excessive shoaling in the GIWW near the MSC-GIWW intersection. Based on the findings, recommendations are given for moving the open-bay portion of the GIWW to the north. The recommendations are developed from a synthesis of observations of the morphology at Pass Cavallo, hydrodynamic processes at the MSC entrance, dredging records, and circulation modeling, by applying the DMS methodology and rapid-assessment techniques.

\section{Summary}

Results are summarized according to the category of process.

\section{Morphology and circulation}

The present location of the GIWW is within about 13,000 ft of the entrance of the MSC. This distance is within the range occupied by the historical flood shoal of Pass Cavallo. Similarly, Sundown Island is located within this range of extent of the historic flood shoal. A flood shoal occupies the region of effective sediment-transporting capacity of the inlet and its flood current, as schematically depicted in Figure 47, which is adapted from the DMS Manual (Kraus et al., in preparation). A flood current deposits sediment at a distance from the inlet where the current sufficiently weakens. The flow weakens because of horizontal expansion of the flood jet in the calm bay water with distance from the entrance into the bay. A substantial flood shoal will not form at the MSC entrance because the jetties prevent littoral sediment from entering the channel, and the strong ebb current tends to sweep out littoral sediment that is deposited in it.

Because the MSC entrance is capturing the tidal prism from Pass Cavallo and because it is a jettied and deep channel, it is much more efficient to water flow than the wide and shallow historic pass. Therefore, the effective range of sediment-transporting capacity for the flood current of the MSC entrance is greater than that of Pass Cavallo. Any sediment mobilized by waves within this range will be transported bayward by this current. The GIWW segment in this range will tend to shoal, and material eroded from Sundown Island will tend to be transported into the GIWW by the flood current.

Figure 48, also taken from the DMS Manual (Kraus et al., in preparation) is a schematic of channel infilling by a current with a predominant direction. Inspection of condition surveys at the GIWW high-shoaling rate section shows a pattern similar to that of the schematic. 


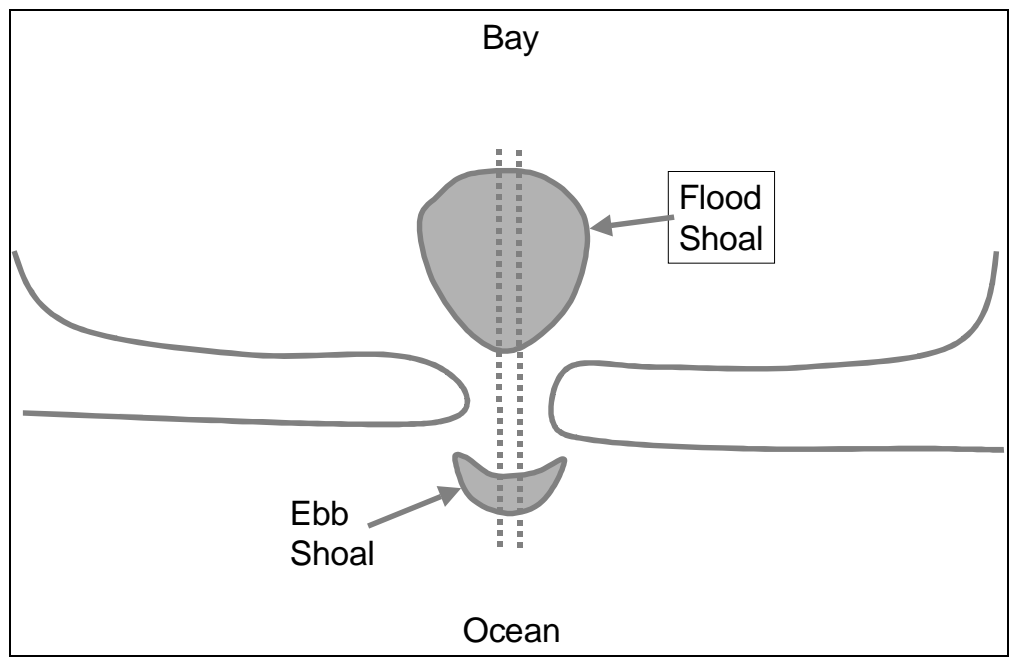

Figure 47. Idealized flood-shoal development

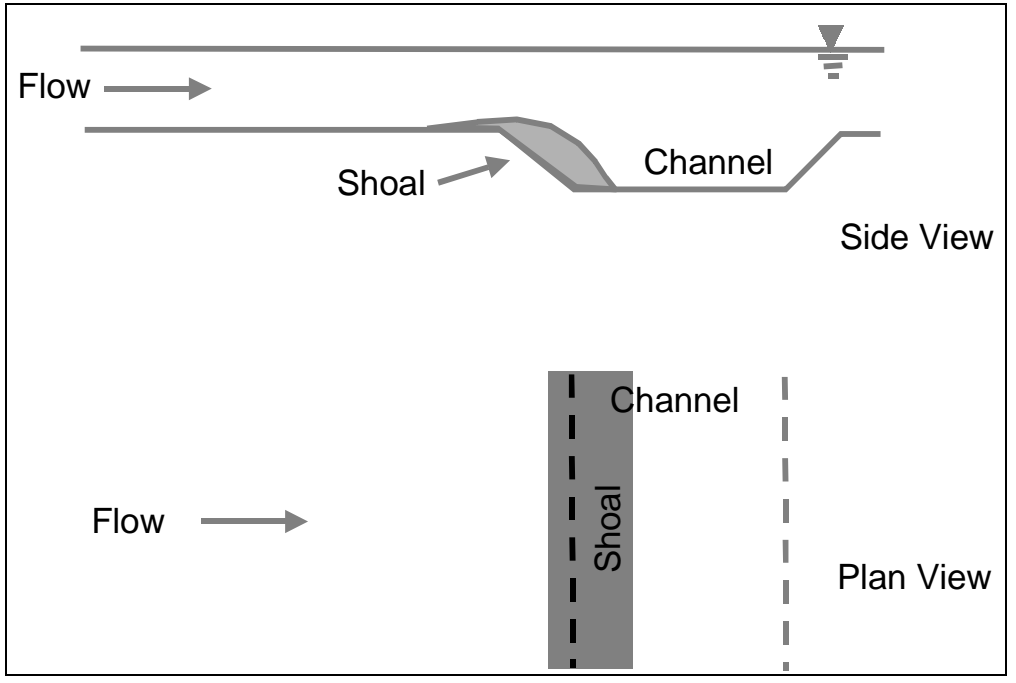

Figure 48. Idealized channel infilling pattern by a current with predominant flow direction

In summary, long-term morphologic evidence indicates that both the GIWW and Sundown Island are located too close to the MSC entrance and are in the range of a strong, sediment-transporting flood current.

\section{Dredging record}

Analysis of dredging records for 1966 to 1995 indicated that the stretch of GIWW north to northeast of Sundown Island (sta 612+000 to 616+000) is experiencing sediment shoaling that is increasing nonlinearly with time as approximately $t^{3 / 2}$. This and neighboring sections of the GIWW had much increased shoaling rates as compared sections more distant from the MSC-GIWW intersection. The shoaling pattern is consistent with previous inferences of sediment transport by the tidal flood jet; with 
distance away from the jet to areas of weaker current, the shoaling rate in the waterway decreases.

Channel cross-section surveys of the MSC and GIWW showed that the MSC tended to fill from both sides, indicating isotropic sediment transport. Cross sections of the GIWW indicated predominant infilling or transport from the south side, as brought by the flood current.

\section{Circulation modeling}

A numerical model of the hydrodynamics in Matagorda Bay was established and calibrated by comparison of predictions to recent (September 1997) measurements of the water level and current. The horizontal current pattern and magnitude of the current were then compared at the present location of the GIWW and at the proposed location.

The modeling confirmed inferences as given in the previous section based on general characteristics of flood shoals and flood jets. It was found that the flood current flowed past Sundown Island toward the GIWW with sufficient strength to transport sediment into the waterway.

Comparison of the magnitudes of the calculated current at the present location of the GIWW and at the proposed location showed that the peak current speed at the proposed location was on the order of one-half that at the existing location. Therefore, because sediment transport follows a nonlinear function of current magnitude, typically on the order of magnitude cube, a decrease in transport would be expected, hence infilling at the relocated channel on the order of one-eighth that occurring at the existing channel. This conclusion holds in the dynamic equilibrium condition, a few years after initial dredging for the relocated channel. If little dredging is necessary, then initial transients as slumping of channel walls will make only a minor contribution to the shoaling.

\section{Recommendations}

The following are recommendations from application of the DMS methodology:

a. If the GIWW is not relocated northward, shoaling in the waterway in the vicinity of Sundown Island can be reduced by armoring the island to prevent material eroded from it from being transported into the waterway by the flood current. The large shallow shoals on the northeast side of Sundown Island might also be dredged to eliminate this material as a source of shoaling.

$b$. If the GIWW is relocated and Sundown Island is to be maintained or protected, then armoring should be placed around the island to reduce erosion by waves and currents (both tidal and wind-generated currents).

c. Relocation of the GIWW northward as under consideration by the Galveston District would be beneficial for three reasons:

(1) Shoaling of the waterway would be greatly reduced because it would be out of the range of influence of a strong flood current.

(2) Sundown Island would not provide the large input of sediment that it presently provides.

(3) Navigation safety would be improved at the new MSC-GIWW intersection because the flood current would be greatly reduced as compared to its 
strength at the present location, and ships would have more time to reduce speed while entering under a flood current.

$d$. If a dredged-material island is created through dredging of the relocated waterway and through normal maintenance of the MSC, then this island should be located on the north side of the GIWW to reduce the potential for the flood current to transport sediment into the channel.

e. If the GIWW is relocated, a low-level monitoring program should be established to confirm the performance (shoaling characteristics - causes and locations) of shoaling in the new waterway and of infilling of the existing GIWW. The infilling of the existing waterway will provide valuable data to the Galveston District for understanding waterway shoaling rates in open-bay areas as a function of the processes. The monitoring would include quarterly condition surveys and maintenance of two current meters combined with water level and wave gauges, one each at the relocated and existing waterways. The monitoring program should be initially established to run for 3 years, with annual reports summarizing the measurements and project performance. 


\section{References}

Atturio, J. M., Basco, D. R., and James, W. P. (1976). "Shoaling characteristics of the Gulf Intracoastal Waterway." TAMU-SG-76-207 and CDS Report No. 187, Civil Engineering Department, Coastal and Ocean Engineering Division, Texas A\&M University, College Station, TX.

Bouma, A. H., and Bryant, W. R. (1969). "Rapid delta growth in Matagorda Bay, Texas.” Lagunas Costeras, Un Sinposio, 171-189.

Harwood, P. J. W. (1973). "Stability and geomorphology of Pass Cavallo and its flood delta since 1856, Central Texas Coast." M.A. thesis, University of Texas at Austin, Austin, TX.

Kraus, N. C., Gosselin, M. S., Craig, K. R., and Taylor, R. B. (in preparation). "DMS: Diagnotic Modeling System, Report 3, DMS Manual," U.S. Army Engineer Research and Development Center, Coastal and Hydraulics Laboratory, Vicksburg, MS.

Kraus, N. C., and Militello, A. (1996). "Hydraulic feasibility of proposed Southwest Corner Cut, East Matagorda Bay, Texas." Technical Report TAMU-CC-CBI-96-03, Conrad Blucher Institute for Surveying and Science, Texas A\&M University-Corpus Christi, Corpus Christi, TX.

. (1999). "Hydraulic study of a multiple inlet system: East Matagorda Bay, Texas," Journal of Hydraulic Research 125(3), 224-232.

Kraus, N. C., Thurlow, C. I., Heilman, D. J., Lindquist, A., and Earle, M. W. (1997). "Needs assessment for water-level gauging along the Texas coast for the U.S. Army Corps of Engineers, Galveston District.” Technical Report CHL-97-29, U.S. Army Engineer Waterways Experiment Station, Vicksburg, MS.

Laroe, L. M. (1997). “La Salle’s last voyage,” National Geographic 191(5), 72-83.

Luettich, R. A., Jr., Westerink, J. J., and Scheffner, N.W. (1992). "ADCRIC: An advanced threedimensional circulation model for shelves, coasts, and estuaries," Technical Report DRP-92-6, U.S. Army Engineer Waterways Experiment Station, Vicksburg, MS.

Mathew, G. A., and Mueller, A. J. (1987). "Freshwater inflow requirements of a Texas estuary," Proceedings of Coastal Zone '87, American Society of Engineers, NY, 852-866.

Militello, A., and Kraus, N. C. (1994). "Reconnaissance investigation of the current and sediment movement in the Lower Laguna Madre between Port Isabel and Port Mansfield, Texas." TAMUCC-CBI-94-04, Conrad Blucher Institute for Surveying and Science, Texas A\&M UniversityCorpus Christi, Corpus Christi, TX. 
Militello, A., and Kraus, N. C. (1995). "Investigation of the current and sediment movement in the lower Laguna Madre, Texas, and implications for dredging in the Gulf Intracoastal Waterway." Proceedings Western Dredging Association 16th Technical Conference, Center for Dredging Studies, Texas A\&M University, College Station, TX, 143-162.

Mueller, A. J. and Mathews, G. A. (1987). "Freshwater inflow needs of the Matagorda Bay system with focus on Peneid shrimp." NOAA Technical Memorandum NMFC-SEFC-189, National Marine Fisheries Service, Southeast Fisheries Center, Galveston, TX.

Price, W. A. (1952). "Reduction of maintenance by proper orientation of ship channels through tidal inlets." Proceedings 2nd Conference on Coastal Engineering, American Society of Civil Engineers, NY, 243-255.

Rhodes, H. J., and Boland, R. A. (1962). "Contribution of Matagorda Bay model to design of Matagorda Bay deep draft navigation project." Proceedings 8th Conference on Coastal Engineering, American Society of Civil Engineers, NY, 598-615.

Simmons, H. B., and Rhodes, H. J. (1966). "Matagorda ship channel model study, Matagorda Bay, Texas: Hydraulic Model Investigations,” Technical Report No. 2-711, U.S. Army Engineer Waterways Experiment Station, Vicksburg, MS.

Texas Department of Transportation. (1994). “The Gulf Intracoastal Waterway in Texas." Texas Department of Transportation, Austin, TX.

U.S. Army Engineer District, Galveston. (1992). "Inlets along the Texas Gulf Coast. Planning assistance of States Program, Section 22 Report," Galveston, TX.

U.S. Congress. (1939). House Document 230, $76^{\text {th }}$ Congress, $1^{\text {st }}$ Session, dated 23 March 1939.

U.S. Congress. (1962). House Document 556, 87 $7^{\text {th }}$ Congress, $2^{\text {nd }}$ Session, dated 23 October 1962.

Van de Kreeke, J. (1985). "Stability of tidal inlets-Pass Cavallo, Texas." Coastal and Shelf Science $21,33-43$.

Ward, G. H. (1982). "Pass Cavallo, Texas: Case study of tidal prism capture," Journal of Waterway, Port, Coastal and Ocean Division 108(WW4), 513-525.

Ward, G. H., Wiersema, J. M., and Armstrong, N. E. (1982). "Matagorda Bay: A management plan," FWS/OBS-82/73, Division of Biological Services, U.S. Fish and Wildlife Service, Washington, DC.

Weiser, E. A., and Armstrong, J. (1962). "Design of deep draft navigation channel from Gulf of Mexico into Matagorda Bay, Texas." Proceedings $8^{\text {th }}$ Conference on Coastal Engineering, American Society of Civil Engineers, NY, 578-597. 


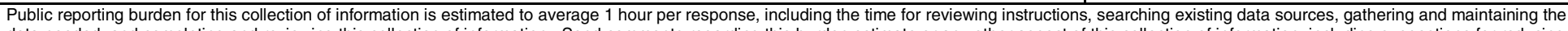

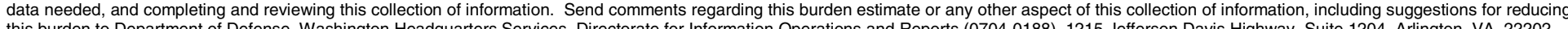

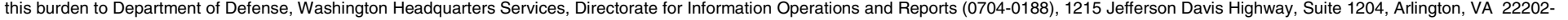

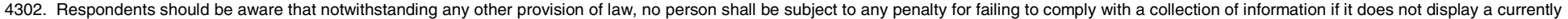
valid OMB control number. PLEASE DO NOT RETURN YOUR FORM TO THE ABOVE ADDRESS.

\begin{tabular}{l|l|l}
\hline 1. REPORT DATE (DD-MM- $Y Y Y Y)$ & 2. REPORT TYPE & 3. DATES COVERED (FrOm - TO)
\end{tabular}

September 2000

\section{TITLE AND SUBTITLE}

Report 1 of a series

DMS: Diagnostic Modeling System

Report 1, Reduction of Sediment Shoaling by Relocation of the Gulf Intracoastal Waterway, Matagorda Bay, Texas

6. AUTHOR(S)

Nicholas C. Kraus, David J. Mark, Soraya Sarruff

5a. CONTRACT NUMBER

5b. GRANT NUMBER

5c. PROGRAM ELEMENT NUMBER

5d. PROJECT NUMBER

5e. TASK NUMBER

5f. WORK UNIT NUMBER

\section{PERFORMING ORGANIZATION NAME(S) AND ADDRESS(ES)}

8. PERFORMING ORGANIZATION REPORT NUMBER

U.S. Army Engineer Research and Development Center

Coastal and Hydraulics Laboratory

Technical Report CHL-99-19

3909 Halls Ferry Road

Vicksburg, MS 39180-6199

9. SPONSORING / MONITORING AGENCY NAME(S) AND ADDRESS(ES)

U.S. Army Corps of Engineers

Washington, DC 20314-1000;

U.S. Army Engineer District, Galveston

2000 Fort Point Road

Galveston, TX 77550

11. SPONSOR/MONITOR'S REPORT NUMBER(S)

\section{DISTRIBUTION / AVAILABILITY STATEMENT}

Approved for public release; distribution is unlimited.

\section{SUPPLEMENTARY NOTES}

\section{ABSTRACT}

The Diagnostic Modeling System (DMS) is intended to provide a rapid, yet reliable capability for identifying and evaluating navigation channel operations and maintenance (O\&M) alternatives based on limited information about the hydrodynamic and sediment-transport conditions at a site. The DMS gives a diagnosis of a problem shoaling area (in contrast to conducting expensive and time-consuming studies), together with guidance for determining possible solutions. The DMS also contains dredging and associated records to document shoaling patterns and measures taken. As a first proof of concept, the methodology of the DMS was applied to investigate a region of increasing sediment shoaling along the Gulf Intracoastal Waterway (GIWW), Matagorda Bay, Texas. Morphological, engineering, and numerical modeling approaches were taken in three parallel paths. The three study methods found that a bird island located near the intersection of the GIWW and Matagorda Ship Channel (MSC) was experiencing significant erosion because of its close proximity to the MSC entrance and strong flood currents. The DMS methodology led to the conclusion that the GIWW should be located several kilometers north of its present location, which would also improve navigation efficiency at the MSC and GIWW intersection.

\section{SUBJECT TERMS}

Coastal inlet

Diagnostic Modeling System

16. SECURITY CLASSIFICATION OF:

\begin{tabular}{|l|l|l|}
\hline $\begin{array}{l}\text { a. REPORT } \\
\text { UNCLASSIFIED }\end{array}$ & b. ABSTRACT & $\begin{array}{l}\text { c. THIS PAGE } \\
\text { UNCLASSIFIED }\end{array}$ \\
\hline
\end{tabular}

Gulf intracoastal waterway Matagorda ship channel OF ABSTRACT
Matagorda Bay

Texas

Pass Cavallo

18. NUMBER
OF PAGES

OF PAGES

62 19a. NAME OF RESPONSIBLE PERSON

19b. TELEPHONE NUMBER (include area code) 
Destroy this report when no longer needed. Do not return it to the originator. 